$32 ?$

$B M /-1664$

3124154

A STUDY OF THE TENSILE FRA CIURE AND

WICROSTRUCTURE OF URANIUM

Tiis docuinent is

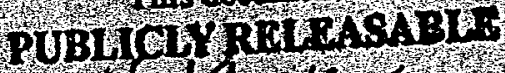

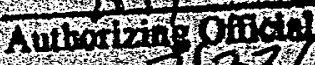
Dade. 123102

BATTELLE MEMORIAL INSTITUTE 


\section{LEGAL NOTICE}

This report was prepared as an account of Government sponsored work. Neither the United Statos, nor the Commission, nor any person octing on behalf of the Commission:

A. Makes any warranty or representation, expressed or implied, with respect to the accurocy, completeness, or usefulness of the information contained in this report, or that the use of any information, apparatus, mothod, or process disclosed in this report may not infringe privately owned rights; or

B. Assumes any liabilities with respect to the use of, or for damages resulting from the use of any informotion, apporatus, meshod, or process disclosed in this report.

As used in the above, "person acting on behalf of the Commission" includes any employee or contractor of the Commission, or employee of such contractor, to the extent that such employee or contractor of the Commission, or employee of such contractor prepares, disseminates, or provides access 10, ony information pursuant to his employment. or contract with the Commission, or his employment with such contractor.

Printed in USA

Price $\$ 2.00$

Available from the

Office of Technical Services

U. S. Department of Commerce

Washington 25, D. C. 

and Materials

(TID-4500, 26th Ed.)

\section{A STUDY OF THE TENSILE FRACTURE AND MICROSTRUCTURE OF URANIUM}

\author{
Edited by \\ Ellis L. Foster, Jr.
}

Work done by

Fred R. Shober

Norman E. Daniel

Ellis L. Foster, Jr.

Arthur A. Bauer

Clarence R. Thompson

Carl W. Melton

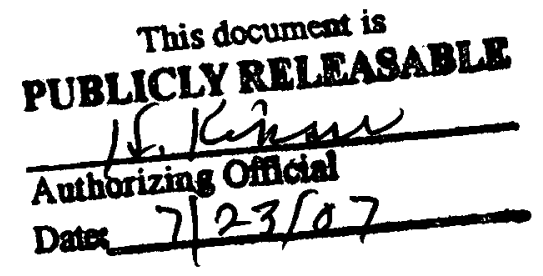

February 14, 1964

BATTELLE MEMORIAL INSTITUTE

505 King Avenue

Columbus 1, Ohio 


\section{TABLE OF CONTENTS}

$\underline{\text { Page }}$

INTRODUCTION .

\section{A STUDY OF THE TENSILE FRACTURE OF URANIUM AT ELEVATED TEMPERATURES}

STUDIES ON SRL MATERIALS .

Introduction . . . . . . . . . . . . . . . . . . . . . 3

Experimental Procedures . . . . . . . . . . . . . . . . . 4

Evaluation of Mechanical Properties . . . . . . . . . . . 5

Metallographic Evaluations . • . • . . . • . . . . . . . . 11

Conclusions . . . . . . . . . . . . . . . . . . . 17

STUDIES ON NLO MATERIALS . • . • •

Introduction . . . . . . . . . . . . . . . . . . . . . 23

Experimental Procedures . . . . . . . . . . . . . . . 23

Evaluation of Mechanical Properties . . . . . . . . . . . . 24

Metallographic Evaluations . . . . . . . . . . . . . . 26

Conclusions . . . . . . . . . . . . . . . . . . . . . 43

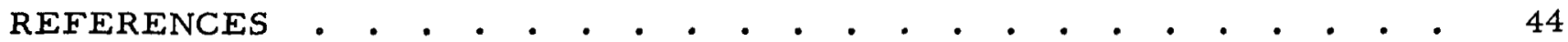

II. MICROSTRUCTURAL STUDIES OF CAST URANIUM

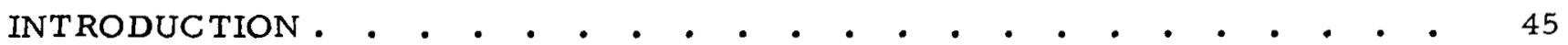

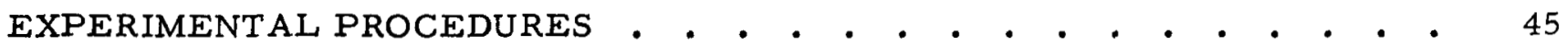

Materials and Specimen Selection . . . . . . . . . . . . 45

Techniques of Specimen Preparation . . . . . . . . . . . . . 46

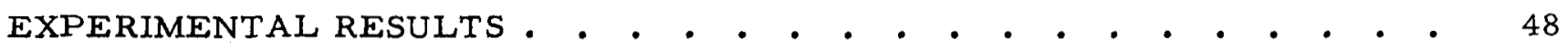

Metallographic Results . • . . . . • . . . . . . . . . 48

Electron-Microscope Results . . . . . . . . . . . . . . 53

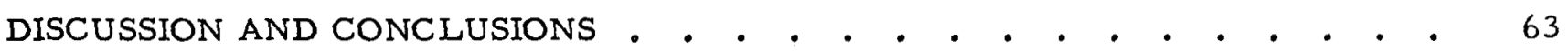




\title{
A STUDY OF THE TENSILE FRACTURE AND MICROSTRUCTURE OF URANIUM
}

\author{
Edited by \\ E. L. Foster, Jr.
}

\begin{abstract}
Tensile tests and exhaustive metallographic examinations were conducted in an effort to relate the mechanical properties, the chemical compositions, and the structures of five grades of SRL uranium to their irradiation stability. Subsequent tensile tests were conducted on seven types of $N L O$ uranium containing various levels of iron, aluminum, and silicon. Special attention was devoted to the mode of fracture exhibited by the various materials and to the existence of grainboundary phases and intergranular fracture. No evidence was noted of grainboundary failure at temperatures up to $450 \mathrm{C}$. Most or all failures were precipitated by secondary phases not associated with the grain boundaries. No definite connection was noted between the chemical composition and the tensile properties of the materials that could be related to their irradiation stability. A supplementary study concerned with the substructure and fine-particle distribution in cast uranium was also undertaken. The major accomplishment of this study was the development of metallographic techniques. Particularly interesting were the microstructures revealed by vacuum-cathodic etching.
\end{abstract}

\section{INT RODUCTION}

Recent studies at Savannah River Laboratory (SRL) and National Lead Company of Ohio (NLO) concerned with increasing the operating temperatures of natural-uraniumfueled reactors have indicated that the re may exist some relationship between the type of fracture exhibited by uranium tensile specimens and the stability of the uranium in the reactor. Past work on the tensile fracture of uranium has been limited, and no attempt has been made to relate the mode of fracture to the irradiation stability of the material. If such a relationship does exist and can be defined, relatively inexpensive tensile tests could prove an invaluable aid in screening uranium fuel for possible reactor applications. By adequate screening, the number of materials requiring evaluation by in-pile irradiation and hot-cell evaluation could be substantially reduced.

Interest for ascertaining the applicability of such a test has been intensified by the current investigations at the se sites concerning the effects of small additions of iron, silicon, and aluminum. A thorough investigation of the behavior of the many compositions attainable may require the examination of an extremely large number of irradiated specimens unless some adequate method of preliminary screening can be developed.

A research program carried out and described in Part I of this report was designed to evaluate the tensile properties and mode of fracture of various uranium compositions in an effort to relate these properties to irradiation stability and composition. The work was carried out in support of studies at SRL and NLO. Exhaustive metallographic examinations were conducted on all specimens to ascertain the effect of composition on the type and initiation of fracture. Since previous studies at SRL had shown $(1)$ that swelling was related to grain-boundary cavitation, particular attention was directed toward rupture or failure of the specimens at grain boundaries.

"References at end of Part $I$. 
A complementary study concerned with the microstructural appearance of cast uranium of varied chemical and casting history was also undertaken in assistance to NLO. This study, Part II of this report, was particularly concerned with the grainboundary phases present in the material. Numerous metallographic preparation techniques, including chemical and electrochemical etching and vacuum-cathodic etching, we re employed. Examinations were conducted by light microscopy and electron mic roscopy. Of particular interest were the structures obtained utilizing the vacuumcathodic etching techniques. 


\title{
I. A STUDY OF THE TENSILE FRACTURE OF URANIUM AT ELEVATED TEMPERATURES
}

\author{
F. R. Shober, N. E. Daniel, and E. L. Foster, Jr.
}

\section{STUDIES ON SRL MATERIALS}

\author{
Introduction
}

Studies of the deformation mechanisms operative in uranium in the alpha region are complicated by the structure of the uranium and difficulties experienced in obtaining sufficiently large crystals of high purity. Lloyd and Chiswik and others have shown that twinning and slip and kinking occur in uranium and that of the se twinning is probably the most important. (2) It has also been shown that at some temperature above $400 \mathrm{C}$ there may be a reduction in the amount of twinning, and slip may be the predominate mode of deformation. (2) The mechanism of fracture of uranium has received very little consideration. As noted by Holden(3), in studies conducted by Bierlein, et al., it was concluded that the uranium deformation was localized in some grains more than in others and that in the se grains fracture occurs at an early stage. The crack thus initiated propagates to cause failure of the specimen. It was also found that the fracture was predominantly transcrystalline. However, in studies conducted by Holden, failure was attributed to grain-boundary tea ring. (3)

A cursory study was made at Battelle utilizing high-carbon-content uranium in tensile tests at several temperatures from 20 to $450 \mathrm{C}$ at a strain rate of 0.005 in. per in. per min. (4) Upon examination of the specimens after testing it was noted that failure apparently proceeded by the initial fracture of the carbide particles, enlargement of the fracture and surrounding metal with continued strain, and, ultimately, rupture of the specimen. This mechanism of fracture is similar to the mechanism suggested by Cottrell in which the plastic cavities are nucleated at foreign particles and tend to grow through plastic deformation and are not stress dependent. (5) It was also noted during the program at Battelle that there is an apparent temperature of approximately $300 \mathrm{C}$ at which uranium exhibits a secondary minimum in ductility only slightly greater than the ductility at room temperature.

Prior to the work conducted at Battelle, personnel at the Savannah River Laboratory $(6)$ had observed abnormal swelling of uranium after irradiation at moderately elevated temperatures. Metallographic examinations of this material revealed large and numerous voids in the center of the thick-walled cylinder. Subsequently, two shorttime tensile tests were performed at two different strain rates on unirradiated uranium. The fracture area when examined metallographically exhibited cracks at some of the grain boundaries. Some of the cracks appeared to have been initiated at uranium carbide particles, and it was thought that these cracks, which apparently formed during tensile testing, might be related to the observed abnormal swelling and void formation in the irradiated material. It has also been suggested that the tendency for crack formation might be related to the impurity content of the uranium. (6) 
Subsequently, five different grades of uranium we re irradiated at the Savannah River Laboratory. (6) These materials contained various levels of aluminum, carbon, iron, and silicon. Two of these materials were obtained from ingot uranium and three from dingot uranium. Regardless of the origin of the materials only those containing approximately $100 \mathrm{ppm}$ of silicon exhibited reasonable resistance to ir radiation-induced swelling. Metallographic examination at SRL revealed that the swelling was due to intergranular cavitation.

Because of the complexity of the subject and the cursory nature of the initial studies conducted at Battelle(7) and SRL, insufficient data had been generated to gain an understanding of the mode and types of failures which occur in the intermediate temperature range and the relationship of the mode and type of failures to the observed irradiation stability of the materials. Therefore, a program was initiated at Battelle in an effort to relate the crack initiation and propagation, the mechanical properties of the materials, the fracture mechanism, and chemistry with the irradiation stability of the metal. Various test temperatures were utilized in testing the five types of uranium employed in this program. The results of this study are given in the paragraphs which follow.

\section{Experimental Procedures}

Five types of materials similar in composition and history to materials irradiated at SRL were chosen for tensile-test studies at Battelle and are listed in Table I- 1 . The irradiated materials were evaluated by SRL on the basis of their resistance to swelling. The metallographic tests conducted on the irradiated materials at $S R L$ indicated that the swelling was due to intergranular cavitation and that the severity of the cavitation was related to the alloy composition of the uranium. (1) The tensile specimens used at Battelle were obtained from companion slugs to those employed in the irradiation tests at SRL.

TABLE I-1. DESCRIPTION OF MATERIALS USED IN THE STUDIES OF SRL MATERIALS

\begin{tabular}{|c|c|c|c|c|c|c|}
\hline \multirow[b]{2}{*}{ Type of Material } & \multirow[b]{2}{*}{ Origin } & \multicolumn{4}{|c|}{ Analysis, $\mathrm{ppm}$} & \multirow[b]{2}{*}{ SRL Comments } \\
\hline & & $\mathrm{C}$ & $\mathrm{Fe}$ & $\mathrm{Si}$ & $\overline{\mathrm{Al}}$ & \\
\hline 1 & Dingot & 28 & 57 & 11 & 32 & $\begin{array}{l}\text { Exceptionally poor resistance to } \\
\text { irradiation-induced swelling }\end{array}$ \\
\hline 2 & Ingot & 420 & 105 & 16 & 6 & $\begin{array}{l}\text { Exceptionally poor resistance to } \\
\text { irradiation-induced swelling }\end{array}$ \\
\hline 3 & Dingot & 25 & 150 & 90 & 24 & $\begin{array}{l}\text { Much more stable than Types } 1 \\
\text { and } 2 \text { and comparable to or } \\
\text { better than sound production } \\
\text { cores }\end{array}$ \\
\hline 4 & Ingot & 424 & 137 & 88 & 6 & Same as Type 3 \\
\hline 5 & Dingot & 27 & 120 & 100 & 100 & Same as Type 3 \\
\hline
\end{tabular}

Note: All cores were alpha extruded at approximately $615 \mathrm{C}$, beta transformed for 10 min in molten salt at $735 \mathrm{C}$, and quenched in oil. 
The tensile specimens were of a necessity cut along the longitudinal axis of the hollow fuel cores. The specimens measured $4.5 \mathrm{in}$. in length with a gage section $0.1875 \mathrm{in}$. in diameter by $2 \mathrm{in}$. in length. A ground finish was used on all specimens to minimize surface effects that might influence the mechanical properties exhibited by the materials and the surface appearance of the specimens after testing.

The basic equipment utilized in the se tests consisted of an Instron Testing Machine, a multitap resistance-wound furnace, a vacuum chamber, strain gages, and related equipment. A schematic drawing showing the relative location of the furnace, the specimen, and the strain gage is shown in Figure I-1. The choice of an Instron unit for these tests was dictated by the fact that this machine is screw driven, and, therefore, a constant head-travel rate can be maintained throughout a test and from test to test. As shown in the drawing, the specimen was heated by radiation from the wall of the vacuum chamber, which permitted maintaining a temperature gradient along the gage length of less than $3 \mathrm{C}$. Thermal cycling during testing was also held to $\pm 3 \mathrm{C}$ as determined by the control the rmocouple located approximately at the center of the gage length. The extensometer consisted of a pair of knife edges which were attached to the specimen, two parallel bars which transmitted the motion of the knife edges to a semicircular flat plate, and a standard SR-4 strain gage which measured the deflection in the plate. The load was measured by a load cell and recorded autographically.

Prior to testing, the system was evacuated and the leak rate checked. Each specimen was then heated at a uniform rate to attain the desired test temperature in $1 \mathrm{hr}$, soaked at this temperature for $30 \mathrm{~min}$, and then tested. A crosshead speed of $0.002 \mathrm{in}$. per min was employed for all tests. This corresponded to a strain rate from $0.001 \mathrm{in.}$ per in. per min when the tests were initiated to 0.00076 in. per in. per min when the tests terminated for the specimen exhibiting the greatest total elongation. Forty specimens were tested, including the duplicates that were run where anomalies seemed to be present in the data. Throughout each run the crosshead movement was plotted autographically against the load, the strain-gage readings were recorded manually, and the temperature was controlled within the desired range of $\pm 3 \mathrm{C}$ as determined by a minimum of two thermocouples.

Evaluation of Mechanical Properties

The data from the tests were plotted to obtain stress-versus-strain curves of each specimen tested. From these curves and measurements of the ruptured specimens, the following data were obtained and tabulated as shown in Table I-2:

(1) Total elongation

(2) Reduction in area

(3) Ultimate tensile strength

(4) Uniform elongation

(5) Modulus of elasticity

(6) Yield strength.

These data were then plotted as a function of the temperature. These graphical representations of the data are shown in Figure I- 2 . 


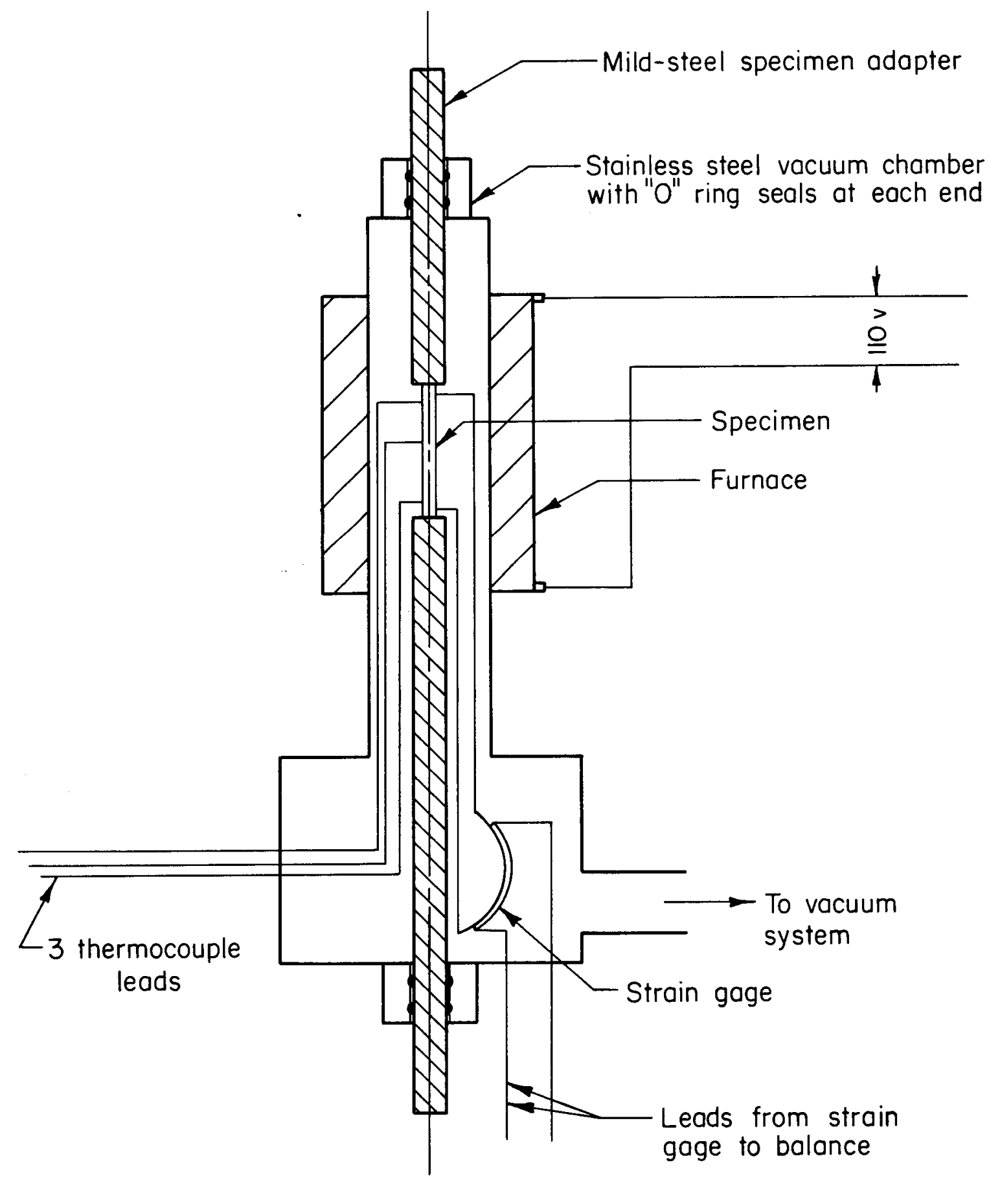

A- 96623

FIGURE I- 1. GRAPHICAL REPRESENTATION OF EQUIPMENT SHOWING RELATIVE LOCATION OF SPECIMEN, FURNACE AND INSTRUMENTATION 
TABLE I-2. SUMMARY OF TENSILE-TEST DATA ${ }^{(a)}$ FOR SRL MATERIALS

\begin{tabular}{|c|c|c|c|c|c|c|c|}
\hline \multicolumn{2}{|c|}{ Test Conditions } & \multirow{2}{*}{$\begin{array}{c}\text { Ultimate } \\
\text { Tensile Strength, } \\
10^{3} \mathrm{psi}\end{array}$} & \multirow{2}{*}{$\begin{array}{c}0.2 \text { Per Cent } \\
\text { Off set Yield } \\
\text { Strength, } \\
10^{3} \mathrm{psi}\end{array}$} & \multirow{2}{*}{$\begin{array}{l}\text { Reduction in } \\
\text { Area, } \\
\text { per cent }\end{array}$} & \multirow{2}{*}{$\begin{array}{l}\text { Elastic } \\
\text { Modulus, } \\
10^{6} \text { psi }\end{array}$} & \multirow{2}{*}{$\begin{array}{c}\text { Total } \\
\text { Elongation, } \\
\text { per cent }\end{array}$} & \multirow{2}{*}{$\begin{array}{l}\text { Uniform } \\
\text { Elongation, } \\
\text { per cent }\end{array}$} \\
\hline $\begin{array}{c}\text { Temperature, } \\
\mathrm{C}\end{array}$ & Time, min & & & & & & \\
\hline \multicolumn{8}{|c|}{ Type 1 Material (Dingot) } \\
\hline 25 & 148 & 73.8 & 36.6 & 11.2 & 27.5 & 12.5 & 6.1 \\
\hline 150 & 273 & 62.8 & 30.0 & 33.4 & 24.4 & 26.0 & 6.1 \\
\hline 250 & 185 & 41.25 & 28.0 & 21.7 & 21.0 & 13.1 & 2.8 \\
\hline 350 & 100 & 31.83 & 24.4 & 21.4 & 16.7 & 8.2 & 2.4 \\
\hline 450 & 215 & 19.68 & 13.1 & 39.9 & 13.4 & 21.0 & 16.0 \\
\hline \multicolumn{8}{|c|}{ Type 2 Material (Ingot) } \\
\hline 25 & 235 & 98.8 & 39.1 & 17.6 & 20.8 & 21.9 & 4.1 \\
\hline 150 & 365 & 70.5 & 34.4 & 36.6 & 20.8 & 32.9 & 14.7 \\
\hline 250 & 283 & 47.3 & 29.1 & 46.8 & 18.4 & 25.5 & 11.9 \\
\hline 350 & 180 & 34.95 & 25.8 & 49.0 & 16.5 & 16.7 & 7.7 \\
\hline 450 & 192 & 22.8 & 17.1 & 71.0 & 14.0 & 19.0 & 15.2 \\
\hline \multicolumn{8}{|c|}{ Type 3 Material (Dingot) } \\
\hline 25 & 166 & 95.75 & 42.1 & 11.6 & 23.6 & 13.4 & 0.3 \\
\hline $150^{(b)}$ & 215 & 77.7 & 40.3 & 30.8 & 20.2 & 16.0 & 2.4 \\
\hline 250 & 140 & 52.6 & 35.8 & 19.6 & 16.8 & 10.0 & 2.1 \\
\hline 350 & 76 & 40.5 & 14.8 & 12.0 & 14.8 & 8.0 & 3.8 \\
\hline 450 & 195 & 25.15 & 19.5 & 67.0 & 12.0 & 19.0 & 14.2 \\
\hline \multicolumn{8}{|c|}{ Type 4 Material (Ingot) } \\
\hline 25 & 247 & 99.4 & 40.0 & 16.3 & 21.3 & 18.6 & -- \\
\hline 150 & 230 & 67.25 & 35.3 & 33.2 & 21.0 & 28.0 & 12.7 \\
\hline 250 & 326 & 57.96 & 33.3 & 45.4 & 21.0 & 29.0 & 8.7 \\
\hline $350^{(b)}$ & 176 & 40.0 & 31.0 & 44.0 & 18.8 & 15.0 & 8.6 \\
\hline 450 & 244 & 19.94 & 16.9 & 67.5 & 13.2 & 21.5 & 16.5 \\
\hline \multicolumn{8}{|c|}{ Type 5 Material (Dingot) } \\
\hline 25 & 170 & 98.5 & 44.7 & 2.7 & 20.5 & 12.0 & - \\
\hline 150 & 173 & 76.0 & 39.4 & 17.8 & 20.2 & 14.8 & 2.2 \\
\hline 250 & 118 & 55.0 & 36.9 & 18.7 & 19.8 & 9.6 & 3.3 \\
\hline 350 & 68 & 39.1 & 31.2 & 12.2 & 16.6 & 6.8 & 6.4 \\
\hline 450 & 215 & 25.4 & 21.7 & 56.5 & 13.9 & 20.7 & 17.3 \\
\hline
\end{tabular}

(a) Type 1 and Type 2 materials exhibited poor resistance to swelling during irradiation. The behavior of the other three materials was comparable to that of the best production cores.

(b) Broke outside of gage region. 

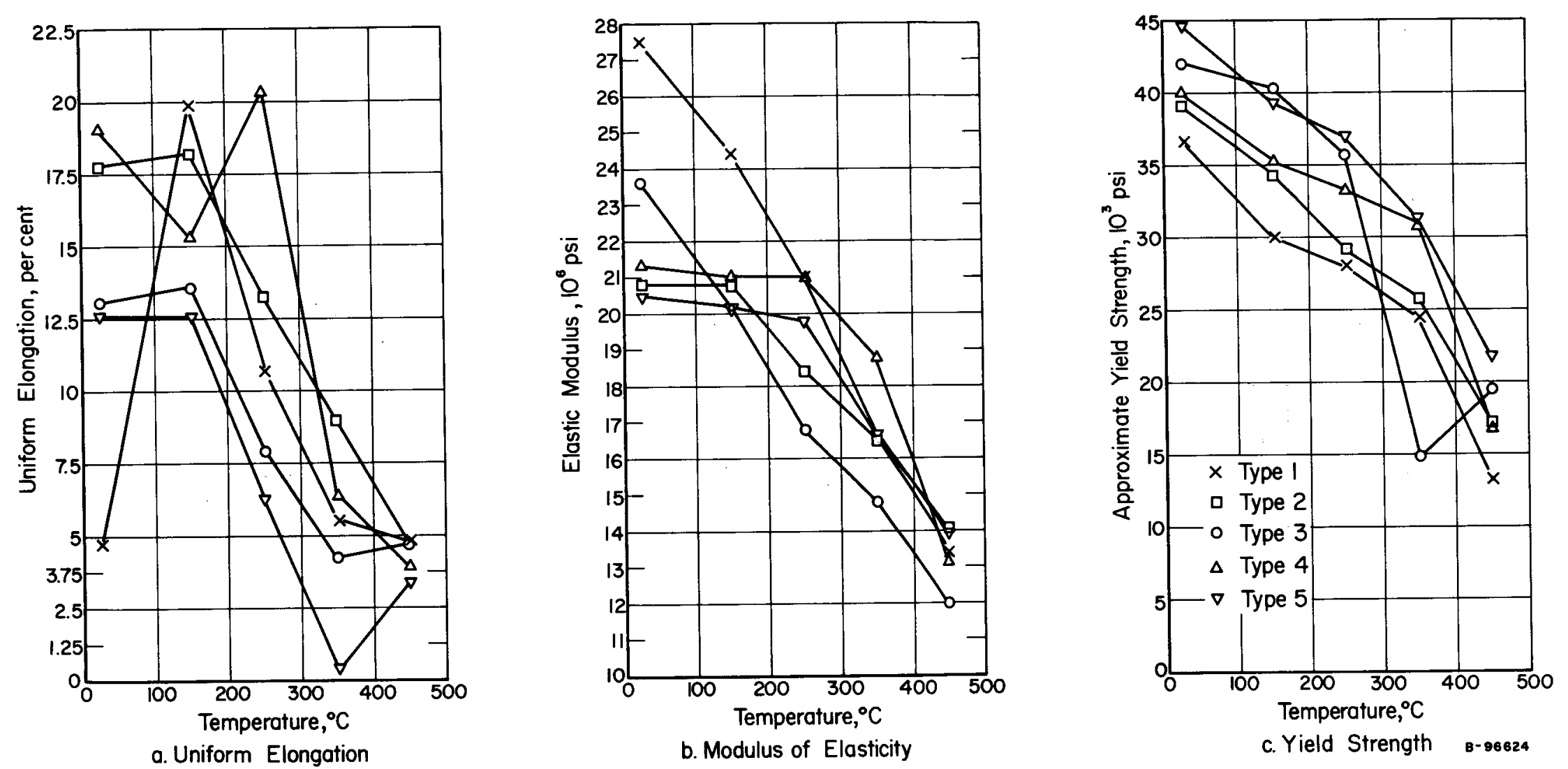

FIGURE I-2. EFFECT OF TEMPERATURE ON MECHANICAL PROPERTIES OF THE SRL MATERIALS 

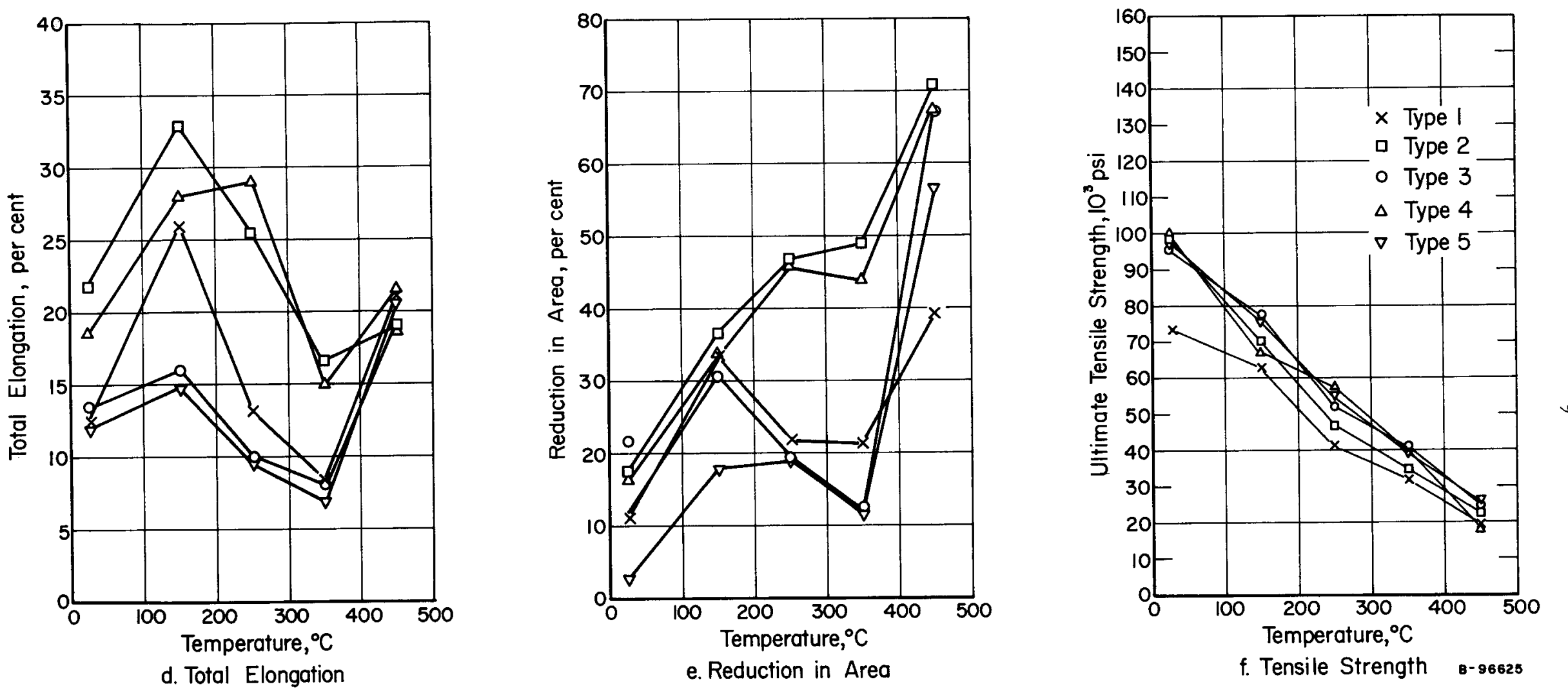

FIGURE I-2。 (CONTINUED) 
A comparison of these graphs shows that the property values when plotted as a function of temperature appear to fall in two definite groups related to dingot and ingot uranium. The major difference between the two is that ingot uranium has a higher carbon content. The fabrication history, heat treatment, and resultant grain size are similar. It would then appear that the grouping noted in the mechanical-properties data is a function of carbon content. Using this difference as a criterion for division, a comparison of properties was made as shown in Table I- 3.

TABLE I-3. COMPARISON OF PROPERTIES OF DINGOT AND INGOT URANIUM

\begin{tabular}{|c|c|c|c|}
\hline & & Dingot Uranium & Ingot Uranium \\
\hline \multirow[t]{2}{*}{ Tensile Strength } & 1. & Increases as a function of total impurity content & 1. Increases as a function of total impurity content \\
\hline & & $\begin{array}{l}\text { Decreases approximately linearly with increas- } \\
\text { ing temperature }\end{array}$ & $\begin{array}{l}\text { 2. Decreases approximately linearly with increas- } \\
\text { ing temperature }\end{array}$ \\
\hline \multirow[t]{2}{*}{ Yield Strength } & 1. & $\begin{array}{l}\text { Generally highest for material having greatest } \\
\text { total impurity content }\end{array}$ & $\begin{array}{l}\text { 1. Generally highest for material having greatest } \\
\text { total impurity content }\end{array}$ \\
\hline & & $\begin{array}{l}\text { Increases at a given temperature with increas- } \\
\text { ing silicon and iron contents }\end{array}$ & $\begin{array}{l}\text { 2. Increases at a given temperature with increas- } \\
\text { ing silicon and iron contents }\end{array}$ \\
\hline Total Elongation & & $\begin{array}{l}\text { Lowest values exhibited by this material, with } \\
\text { maximum at } 150 \mathrm{C} \text { and minimum at } 350 \mathrm{C}\end{array}$ & $\begin{array}{l}\text { 1. Highest values exhibited by this material with } \\
\text { maximum at } 150 \mathrm{C} \text { and minimum at } 350 \mathrm{C}\end{array}$ \\
\hline \multirow[t]{2}{*}{ Uniform Elongation } & 1. & $\begin{array}{l}\text { Lowest values shown by this material, decreas- } \\
\text { ing as a function of increasing temperature } \\
\text { from } 150 \text { to } 450 \mathrm{C}\end{array}$ & $\begin{array}{l}\text { 1. Highest values shown by this material, decreas- } \\
\text { ing as a function of increasing temperature } \\
\text { from } 150 \text { to } 450 \mathrm{C}\end{array}$ \\
\hline & 2. & $\begin{array}{l}\text { Silicon and aluminum contents are at maxi- } \\
\text { mum in the material showing minimum } \\
\text { uniform elongation }\end{array}$ & \\
\hline Reduction in Area & 1. & $\begin{array}{l}\text { Increases with increasing temperature to } 150 \mathrm{C} \text {, } \\
\text { exhibits an inflection point and decreases to a } \\
\text { minimum at } 350 \mathrm{C}\end{array}$ & $\begin{array}{l}\text { 1. Increases with increasing temperature, showing } \\
\text { a slight plateau at } 250 \text { and } 350 \mathrm{C}\end{array}$ \\
\hline
\end{tabular}

It is thought that the minimum point exhibited in the total-elongation curves may be related to the combined effect of deformation mechanisms prevalent in uranium at the test temperatures studied. Therefore, a discussion of the uniform-elongation and reduction-in-area curves is in order since they should reflect the predominant effect of the deformation mechanism at the test temperature considered.

The uniform elongation is probably a function of the deformation mechanism. The deformation mechanism is not associated with fracture while the reduction in area is. Earlier work showed that twinning is the predominant deformation mechanism at temperatures up to $400 \mathrm{C}$. (3) The uniform-elongation curve and the metallography pexformed after testing support the se earlier observations. Photomicrographs taken in sections of specimens where the material was deformed uniformly show a decreasing number of twins with increasing test temperature. A similar reduction in uniform elongation with increasing temperature is also noted. The rate of decrease is essentially independent of material composition. The absolute value of the uniform elongation, 
however, does appear to be a function of material composition, but because of the numbe $r$ of elements involved and their relative amounts their respective influence on the twinning mechanism is unknown.

The reduction-in-area data, which should be indicative of the deformation mechanism associated with fracture or the fracture mechanism itself, differ for the materials under consideration. Examination of tested dingot specimens in the vicinity of the fracture or the necked-down area showed transcrystalline cracks, not associated with carbide particles, which have opened up as the result of large amounts of deformation for test temperatures up to and including $350 \mathrm{C}$. Specimens of this same material tested at $450 \mathrm{C}$ showed regularly shaped voids in the necked-down area. The reduction in area for dingot uranium was maximum at $450 \mathrm{C}$. The ingot uranium when examined in the same manner showed large voids in as sociation with second-phase particles or stringers of second-phase particles for all test temperatures. The reduction in area exhibited by the ingot uranium was greater at all test temperatures than that of the dingot. It thus appears that the reduction of area is related to the crack- and voidassociated fractures.

The fact that the high-aluminum (100 ppm) materials exhibited the lowest elongation and reduction-in-area values indicates that the addition of even this small quantity of aluminum may have an adverse effect upon the fabrication characteristics of uranium.

The relationship of irradiation stability to mechanical properties is inconclusive; however, both ingot and dingot uranium exhibiting the highest yield strength, ultimate strength, and total elongation and the lowest uniform elongation were found to show the greatest irradiation stability at elevated temperatures. This is attributed to the fact that under a given set of irradiation conditions the radiation-induced stress necessary to cause plastic deformation is attained at an earlier time in the irradiation cycle for those materials exhibiting the lower yield strengths. However, the irradiation stability may be due to the fact that the Type 1 and Type 2 materials are more prone to intergranular cavitation. Once cavitation occurs the concentration of gaseous irradiation products within the cavities exerts forces in excess of those that can be restrained by the uranium, and, therefore, yielding occurs.

\section{Metallographic Evaluations}

After completion of the mechanical tests, each specimen was measured to obtain the percentage elongation within the 2-in. gage length and the reduction in diamete $r$ along the length of the specimen. The specimens were then examined and photographed at $5 \mathrm{X}$ to record the appearance of the fracture and the specimen surfaces. No surface cracking was noted in any of the specimens tested. During a previous study, where machined but not ground specimens were employed, some of the specimens tested at the

lower temperature had exhibited pronounced surface cracks. (7) It is believed that the surface cracks noted in the previous study were a result of specimen preparation rather than a manifestation of a peculiarity of the material.

Photomacrographs of specimens tested during the current study are shown in Figures I- 3 through I- 7. It should be noted that the dingot-uranium specimen, shown in Figures I-3, I-5, and I-7, exhibited a relatively brittle fracture when tested at $350 \mathrm{C}$ 


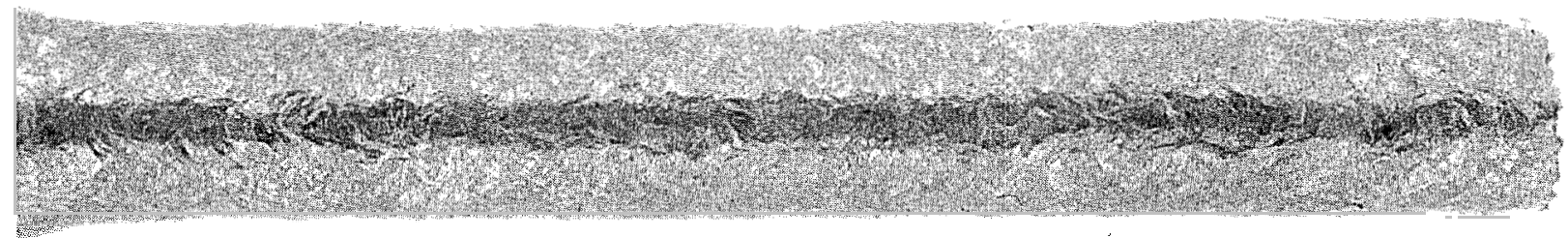

$5 \mathrm{X}$

a. Tested at $25 \mathrm{C}$

$\mathrm{RM} 22878$

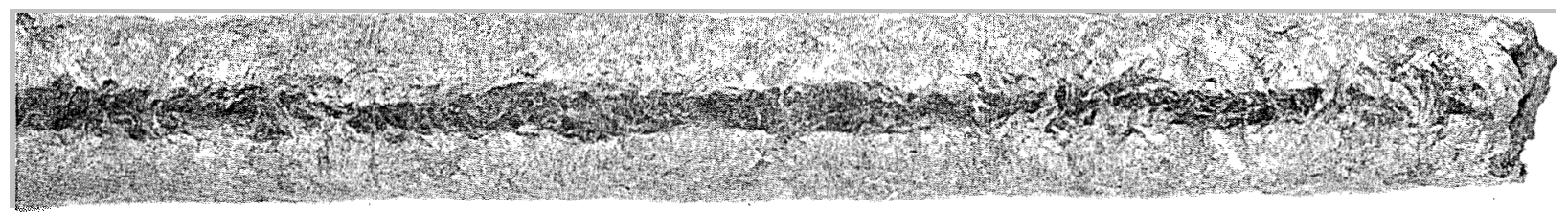

$5 X$

b. Tested at $150 \mathrm{C}$

RM22877

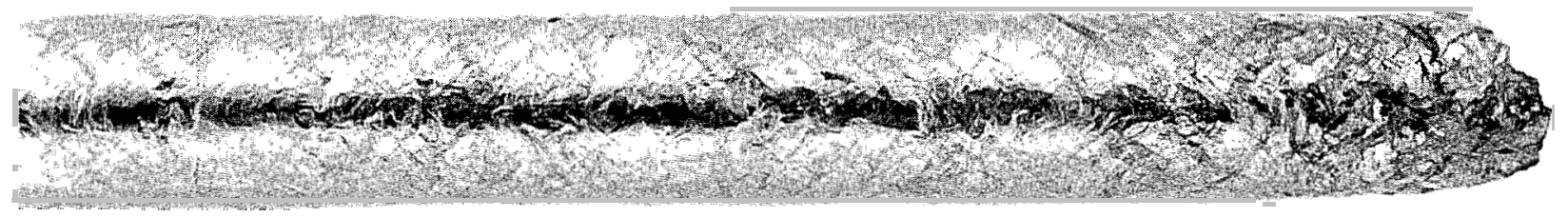

$5 X$

c. Tested at $250 \mathrm{C}$

$\mathrm{RM} 22876$

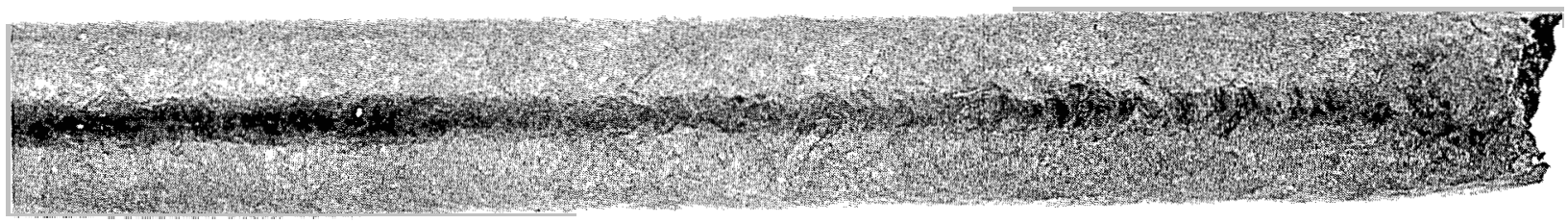

$5 \mathrm{X}$

d. Tested at $350 \mathrm{C}$

RM22875

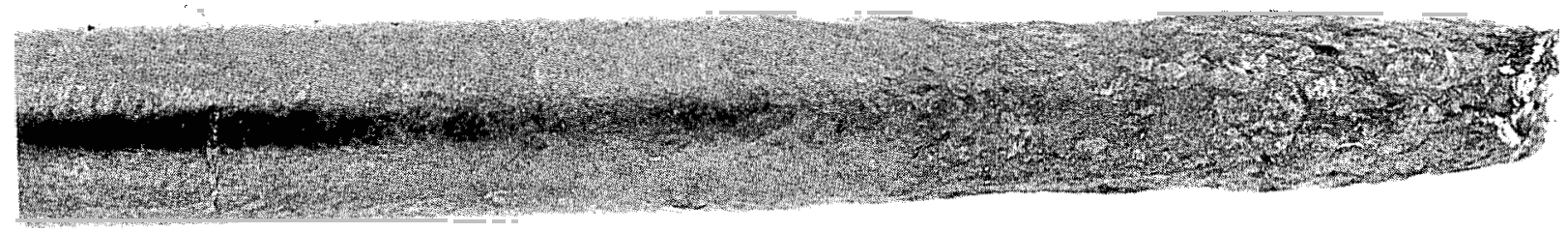

$5 \mathrm{x}$

e. Tested at $450 \mathrm{C}$

RM22873

FIGURE I-3. TYPE 1 URANIUM (DINGOT) TENSILE SPECIMENS

The fractures are typical of those exhibited by the dingot uranium, which displayed a pronounced secondary embrittlement at $350 \mathrm{C}$. 

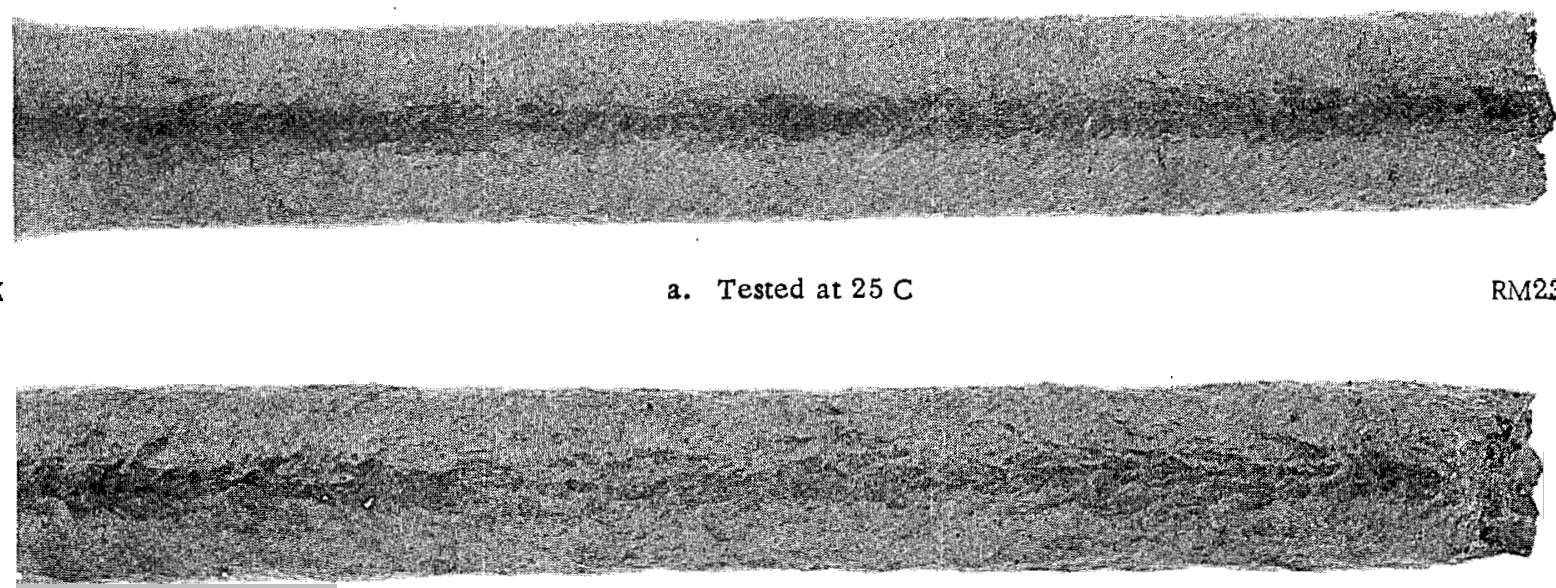

$5 X$

b. Tested at $150 \mathrm{C}$

RM23583

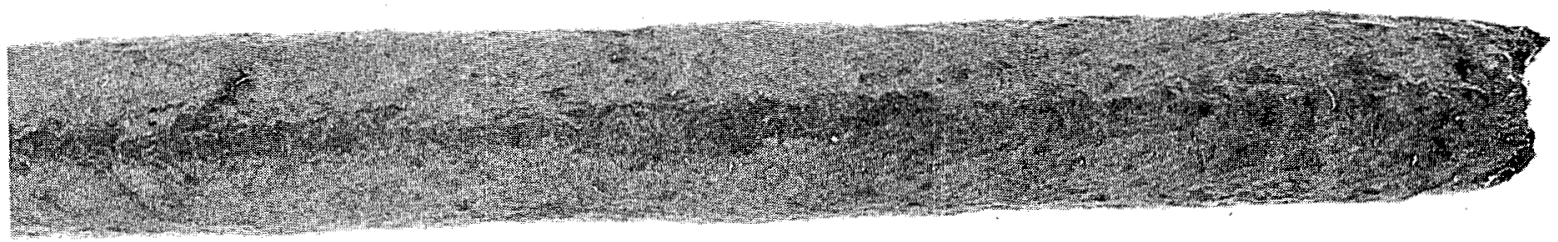

$5 \mathrm{X}$

c. Tested at $250 \mathrm{C}$

RM23580

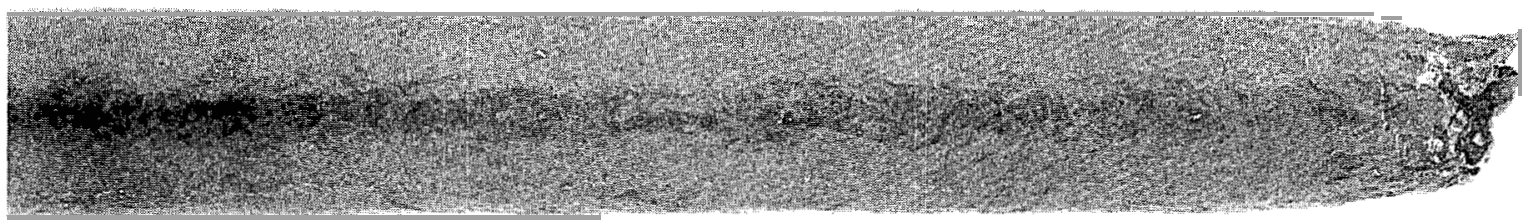

$5 X$

d. Tesied at $350 \mathrm{C}$

RM23581

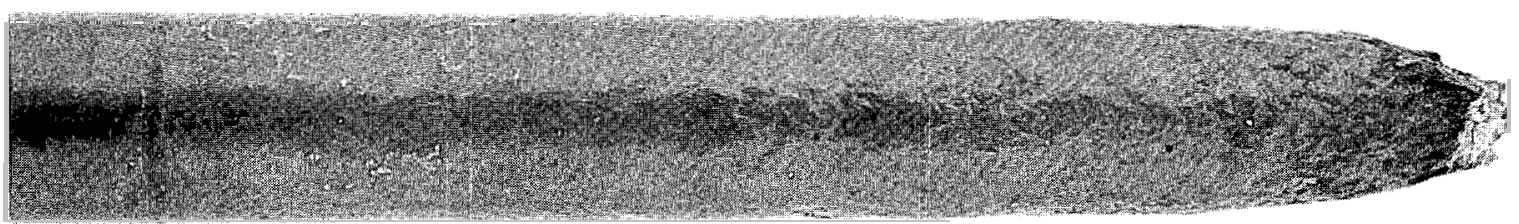

FIGURE I-4. TYPE 2 URANIUM (INGOT) TENSILE SPECIMENS

Notice the difference in the appearance of the fracture area in the specimen tested at $350 \mathrm{C}$ when compared to the Type 3 and Type 5 materials. 


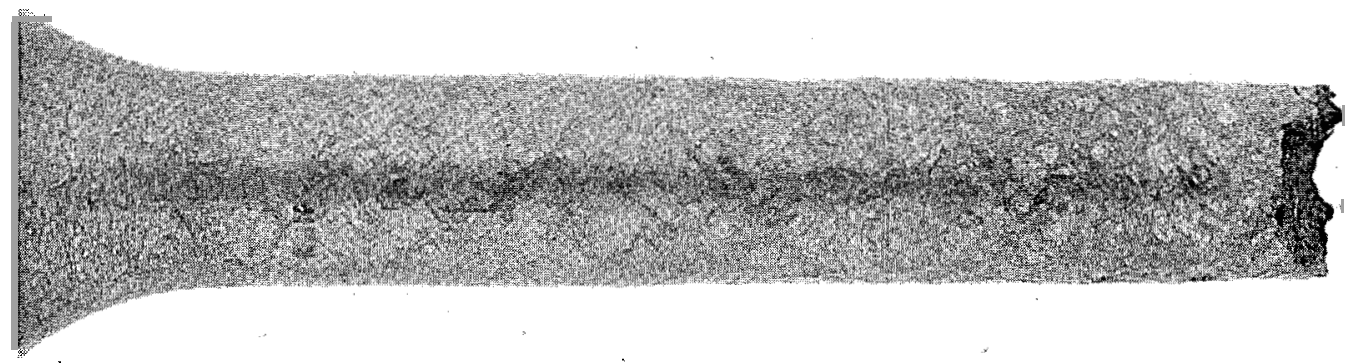

$5 X$

a. Tested at $250 \mathrm{C}$

RM23558

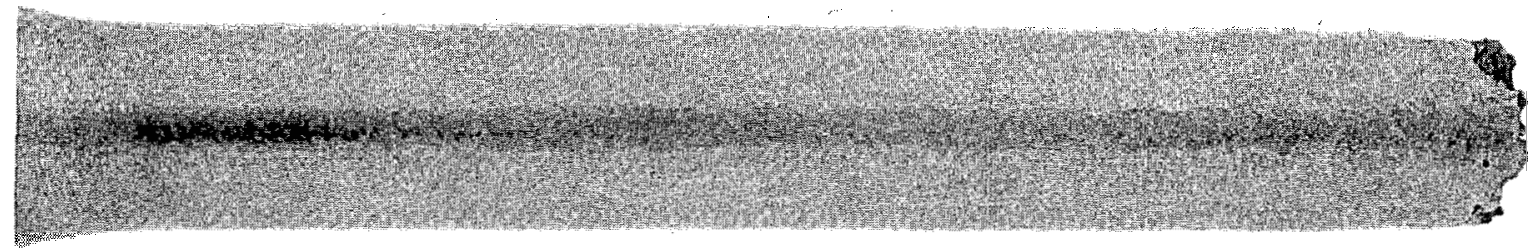

$5 X$

b. Tested at $350 \mathrm{C}$

RM23553

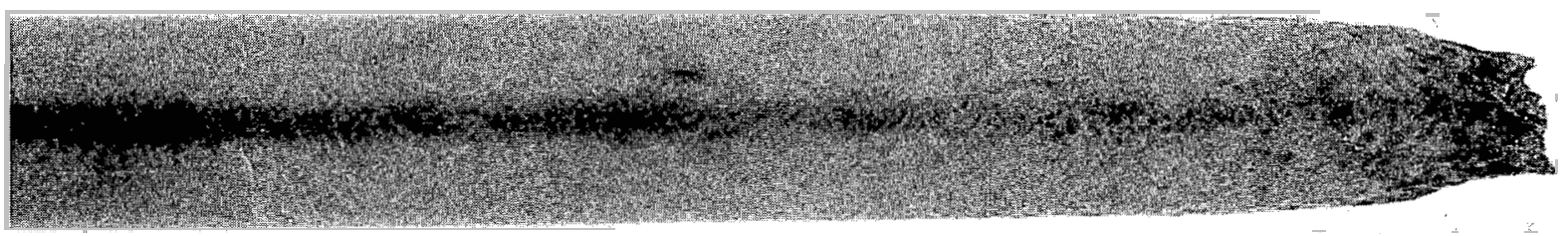

$5 \mathrm{x}$

c. Tested at $450 \mathrm{C}$

RM23554

FIGURE I-5, TYPE 3 URANIUM (DINGOT) TENSILE SPECIMENS

Note the lack of necking in the first two specimens. This behavior was more pronounced in the dinget uraniums than in the ingot uraniums. 


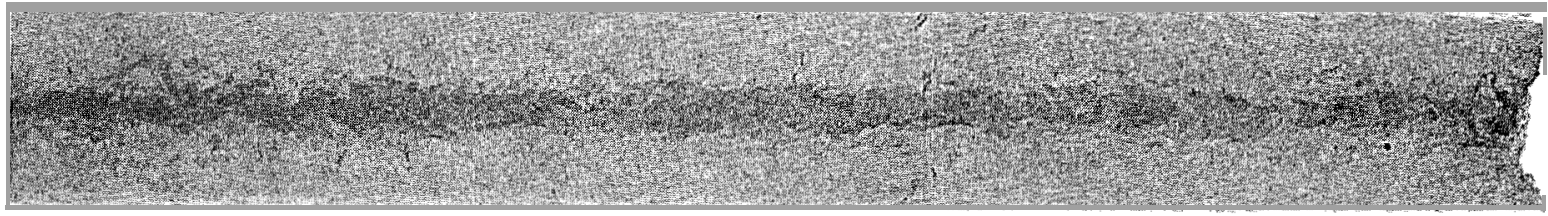

$5 X$

a. Tested at $25 \mathrm{C}$

RM23552

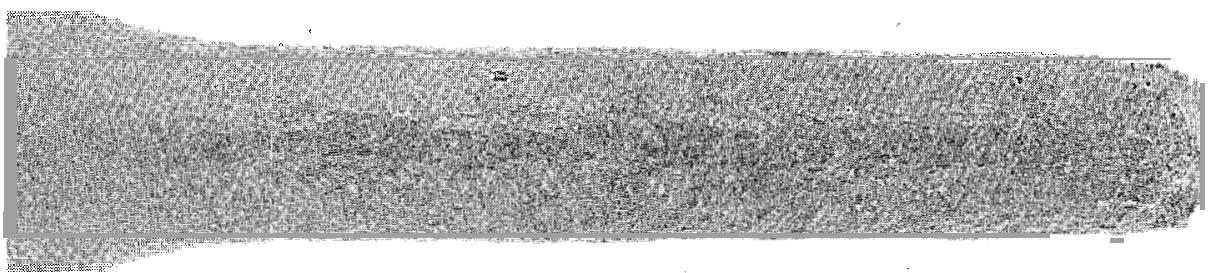

$5 X$

b. Tested at $150 \mathrm{C}$

RM23550

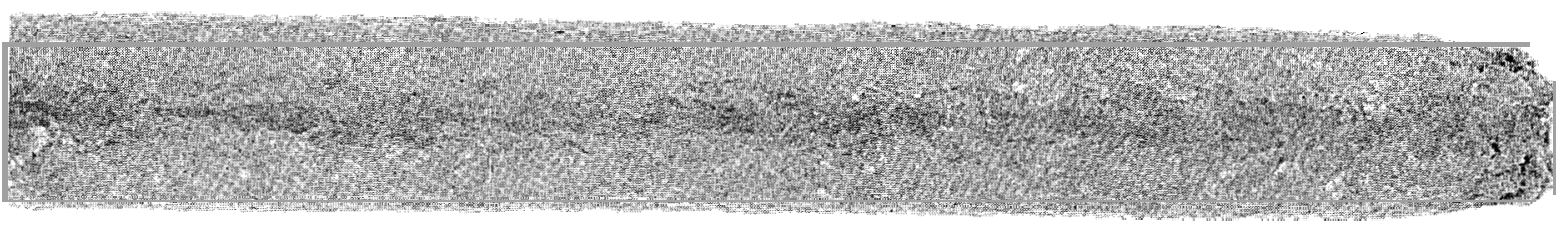

$5 X$

c. Tested at $250 \mathrm{C}$

RM23549

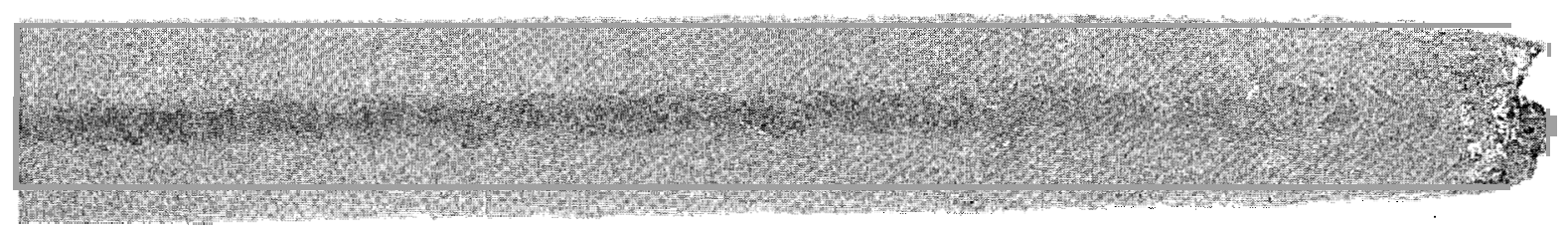

$5 X$

d. Tested at $350 \mathrm{C}$

RM23556

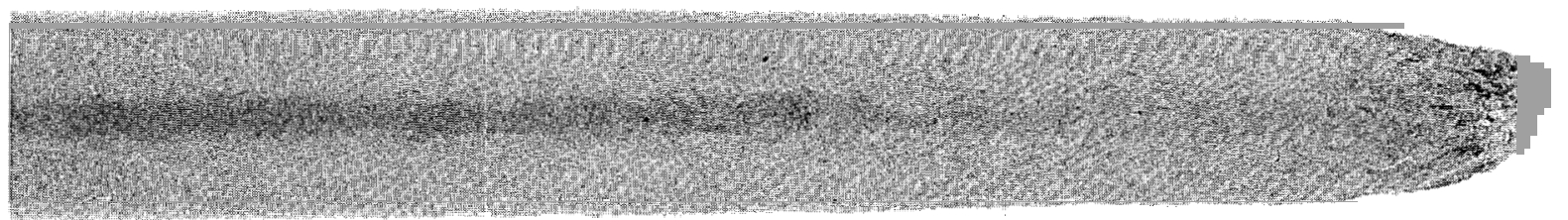

$5 x$

e. Tested at $450 \mathrm{C}$

RM23551

FIGURE I-6. TYPE 4 URANIUM (INGOT) TENSILE SPECIMENS

This material is similar to the Type 2 uranium except for an increased silicon content. Notice the similarity in the fractures to those of the Type 2 uranium and how they differ from the fracture exhibited by the Type 3 and Type 5 uranium specimens. 


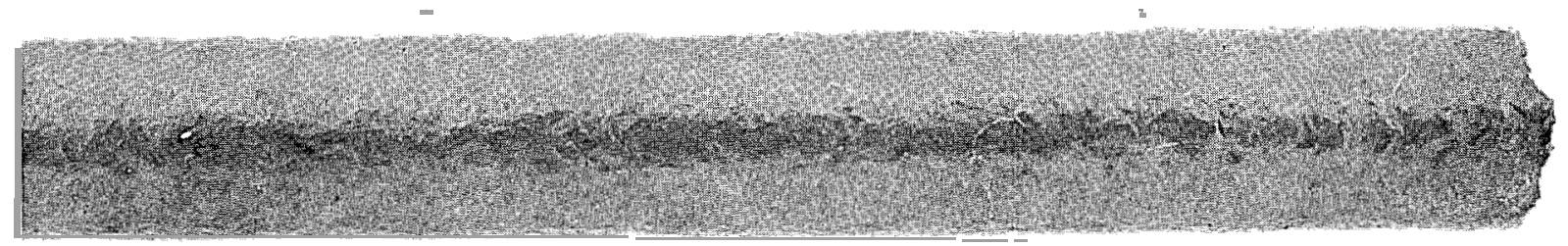

$5 \mathrm{X}$

a. Tested at $25 \mathrm{C}$

RM23575

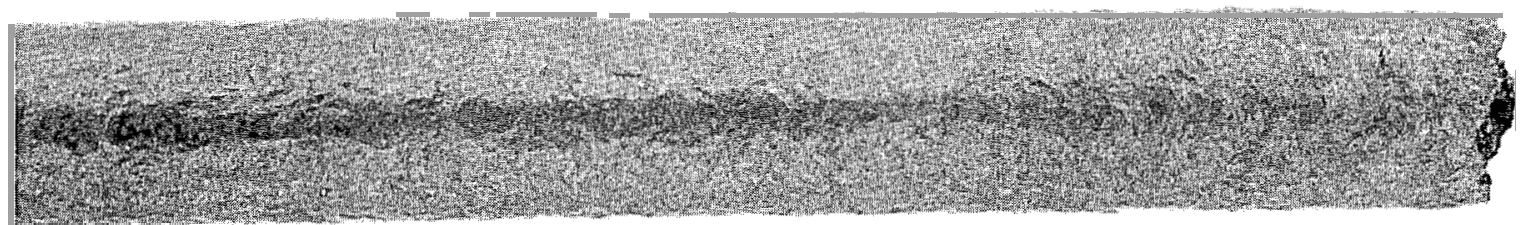

$5 \mathrm{X}$

b. Tested at $150 \mathrm{C}$

RM23579

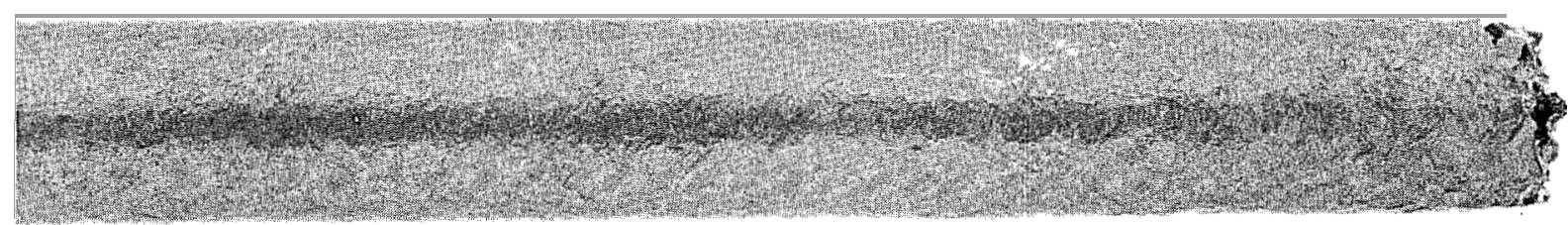

$5 X$

c. Tested at $250 \mathrm{C}$

RM23577

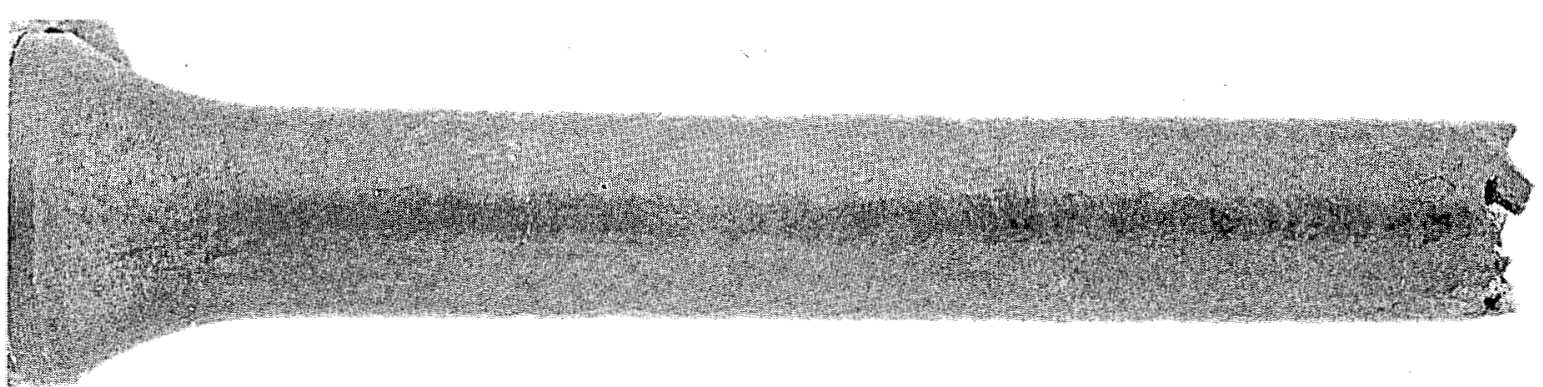

$5 \mathrm{X}$

d. Tested at $350 \mathrm{C}$

$\mathrm{RM} 23578$

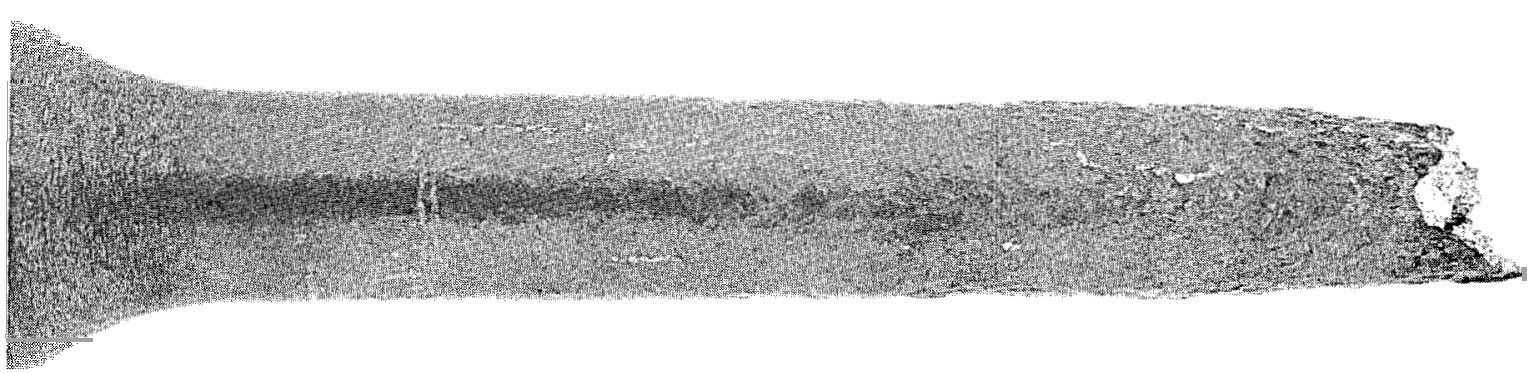

FIGURE I -7. TYPE 5 URANIUM (DINGOT) TENSILE SPECIMENS

Notice the absence of necking in the specimen tested at $350 \mathrm{C}$. At both 25 and $350 \mathrm{C}$ this material exhibited less elongation than it did at roorn temperature. 
compared to the fracture exhibited by the specimens from ingot uranium tested at the same temperature and shown in Figures I- 4 and I- 6.

After photographing, the specimens were mounted, polished, and examined by metallog raphic techniques at magnifications up to $1000 \mathrm{X}$ utilizing bright-field and polarized-light illumination. Of particular interest were the fracture areas and the portions of the specimens where rupturing had just been initiated. In Figures I- 8 through I- 12 are shown photomicrographs typical of the structures exhibited by selected specimens. The fracture mechanisms exhibited by the Types 1,3 , and 5 dingot uraniums appeared almost identical metallographically. Each tended to fail by void formation and crack propagation except when tested at $350 \mathrm{C}$, where cracks formed and progressed as the test progressed. The se rupture modes are in Figures I-8, I-9, and I- 10 . Figure I- 8 shows the appearance of the fracture area after testing at 250,350 , and $450 \mathrm{C}$; Figure I- 9 shows the initiation and propagation of cracks in a specimen tested at $350 \mathrm{C}$. Notice that the cracks do not appear to be initiated in nor are they propagated by grain boundaries. In fact, no evidence was found in any of the specimens to suggest that the grain boundaries played a major role in the fracturing of the specimens.

In Figure I- 10 are shown the areas furthest removed from the fracture in which cracks or voids were detected. The specimens tested at $250 \mathrm{C}$ exhibited small fissures which became more rounded as the fracture area was approached. The photomicrograph of the specimen tested at $350 \mathrm{C}$ shows the small fissures perpendicular to the direction of the applied stress; these elongated but did not round out as did the fissures formed at the higher and lower temperatures. The specimen tested at $450 \mathrm{C}$ exhibited small voids which enlarged and assumed an orientation parallel with the direction of the applied stress in the fracture area. The Type 5 uranium differed from the Type 1 and Type 3 uranium only in that the voids and cracks were somewhat smaller but more numerous.

In Figures I- 11 and I- 12 are shown photomic rographs of the Type 2 ingot uranium. This material tended to fracture in all cases in much the same manner as the materials tested in the original program performed for NLO. (7) Initiation of fracture was associated with the fracture or parting of the carbide particles. The resulting voids then increased in size and eventually led to rupture of the specimen. This is illustrated in the photomicrographs shown in Figure I-11, where the formation of the voids has just been initiated, and in Figure I-12, where the voids have increased in size and caused rupture to occur. The Type 4 uranium differed in the respect that the carbide particles were larger, less inclined to form stringers, and, apparently, more prone to fracture during testing.

\section{Conclusions}

As a result of the mechanical tests and metallographic evaluations discussed in the preceding sections the following conclusions can be made:

(1) Under the conditions imposed by the se tests utilizing an abnormally low strain rate both production-grade ingot and dingot uranium will exhibit a secondary minimum in total elongation at approximately $350 \mathrm{C}$. This minimum will be most pronounced in the low-carbon materials. 


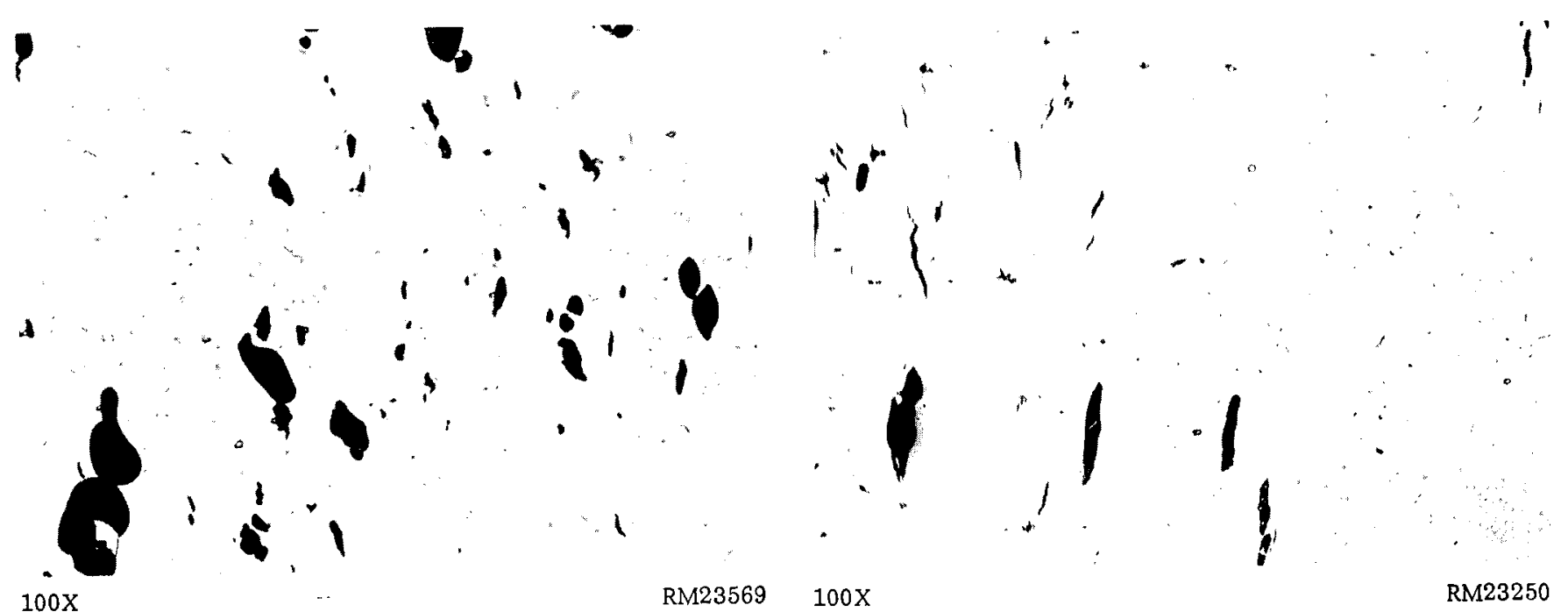

a. Tested at $250 \mathrm{C}$

b. Tested at $350 \mathrm{C}$

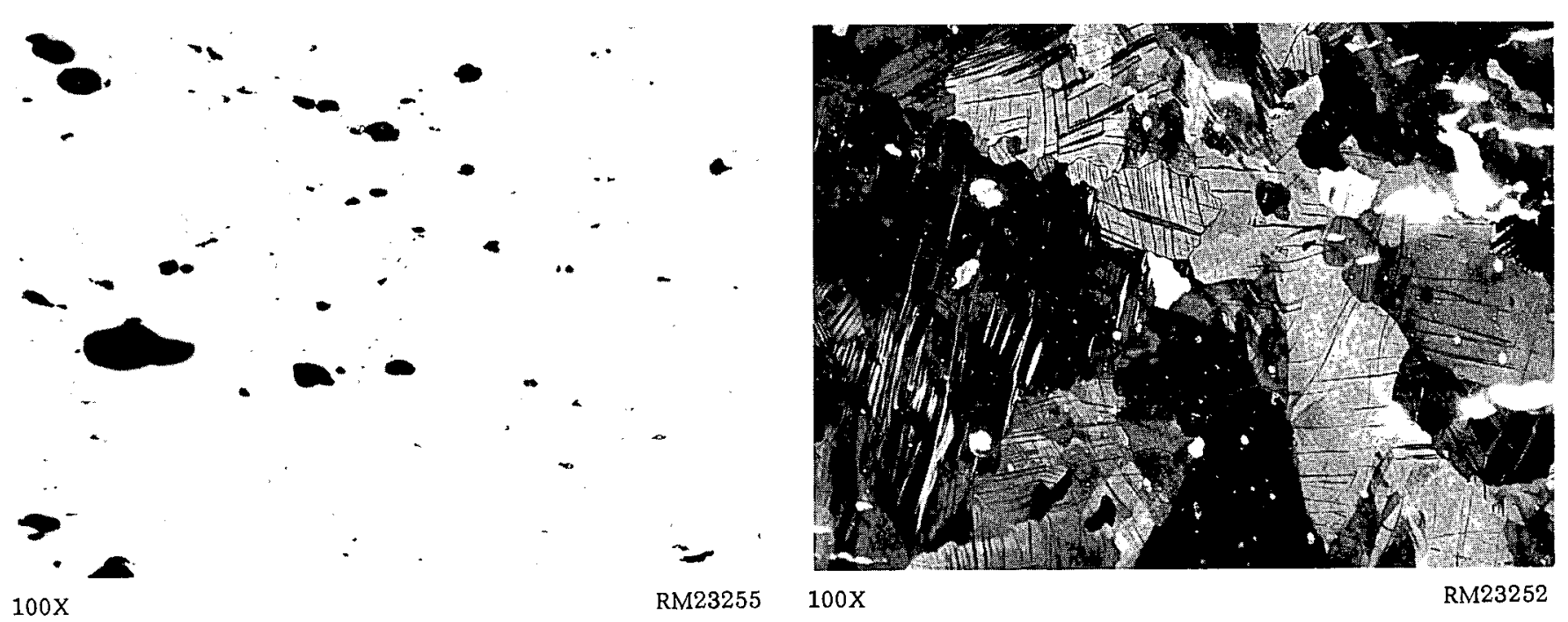

c. Tested at $450 \mathrm{C}$

d. Tested at $350 \mathrm{C}$

FIGURE I-8. SPECIMENS OF TYPE 3 URANIUM (DINGOT) AFTER TENSILE TESTING The areas shown are adjacent to the fracture. 

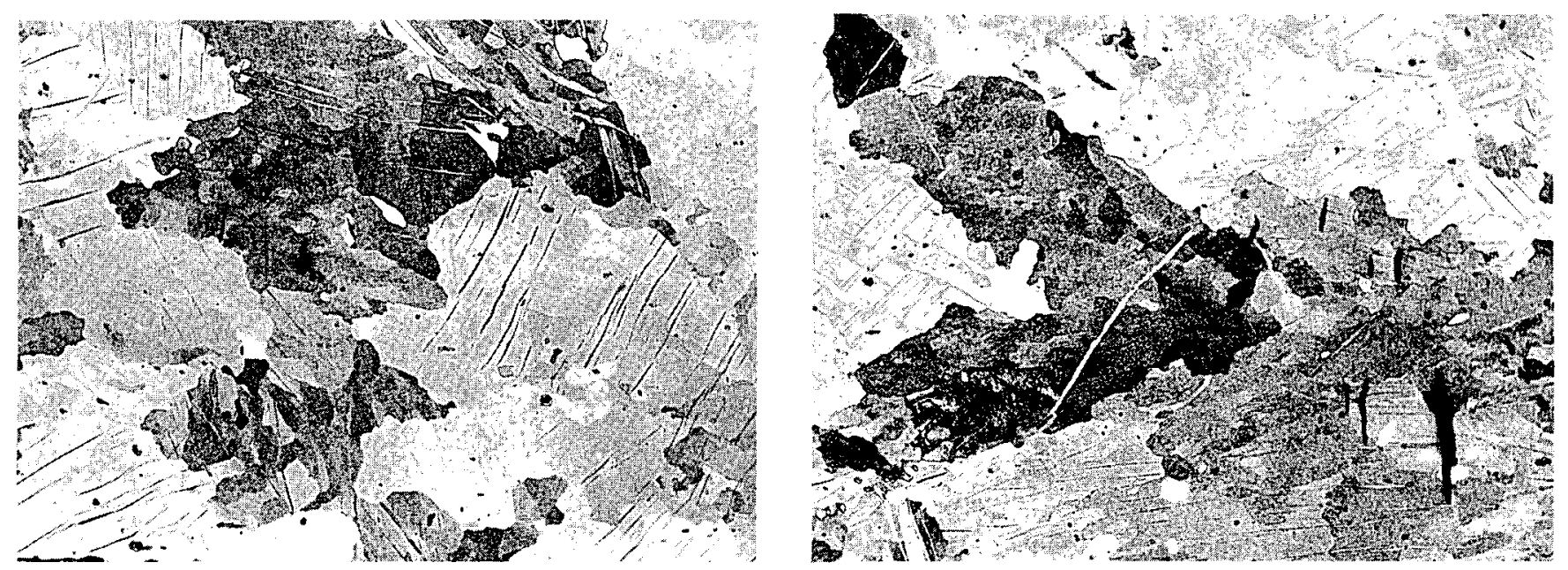

RM22908

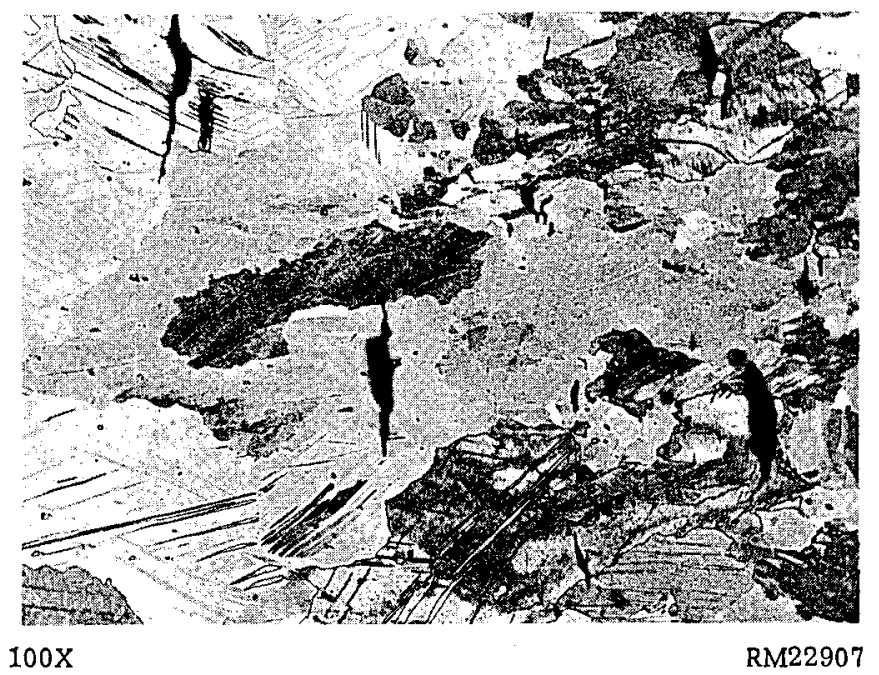

FIGURE I -9. PHOTOMICROGRAPHS OF ETCHED SPECIMEN OF TYPE 1 URANIUM (DINGOT) AFTER TESTING AT 350 C

This type of specimen preparation proved useful on only a limited number of specimens. Notice that the cracks do not appear to be associated with the grain boundaries. 


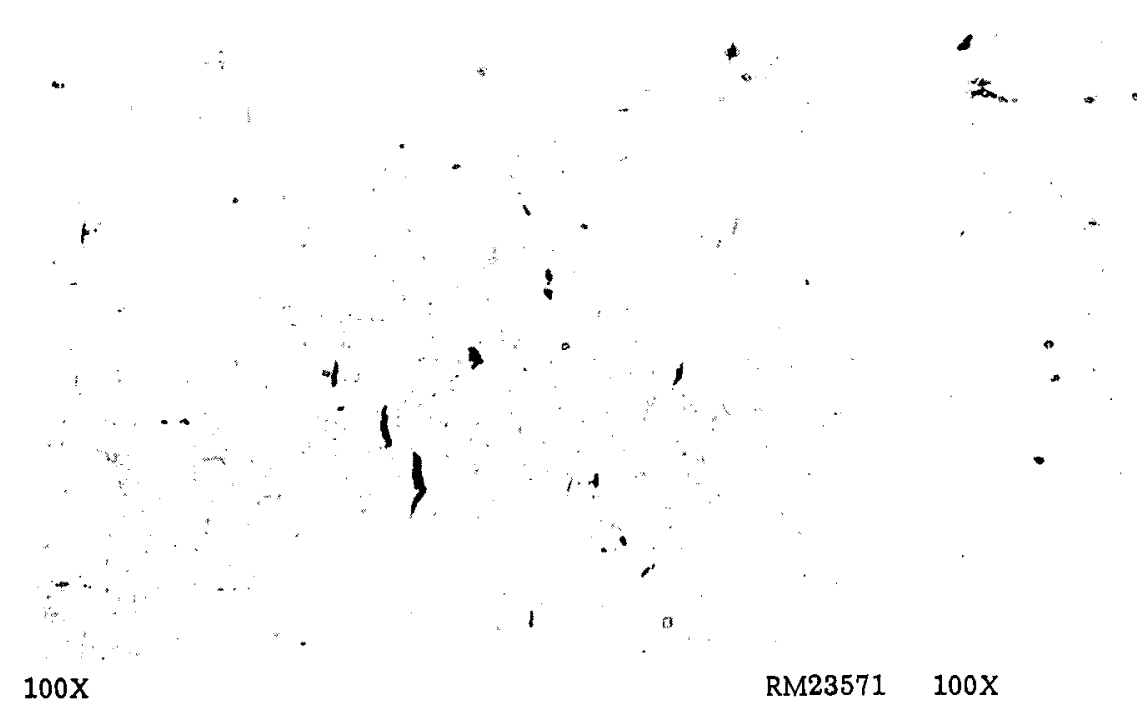

$\mathrm{RM} 23251$

a. Tested at $250 \mathrm{C}$

b. Tested at $350 \mathrm{C}$

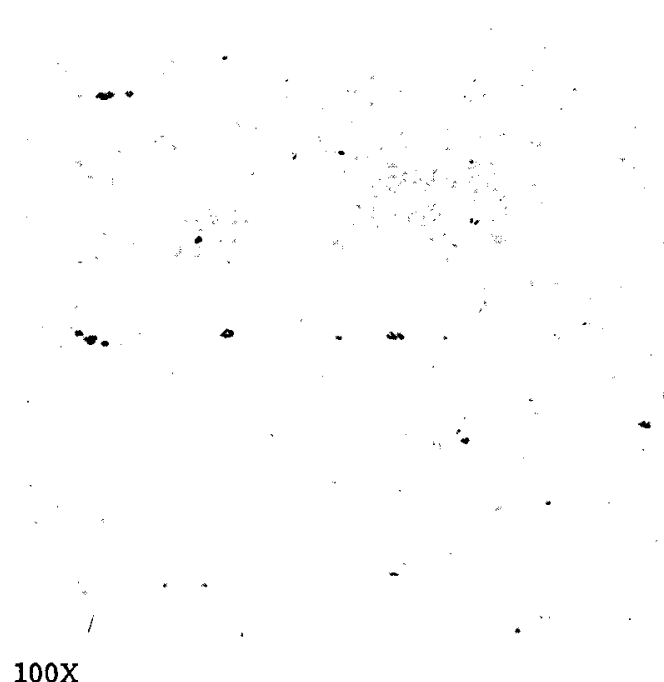

c. Tested at $450 \mathrm{C}$

$\mathrm{RM} 23256$

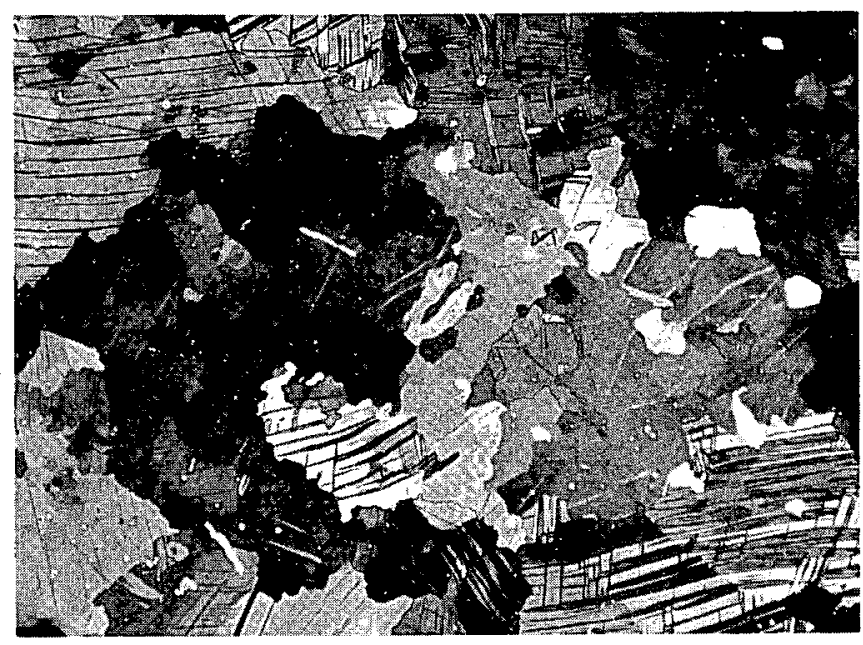

$100 \mathrm{X}$

RM23253

d. Tested at $350 \mathrm{C}$

FIGURE I-10. SPECIMENS OF TYPE 3 URANIUM (DINGOT) AFTER TENSILE TESTING

The areas shown are those furthest from areas in the specimen in which rupturing appears to have been initiated. Notice that at $350 \mathrm{C}$ the ruptures are predominantly cracks at right angles to the direction of the applied stress. 


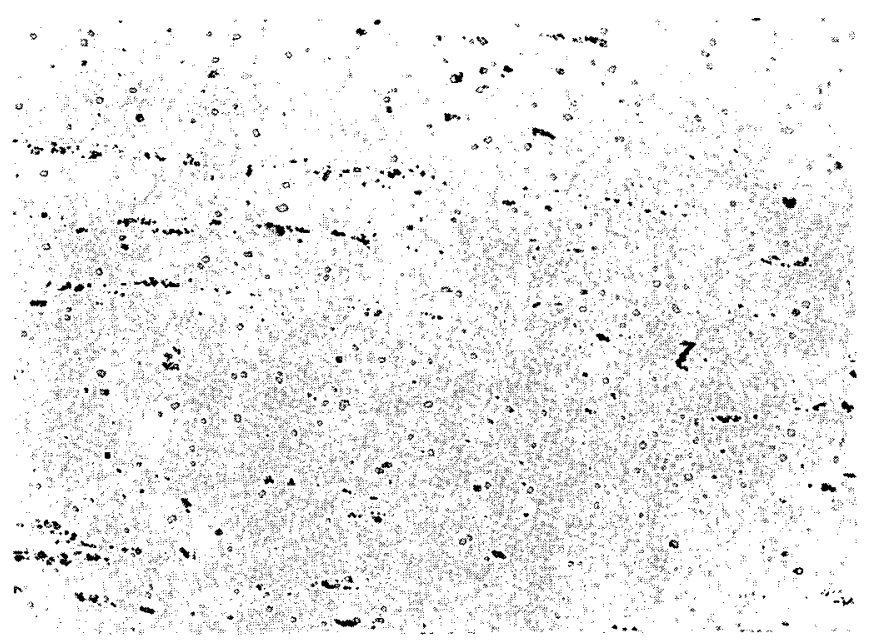

$100 X$
RM23593 a. Tested at $150 \mathrm{C}$

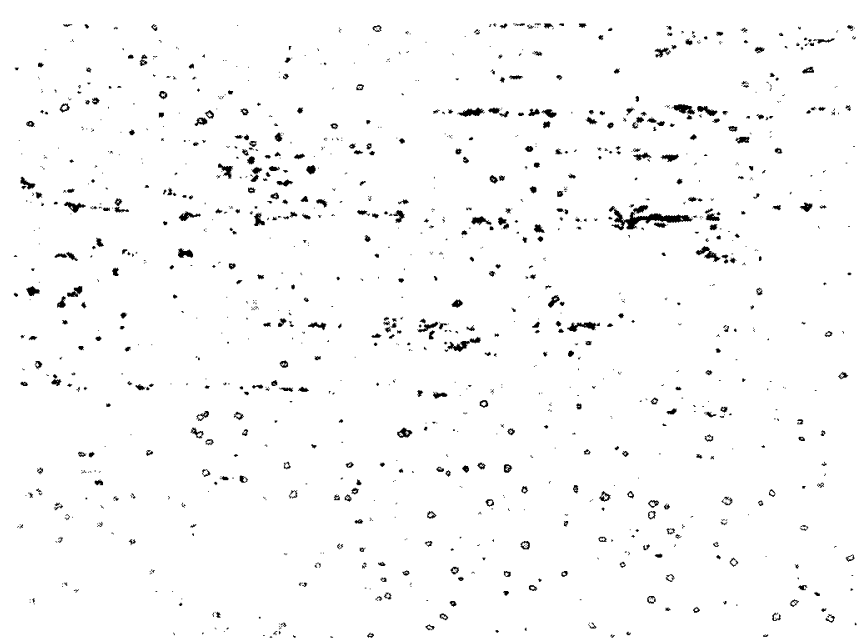

$100 \mathrm{X}$

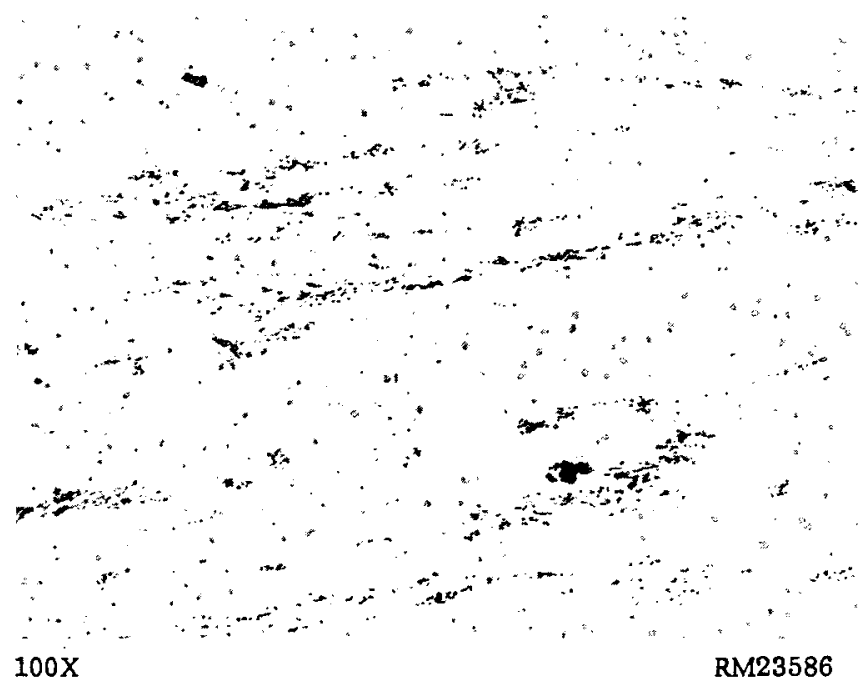

b. Tested at $250 \mathrm{C}$

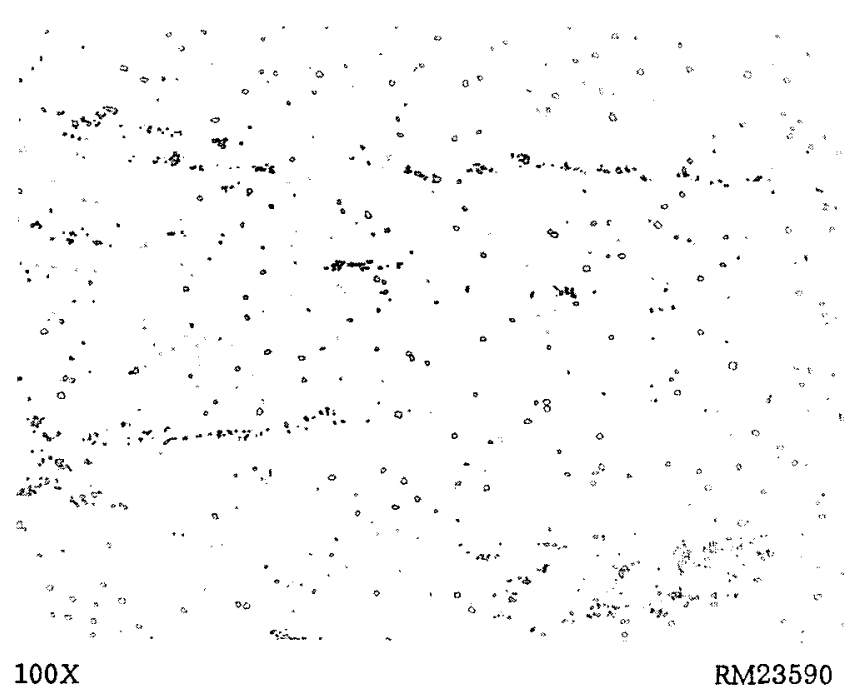

d. Tested at $450 \mathrm{C}$

c. Tested at $350 \mathrm{C}$

FIGURE 1-11. TYPE 2 URANIUM (INGOT) SPECIMENS AFTER TENSILE TESTING

The areas shown were those in which the first evidence of rupturing was noted. 


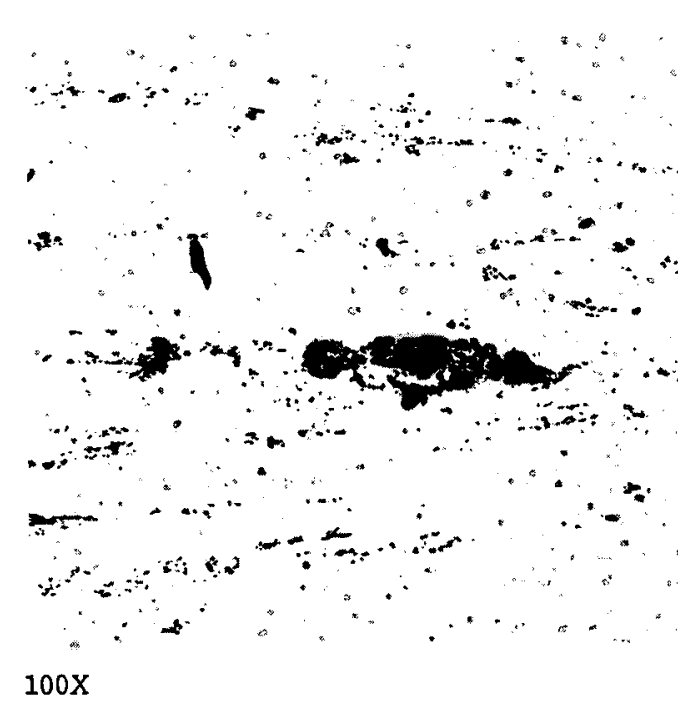

a. Tested at $150 \mathrm{C}$

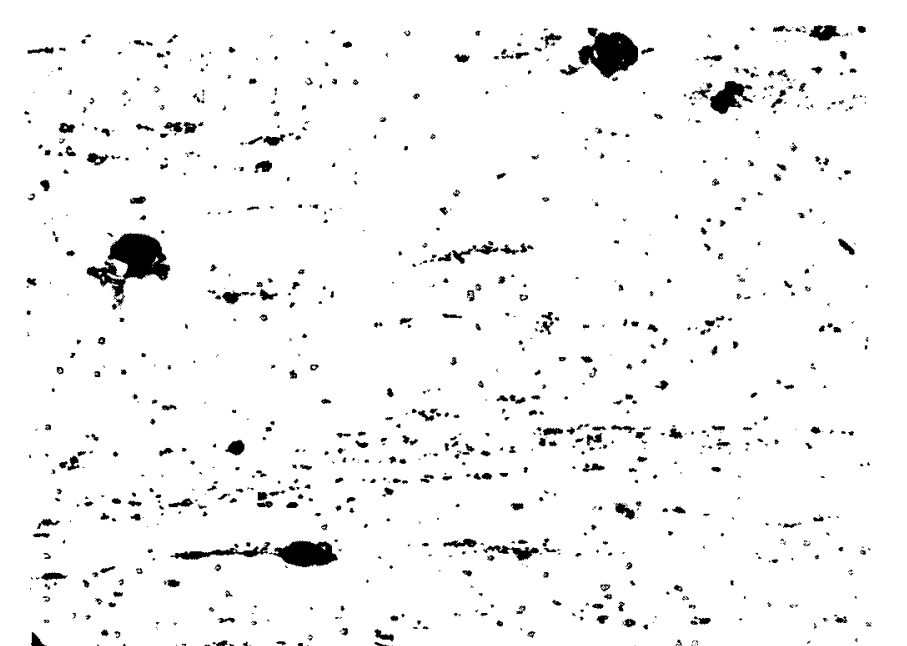
$100 \mathrm{X}$
RM23591 100X

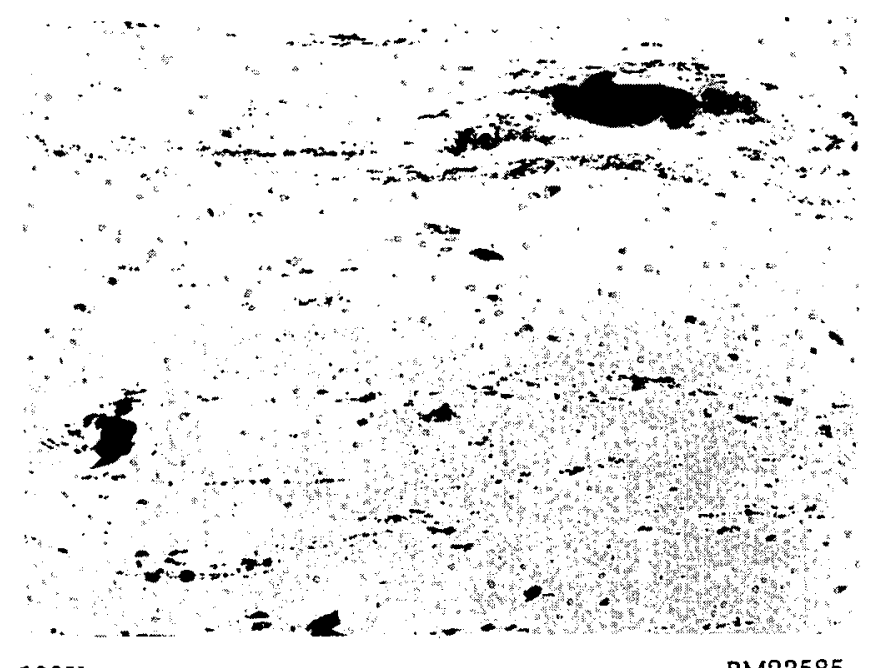

RM23585

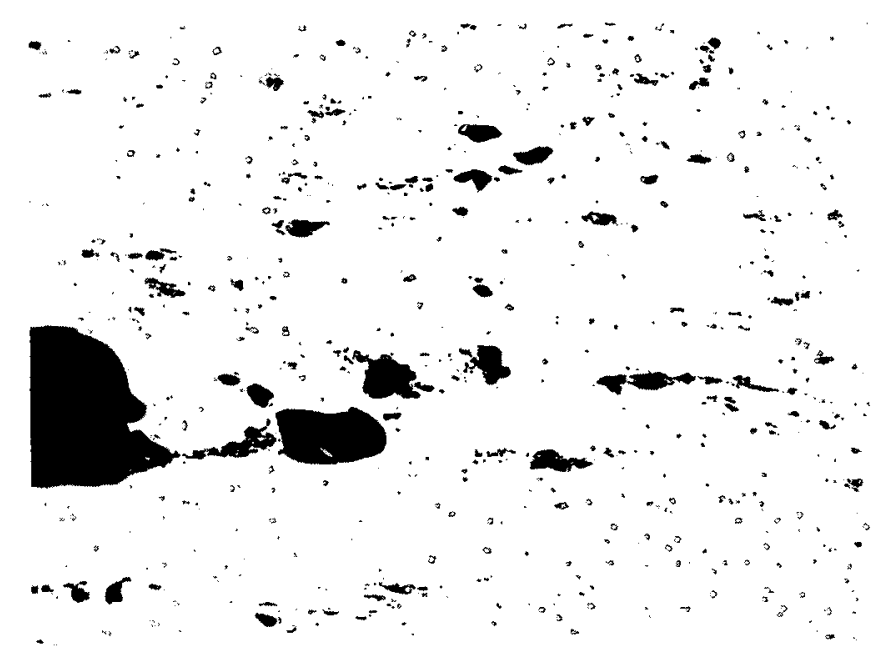

RM23587 $100 \mathrm{X}$

RM23589

c. Tested at $350 \mathrm{C}$

d. Tested at $450 \mathrm{C}$

FIGURE I-12. TYPE 2 URANIUM (INGOT) SPECIMENS AFTER TENSILE TESTING

The areas depicted were adjacent to the fracture. 
(2) It is believed that the greater elongation exhibited by the ingot uranium is due to the larger number of voids which occur during testing. This results in elongation over a greater area of the specimens and also decreases stress concentrations within a specific area. The smaller number of voids or fissures in the low-carbon material results in localized concentration of the stresses within the specimen and therefore to earlier rupture.

(3) The surface cracks or ruptures noted in previous tests were a result of the machine finish, since none were noted in the se tests where ground specimens were employed.

(4) The additions of aluminum, iron, and silicon to the Type 4 uranium probably contributed to the larger particle size of the carbides and decreased the number of stringers in this material.

(5) In all but one case the material which exhibited the greatest yield strength also exhibited the greatest irradiation stability. This property might be used to screen candidate materials prior to irradiation tests.

\section{STUDIES ON NLO MATERIALS}

Introduction

Because of the limited range of compositions studied and the complexity of the subject, insufficient data were obtained in the studies of SRI, materials to relate conclusively the irradiation stability of the materials to their chemical composition and their mechanical properties and modes of fracture. Therefore, further studies in this area were desirable. Since higher operating temperatures are desired in future fuel loadings and it is believed essential that the fuel contain additions of aluminum, iron, and silicon, it appeared also desirable to ascertain the effects of the se additions at levels somewhat greater than the levels investigated. Therefore, a program was initiated at Battelle at the request of the National Lead Company of Ohio in which seven different types of uranium were evaluated by tensile testing at 250,350, and $450 \mathrm{C}$ and exhaustive metallog raphic examinations in an effort to determine the effects of the various additions on the mechanical properties of uranium and its mode of fracture. Specifically, the metallographic examinations were intended to provide more information on the relationship of fracture with the grain boundaries and grain-boundary phases that might be exhibited by the materials. The complementary study concerned with the microstructural differences in cast uranium of varied chemistry and casting history discussed in Part II of this report was also concerned with the grain-boundary phases.

\section{Experimental Procedures}

The analyses of the seven materials chosen for evaluation are listed in Table I-4. These compositions were chosen primarily on the basis of carbon content and various 
levels of aluminum, iron, and silicon. The carbon content of the materials was within the range normally encountered in ingot uranium. The aluminum levels we re all low except for the Type B material, which contained $292 \mathrm{ppm}$ aluminum. The iron and silicon ranges were somewhat wider than normally encountered in production material. The iron content varied between 72 to $263 \mathrm{ppm}$, and the silicon level varied between 25 and $326 \mathrm{ppm}$.

TABLE I-4. CHEMICAL COMPOSITION OF URANIUM TENSILE SPECIMENS PREPARED FROM THE NLO MATERIAL

\begin{tabular}{cccccccc}
\hline & \multicolumn{7}{c}{ Chemical Analysis(a), ppm } \\
\cline { 2 - 8 } Element & Type A & Type B & Type C & Type D & Type E & Type F & Type G \\
\hline A1 & $<6$ & 292 & 11 & 8 & 6 & 8 & 7 \\
$\mathrm{~B}$ & $<0.15$ & $<0.15$ & $<0.15$ & $<0.15$ & $<0.15$ & $<0.15$ & $<0.15$ \\
$\mathrm{Be}$ & $<1$ & $<1$ & $<1$ & $<1$ & $<1$ & $<1$ & $<1$ \\
$\mathrm{BI}$ & $<1$ & $<1$ & $<1$ & $<1$ & $<1$ & $<1$ & $<1$ \\
$\mathrm{C}$ & 451 & 522 & 495 & 518 & 590 & 818 & 760 \\
$\mathrm{Cd}$ & $<0.2$ & $<0.2$ & $<0.2$ & $<0.2$ & $<0.2$ & $<0.2$ & $<0.2$ \\
$\mathrm{Cr}$ & 7 & 9 & 9 & 7 & 6 & 31 & 5 \\
$\mathrm{Cu}$ & 4 & 8 & 11 & 5 & 2 & 7 & 3 \\
$\mathrm{Fe}$ & 143 & 114 & 153 & 101 & 72 & 253 & 263 \\
$\mathrm{Mg}$ & 6 & 7 & 6 & 9 & 9 & 10 & 5 \\
$\mathrm{Mn}$ & 7 & 6 & 6 & 7 & 5 & 10 & 4 \\
$\mathrm{Mo}$ & $<6$ & $<6$ & $<6$ & $<6$ & $<6$ & $<6$ & $<6$ \\
$\mathrm{~N}$ & 43 & 41 & 53 & 67 & 59 & 49 & 29 \\
$\mathrm{Ni}$ & 18 & 31 & 25 & 23 & 22 & 38 & 23 \\
$\mathrm{~Pb}$ & 2 & 3 & 2 & 3 & $<1$ & 4 & $<1$ \\
$\mathrm{Si}$ & 99 & 98 & 96 & 326 & 25 & 61 & 326 \\
$\mathrm{Sn}$ & $<1$ & 1 & 4 & 1 & $<1$ & 2 & $<1$ \\
$\mathrm{~V}$ & $<5$ & $<5$ & $<5$ & $<5$ & $<5$ & $<5$ & $<5$ \\
$\mathrm{Zn}$ & $<20$ & $<20$ & $<20$ & $<20$ & $<20$ & $<20$ & $<20$ \\
\hline \hline
\end{tabular}

(a) Analyses were performed at NLO.

Six tensile test specimens were cut from a longitudinal section of each hollow fuel core. The specimens measured $4.5 \mathrm{in}$. in length and had a gage section 0.1875 in. in diameter by 2 in. in length after grinding. All tests were concluded in the same manner as discussed earlier. Thirty six specimens were tested, including duplicates run where deemed desirable.

\section{Evaluation of Mechanical Properties}

Stress-strain data were plotted for each specimen tested. From these curves and measurements of the ruptured specimens, the following data were obtained and tabulated as shown in Table I-5.

(1) Fracture strength

(2) Ultimate strength

(3) Reduction in area

(4) Total elongation

(5) Modulus of elasticity

(6) Yield strength

(7) Uniform elongation. 
TABLE I-5. TENSILE PROPERTIES OF THE NLO URANIUM SPECIMENS AT ELEVATED TEMPERATURES

\begin{tabular}{|c|c|c|c|c|c|c|c|c|c|c|}
\hline \multicolumn{2}{|c|}{ Test Conditions } & \multirow[b]{2}{*}{$\begin{array}{l}\text { Maximum } \\
\text { Load, lb }\end{array}$} & \multirow{2}{*}{$\begin{array}{c}\text { Fracture } \\
\text { Load, } \\
\text { lb }\end{array}$} & \multirow{2}{*}{$\begin{array}{c}\text { Fracture } \\
\text { Strength, } \\
10^{3} \text { psi }\end{array}$} & \multirow{2}{*}{$\begin{array}{l}\text { Ultimate } \\
\text { Strength, } \\
10^{3} \text { psi }\end{array}$} & \multirow{2}{*}{$\begin{array}{l}\text { Reduction } \\
\text { in Area, } \\
\text { per cent }\end{array}$} & \multirow{2}{*}{$\begin{array}{c}\text { Total } \\
\text { Elongation, } \\
\text { per cent }\end{array}$} & \multirow{2}{*}{$\begin{array}{c}\text { Elastic } \\
\text { Modulus, } \\
10^{6} \text { psi }\end{array}$} & \multirow{2}{*}{$\begin{array}{c}0.2 \text { Per } \\
\text { Cent } \\
\text { Offset } \\
\text { Yield } \\
\text { Strength, } \\
10^{3} \text { psi }\end{array}$} & \multirow{2}{*}{$\begin{array}{c}\text { Uniform } \\
\text { Elongation } \\
\text { in } 2 \mathrm{In} ., \\
\text { in. }\end{array}$} \\
\hline $\begin{array}{c}\text { Temperature, } \\
\text { C }\end{array}$ & $\begin{array}{l}\text { Time, } \\
\text { min }\end{array}$ & & & & & & & & & \\
\hline 250 & 286 & 1970 & 1746 & 60.8 & 68.5 & 32.2 & 23.0 & 23.2 & 37.0 & 0.204 \\
\hline 350 & 202 & 1430 & 1240 & 43.2 & 50.0 & 46.8 & 18.0 & 20.0 & 33.9 & 0.129 \\
\hline 450 & 169 & 778 & 210 & 7.3 & 27.1 & 62.8 & 17.0 & 17.0 & 23.3 & 0.190 \\
\hline \multicolumn{11}{|c|}{ Type B Uranium } \\
\hline \multicolumn{11}{|c|}{ Type C Uranium } \\
\hline 250 & 286 & 1820 & 1620 & 58.8 & 66.0 & 40.7 & 23.5 & -- & 40.0 & 0.184 \\
\hline 350 & 178 & 1386 & 1100 & 40.4 & 50.8 & 42.8 & 15.5 & 21.8 & 36.6 & 0.093 \\
\hline 450 & 215 & 565 & 3 & 0.11 & 20.0 & 70.7 & 22.5 & 11.2 & 17.8 & 0.016 \\
\hline \multicolumn{11}{|c|}{ Type D Uranium } \\
\hline 250 & 280 & 2150 & 1950 & 67.95 & 74.8 & 39.6 & 24.0 & 26.0 & 41.0 & 0.164 \\
\hline 350 & 169 & 1610 & 1500 & 51.5 & 55.2 & 21.0 & 14.5 & 25.0 & 39.5 & 0.105 \\
\hline \multicolumn{11}{|c|}{ Type F Uranium } \\
\hline 250 & 272 & 2000 & 1675 & 60.9 & 72.5 & 53.8 & 22.5 & -- & 37.5 & 0.169 \\
\hline 350 & 131 & 1525 & 642 & 23.1 & 55.5 & 48.7 & 11.5 & 23.0 & 35.0 & 0.091 \\
\hline 450 & 191 & 755 & 340 & 12.4 & 27.4 & 69.6 & 18.5 & 16.8 & 24.6 & 0.013 \\
\hline \multicolumn{11}{|c|}{ Type G Uranium } \\
\hline 250 & 247 & 1760 & 1300 & 47.5 & 64.5 & 31.2 & 22.5 & -- & 42.5 & 0.167 \\
\hline 350 & 175 & 1270 & 880 & 31.9 & 46.1 & 46.5 & 16.0 & 25.2 & 36.8 & 0.066 \\
\hline 450 & 214 & 835 & 242 & 8.85 & 30.4 & 71.1 & 19.0 & 17.3 & 26.2 & 0.028 \\
\hline
\end{tabular}



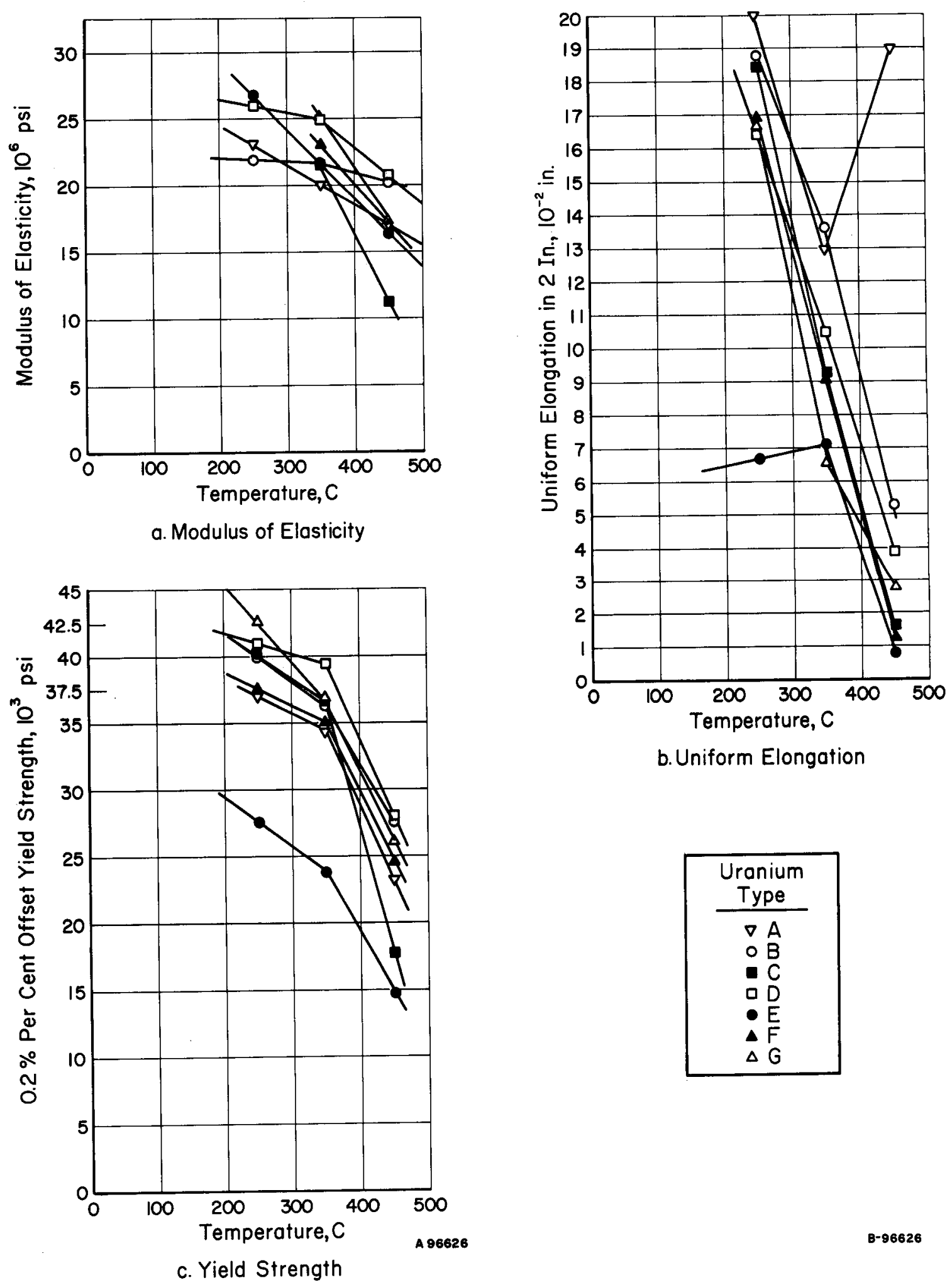

b. Uniform Elongation

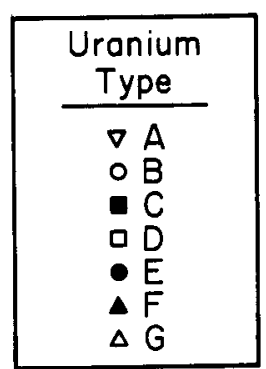

FIGURE I-13. EFFECT OF TEMPERATURE ON THE MECHANICAL PROPERTIES OF THE NLO MATERIALS 

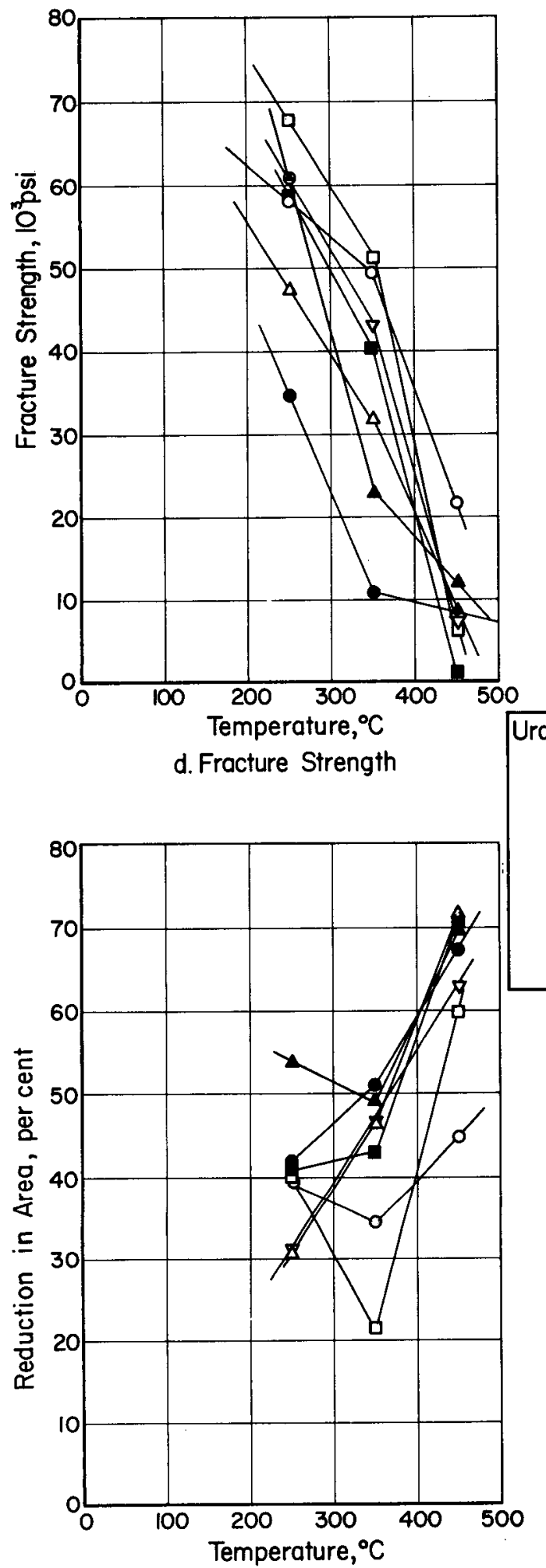

f. Reduction in, Area

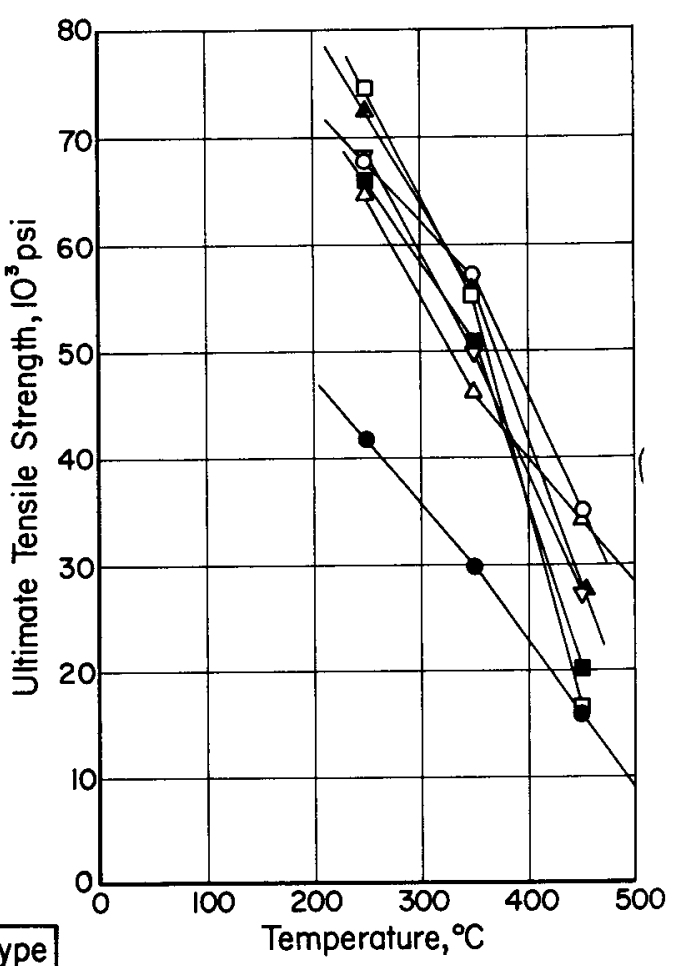

e. Tensile Strength

$\nabla \mathrm{A}$

- B

- C

$\square \mathrm{D}$

- $E$

$\triangle F$

$\Delta G$

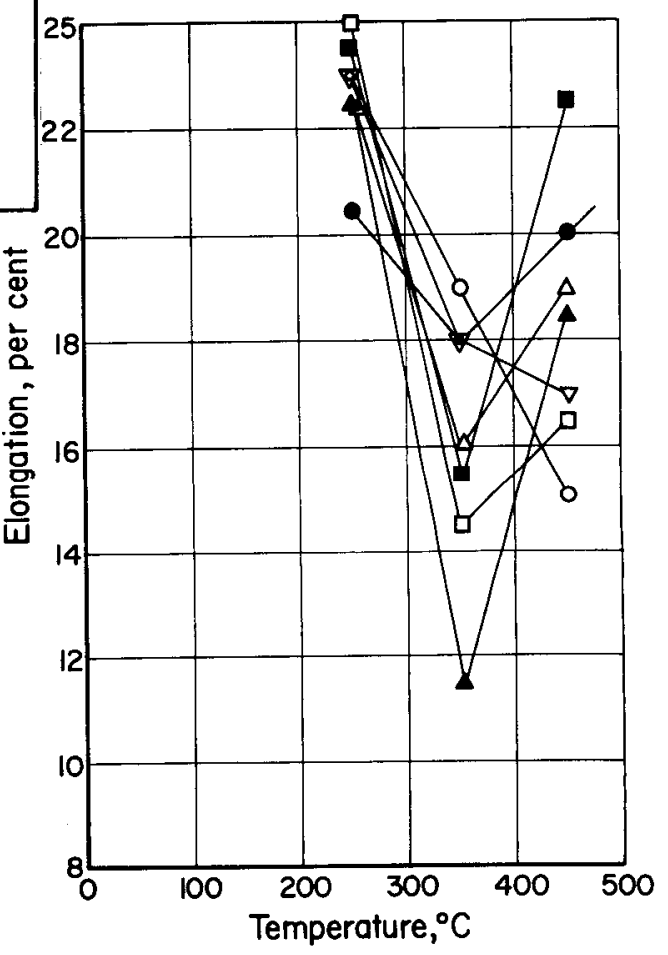

g. Total Elongation :-96627

FIGURE I-13. (CONTINUED) 
These data were then graphed on rectangular coordinate pape $r$ as a function of the temperature as shown in Figure I- 13. The total elongation to maximum load was assumed to be the uniform elongation. An examination of total elongation versus temperature showed that all but two of the materials tested exhibited a pronounced minimum at $350 \mathrm{C}$ similar to that shown in the previous study. The two materials that failed to exhibit a decrease in elongation were the Types A and B uranium; the se materials also exhibited the greatest amount of uniform elongation at all temperatures. No explanation for this similar behavior is apparent from the chemical composition of the materials. The composition of the Type A material was typical of normal production fuel cores. The Type B material had a high aluminum content and a normal carbon content and contained small quantities of iron and silicon. The minimum elongation at $350 \mathrm{C}$ was exhibited by the Type $F$ uranium, which contained the largest carbon content. Further attempts to correlate the elongation, uniform or total, with the chemistry of the materials were unproductive except in the case of the Type B uranium tested at $450 \mathrm{C}$. This material exhibited the greatest ultimate strength at this temperature and less reduction in area and elongation than did other materials. This behavior is attributed to the high content of aluminum of the specimens and seems to substantiate the data obtained during the previous study in which it was noted that aluminum appeared to stiffen the alloy at elevated temperatures.

The ultimate strengths of all of the materials except the Type $E$ were fairly well grouped except at $450 \mathrm{C}$ where considerable spread was noted. The Type E uranium exhibited extremely low ultimate strengths at all temperatures. The fracture strength of this material was also low at 250 and $350 \mathrm{C}$, but comparable with other materials at $450 \mathrm{C}$. The low strength properties were also reflected in its yield strength and can be correlated with its chemistry. This material contained fewer interstitials than any of the other materials tested. The results indicate that the improvements of physical properties that can be attributed to small quantities of aluminum, iron, and silicon ( 1 to $300 \mathrm{ppm}$ ) are evident at temperatures up to $350 \mathrm{C}$ but are not as pronounced as the test temperature increases.

The modulus-of-elasticity values that are shown are at best approximations but would indicate that silicon in quantities up to $326 \mathrm{ppm}$ is effective in increasing the modulus of elasticity of the materials at temperatures up to $450 \mathrm{C}$. This is shown by the modulus exhibited by the Type $D$ and Type $G$ materials, which both contained $326 \mathrm{ppm}$ silicon.

Metallographic Evaluations

Upon completion of the mechanical tests, each specimen was measured to obtain the elongation within the 2 -in. gage length and the reduction in area along the length of the specimen. The specimens were then examined at magnifications up to $40 \mathrm{X}$ and photographed at $5 \mathrm{X}$ to record the surface appearance, the appearance of the fracture, and the degree of necking exhibited by the reduced section. No surface cracks were evident in any of the specimens upon examination. The photographs are shown in Figures I- 14 through I-20. The Types A, D, and G materials exhibited brittle-type fractures at $250 \mathrm{C}$, the Type $\mathrm{F}$ uranium exhibited some evidence of necking at $250 \mathrm{C}$, and the Types B, C, and E materials exhibited fractures which were neither brittle nor plastic in nature with some pullout of material. At $350 \mathrm{C}$ only the Types A and G uranium exhibited any appreciable necking prior to fracture. At $450 \mathrm{C}$ all of the 


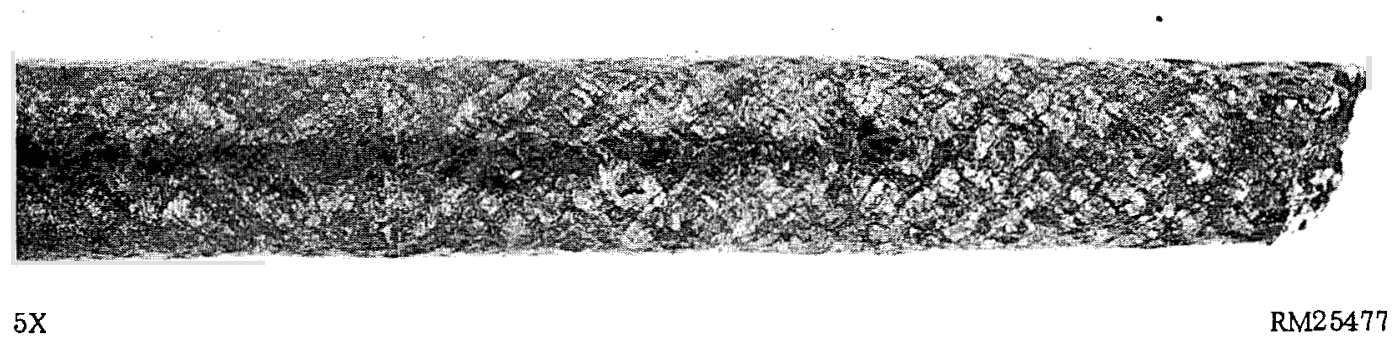

a. Tested at $250 \mathrm{C}$

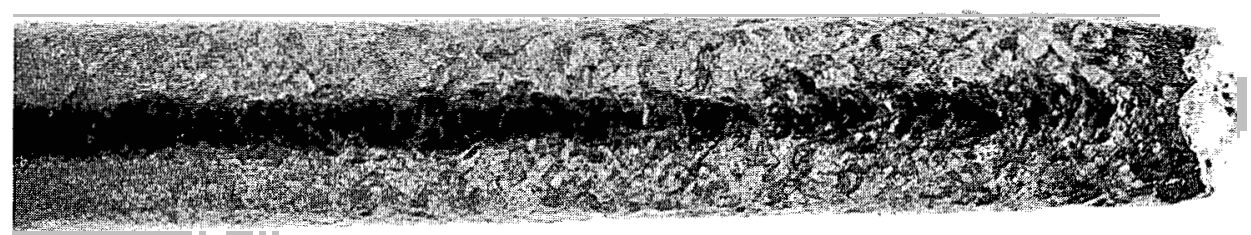

$5 X$

$\mathrm{RM} \angle D 4^{\prime} / 6$

b. Tested at $350 \mathrm{C}$

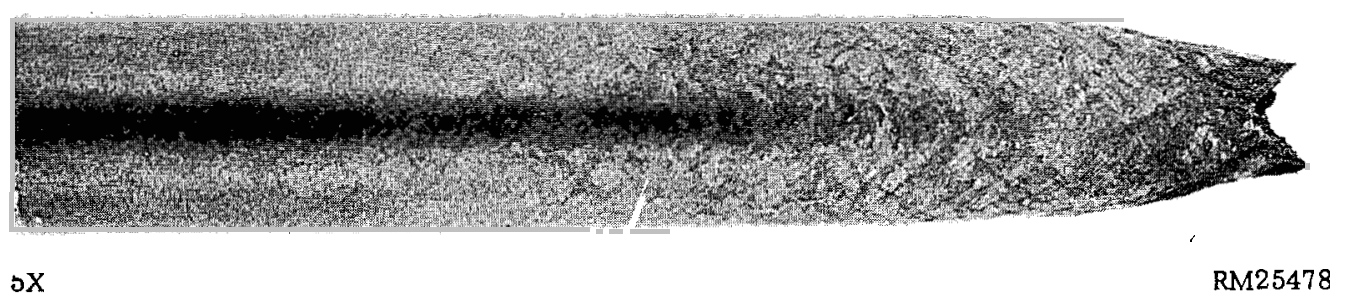

c. 'l'ested at $450 \mathrm{C}$

FIGURE I-14. TYPE A UKANIUM TENSILE SPECIMENS AFTER TESTING 


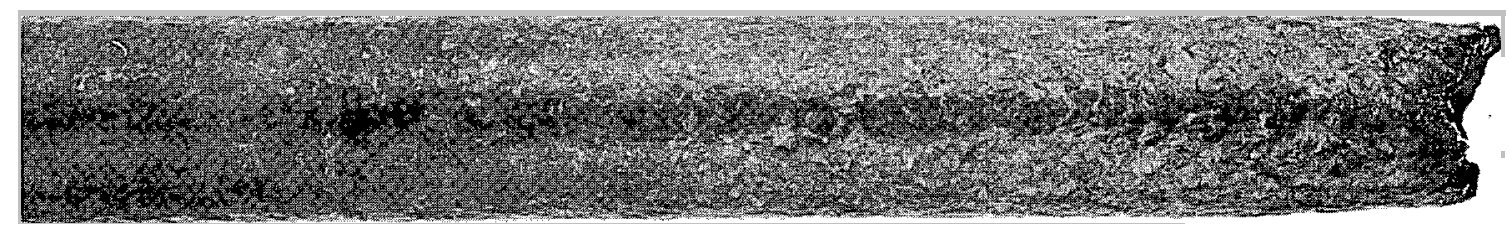

$5 x$

$\mathrm{RM} 25504$

a. Tested at $250 \mathrm{C}$

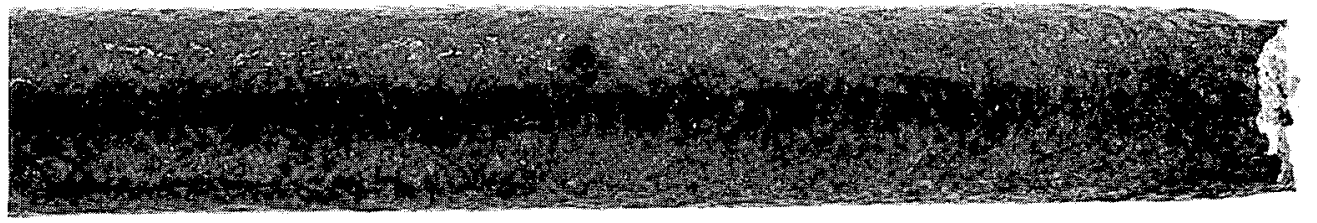

$5 x$

RM25505

b. Tested at $350 \mathrm{C}$

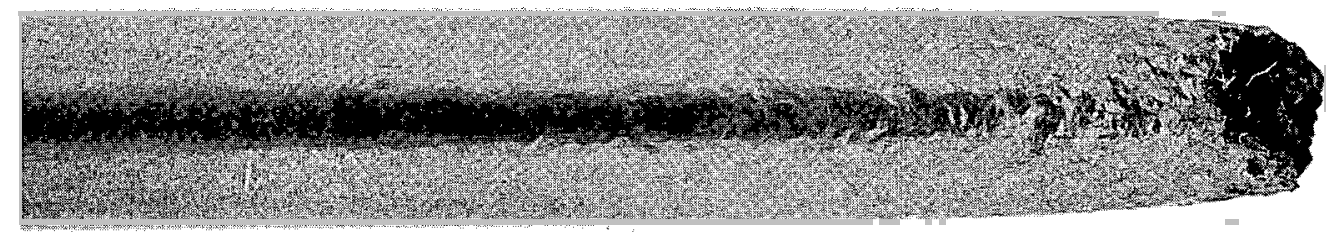

$5 \mathrm{X}$

RM25506

c. Tested at $450 \mathrm{C}$

FIGURE I-15. TYPE B URANIUM TENSILE SPECIMENS AFTER TESTING

The specimen tested at $450 \mathrm{C}$ exhibited less reduction in area and elongation than did any other material tested. It also exhibited the greatest ultimate strength. 


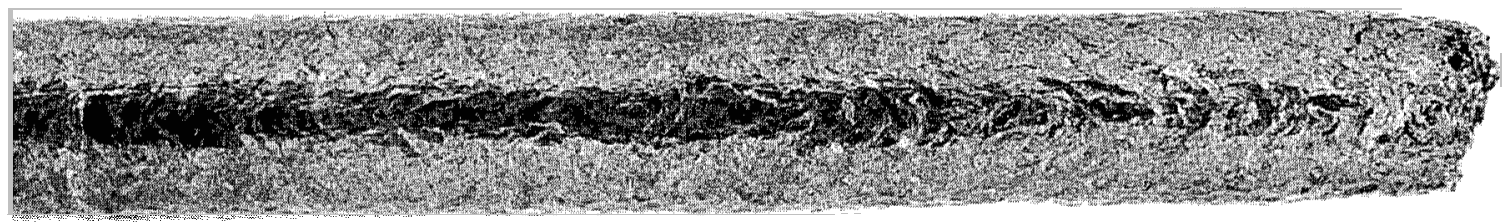

$5 X$

RM25513

a. Tested at $250 \mathrm{C}$

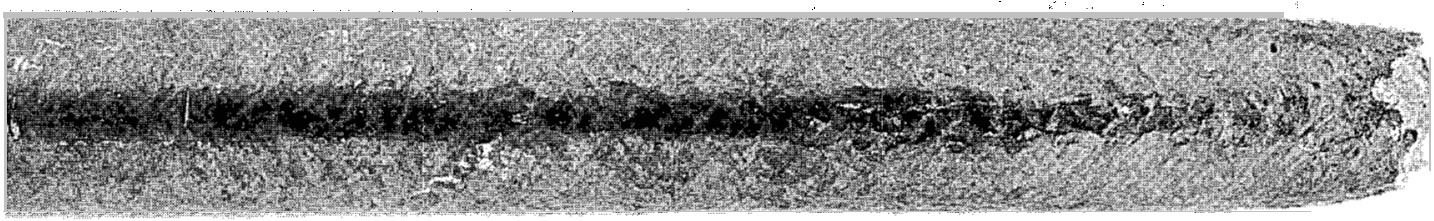

$5 \mathrm{X}$

RM25514

b. Tested at $350 \mathrm{C}$

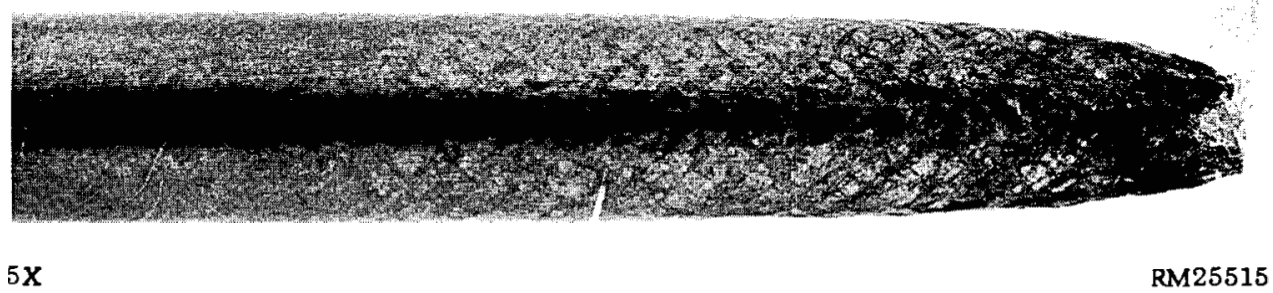

c. rested at $450 \mathrm{C}$

FIGURE I-16. TYPE C URANIUM TENSILE SPECIMENS AFTER TESTING 


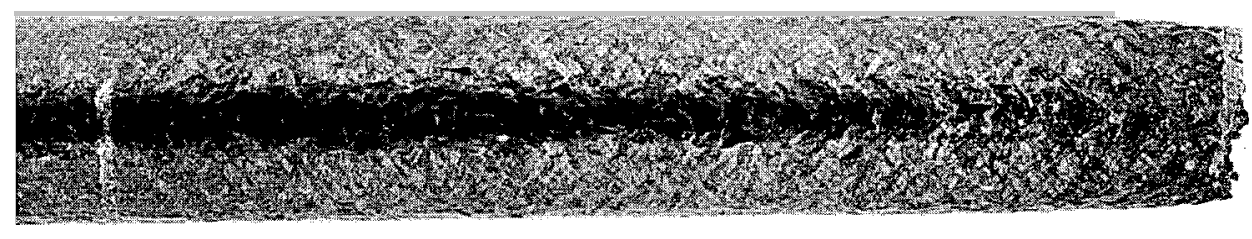

$5 \mathrm{x}$

RM25522

a. Tested at $250 \mathrm{C}$

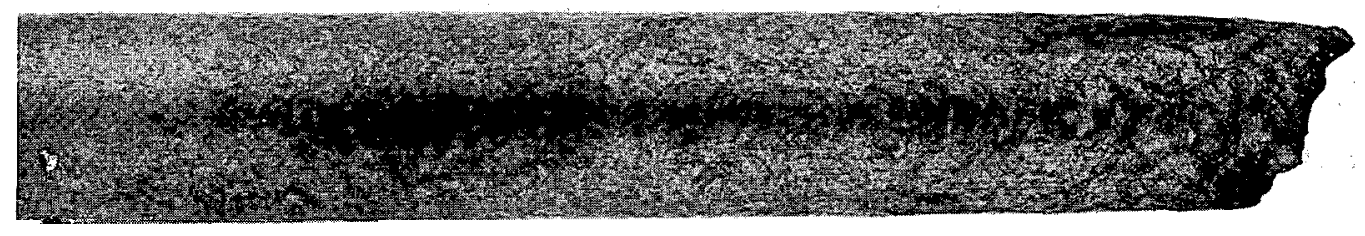

$5 \mathrm{X}$

RM25523

b. Tested at $350 \mathrm{C}$

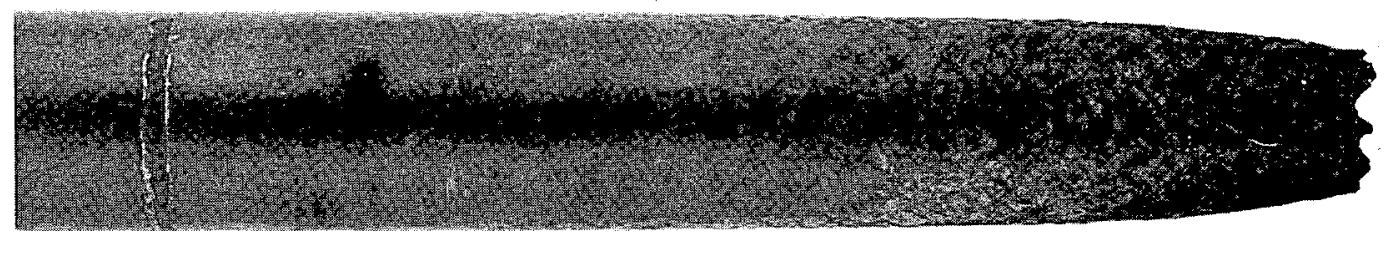

$5 \mathrm{X}$

RM25524

c. Tested at $450 \mathrm{C}$

FIGURE I-17. TYPE D URANIUM TENSILE SPECIMENS AFTER TESTING 


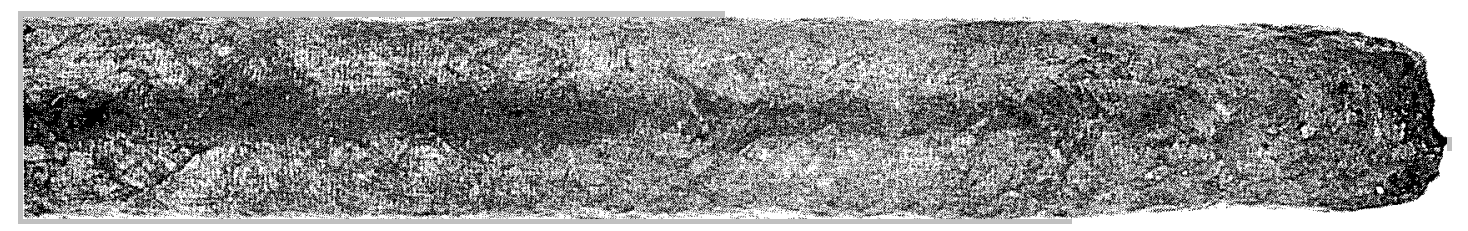

$5 X$

a. Tested at $250 \mathrm{C}$

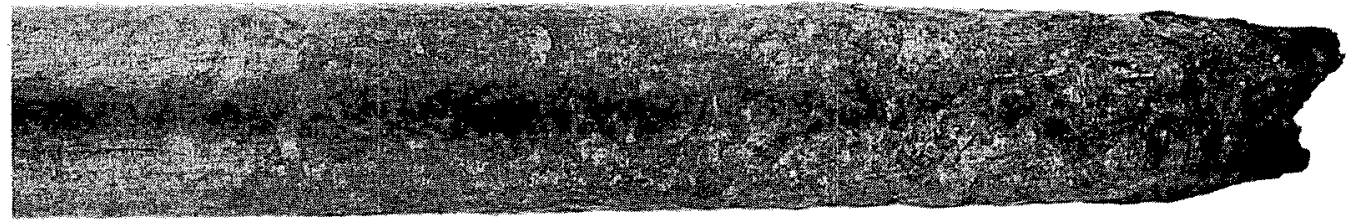

$5 x$

b. Tested at $350 \mathrm{C}$

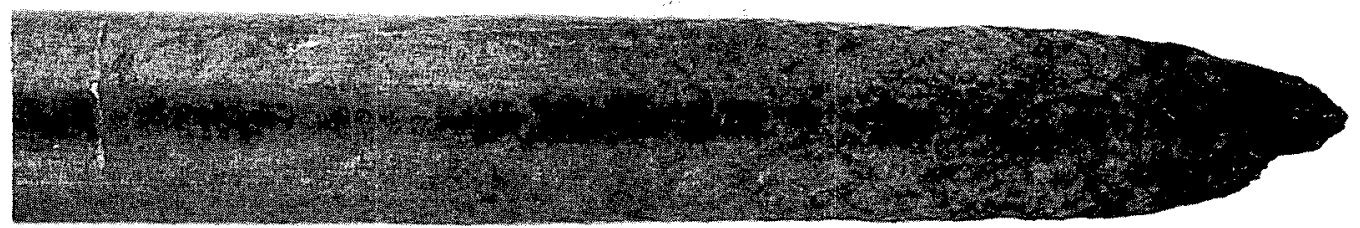

$5 X$

RM25533

c. 'iested at $450 \mathrm{C}$

FIGURE I-18. TYPE E URANIUM TENSILE SPECIMENS AFTER TESTING

Note the appearance of the specimen tested at $350 \mathrm{C}$ which exhibited a larger reduction in area than the specimen tested at $250 \mathrm{C}$ but less total elongation. 


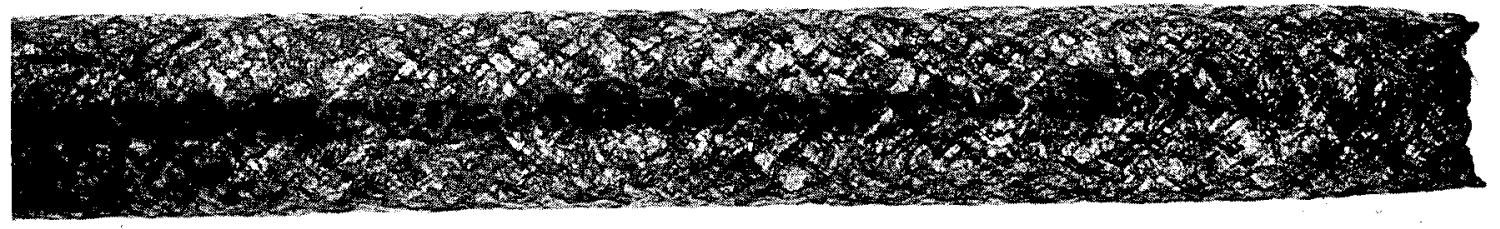

$5 \mathrm{X}$

RM25540

a. Tested at $250 \mathrm{C}$

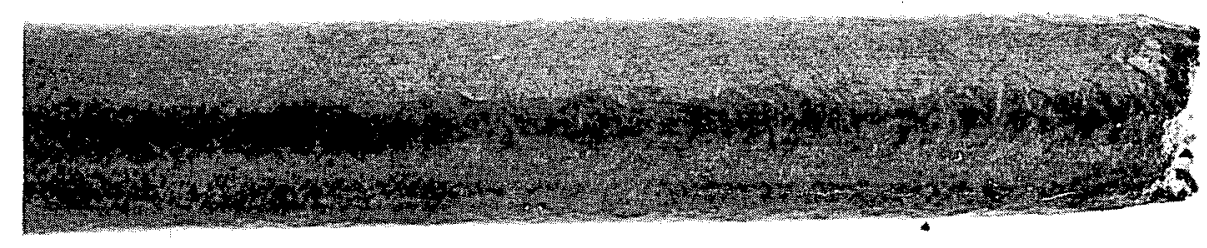

$5 X$

RM25541

b. Tested at $350 \mathrm{C}$

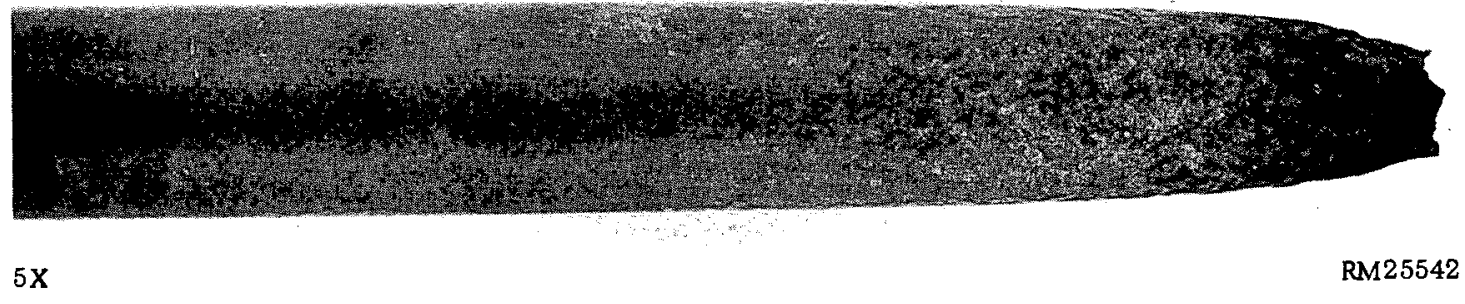

c. Tested at $450 \mathrm{C}$

FIGURE I-19. TYPE F URANIUM TENSILE SPECIMENS AFTER TESTING 


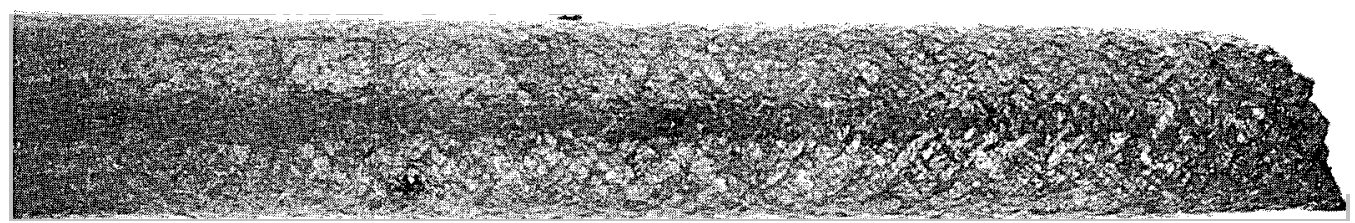

$5 \mathrm{x}$

RM25549

a. Tested at $250 \mathrm{C}$

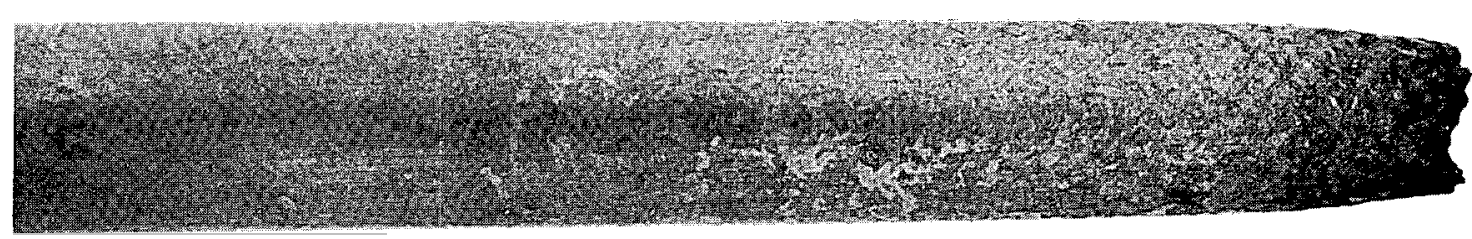

$5 \mathrm{X}$

RM25550

b. Tested at $350 \mathrm{C}$

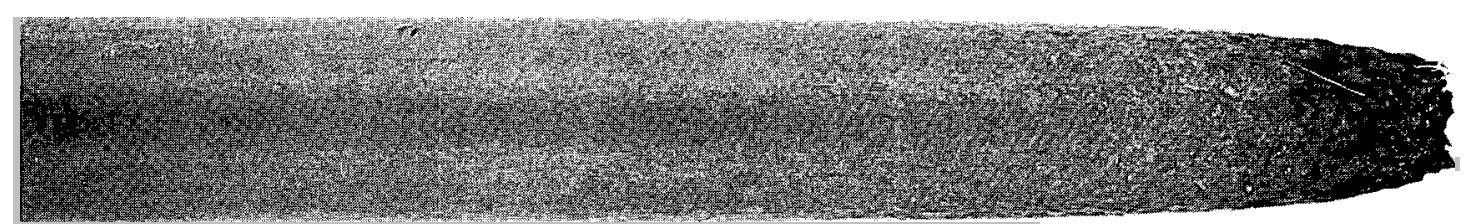

$5 x$

RM25551

c. Tested at $450 \mathrm{C}$

FIGURE I -20. TYPE G URANIUM TENSILE SPECIMENS AFTER TESTING 
materials except the Type B uranium exhibited a typical cup-cone-type fracture appearing more pronounced in the Types $C, D$, and $E$ materials than in the other specimens.

After they were photographed the specimens were mounted, polished, and examined by metallographic techniques at magnifications up to $1000 \mathrm{X}$ utilizing brightfield illumination. Numerous polishing and etching techniques were employed in an effort to delineate those areas where fracture or rupturing had been initiated. Previous experience has shown that polarized light is not suitable for this type of study since it is often impossible to distinguish small fissures in a highly disturbed uranium matrix. Of particular interest was the vacuum cathodic-etching technique which was employed in the latter stages of the program on selected specimens where grain-boundary rupturing was suspected. Etching times of $5 \mathrm{sec}$ to $2 \mathrm{~min}$ were employed. During the early stages of cathodic etching (up to $30 \mathrm{sec}$ ) the oxide film was removed selectively from the specimens, and the specimen presented a surface which appeared to contain secondphase material in an orderly array. Further etching, often times up to 2 min, revealed the true structure of the material. As is often the case in uranium metallography, techniques which proved suitable for one material proved totally inadequate for othe $r$ materials which were very similar. In the present study, for instance, vacuum-cathodic etching techniques were not suitable for use in the fracture area of the specimens because of the uneven etching that prevailed.

The examination of these structures revealed that in the Type B and Type D specimens the carbides tended to agglomerate into massive stringers and that fracture was initiated for the most part in or at the carbide particles. Fracture appeared to progress through cracking perpendicular to the applied stress at both 250 and $350 \mathrm{C}$ in the Type $\mathrm{B}$ uranium. In the Type D uranium there were many small voids, none of which attained any great size, and ultimate fracture appears to have resulted from agglomeration of these voids. Both the Type B and Type D uranium exhibited little elongation at $450 \mathrm{C}$, and in both cases the fracture was due to agglomeration of voids. The role of carbides in initiating and propagating fracture in the se specimens is illustrated in Figures I- 21 through I-23. Notice in the bright-field photomicrograph of the fissured region furthest from the rupture of the specimen tested at $250 \mathrm{C}$ (Figure I-2la) that all of the fissures may not be associated with carbides. In Figure I- 22 are shown the areas associated with the fracture. Notice how the voids tend to agglomerate, especially at 250 and $450 \mathrm{C}$. In Figure I-23 is shown an extreme example of the carbide stringers after polishing and after vacuum-cathodic etching. In the last photograph (Figure I-23c) is shown one of the few areas in which there was any rupturing that could be related to a grain boundary.

In both the Type $A$ and Type $F$ specimens the carbide particles were small and well dispersed. Rupture was apparently initiated at the carbide particles and proceeded by void enlargement and agglomeration. In both cases deformation was highly localized in the specimens tested at $350 \mathrm{C}$. The high localization of deformation and void formation propably accounts for the low reduction-in-area values at $350 \mathrm{C}$ also. In Figure I- 24 are shown typical areas adjacent to the fracture at 250, 350, and $450 \mathrm{C}$. Notice the small number of voids in the $350 \mathrm{C}$ specimen when compared with the specimens tested at 250 and $450 \mathrm{C}$. The Type $F$ uranium contained $818 \mathrm{ppm}$ carbon, but from the examination of the specimens it did not appear to contain any more carbides than specimens made from material containing 500 ppm carbon.

In Figures I- 25 and I- 26 are shown areas adjacent to the fracture in specimens from the Types $C$ and $G$ uranium, respectively. Notice that the carbide particles are 


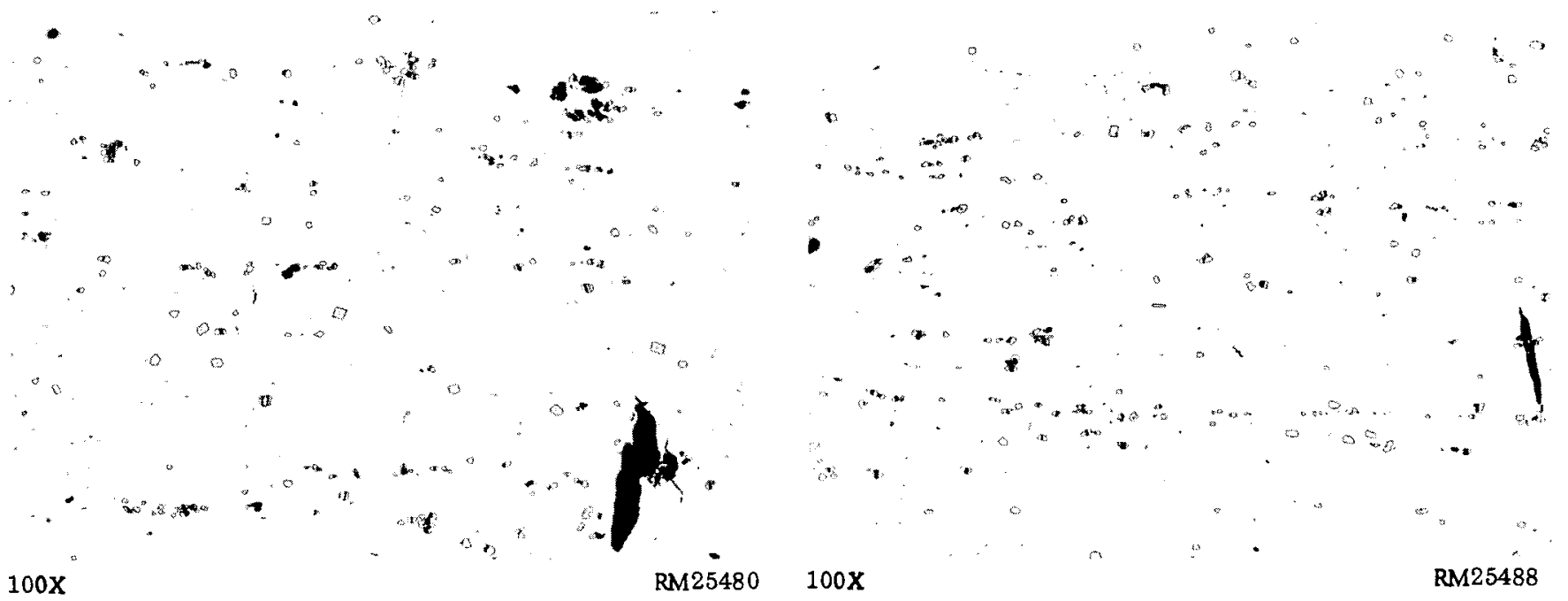

a. Tested at $250 \mathrm{C}$

b. Tested at $350 \mathrm{C}$

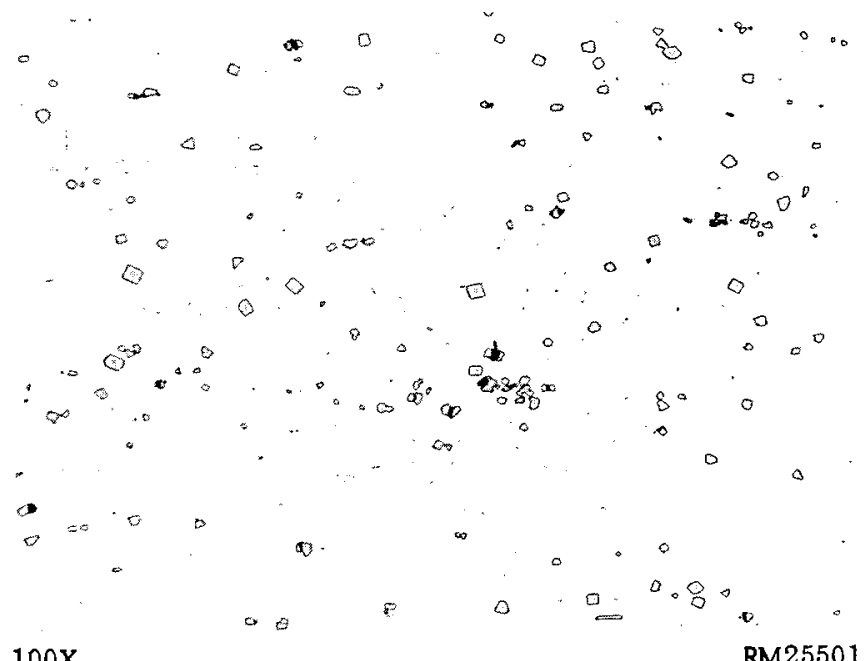

c. Tested at $450 \mathrm{C}$

FIGURE I-21. FISSURED AREA FURTHEST FROM THE RUPTURE IN T YPE B URANIUM TENSILE SPECIMENS

Direction of applied stress is horizontal. 


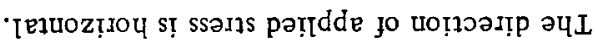

SNGWIOAdS GTISNGI WNINマYC

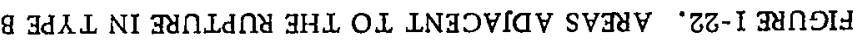

jogt je patsal 'p

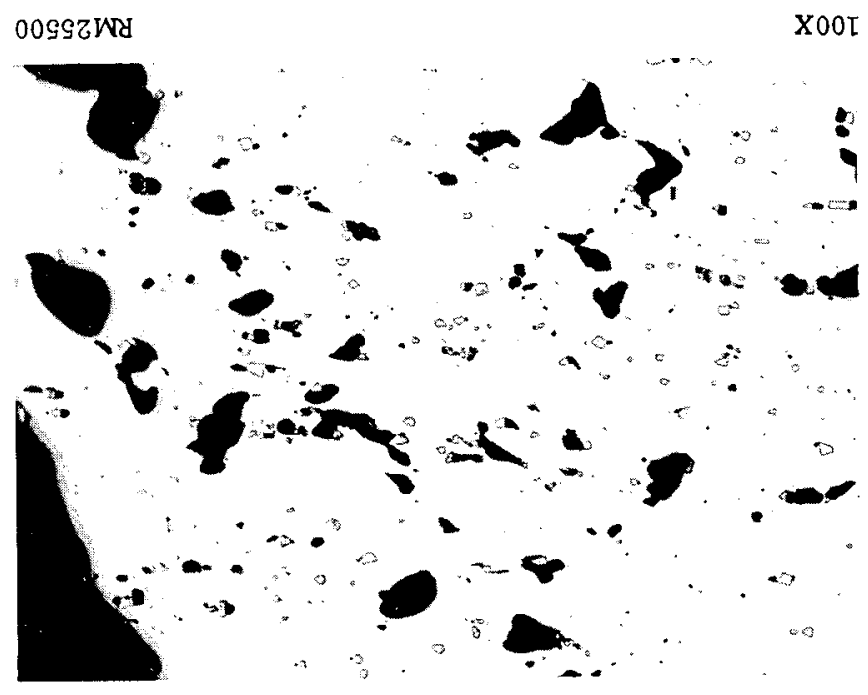

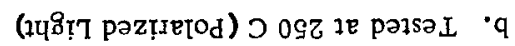

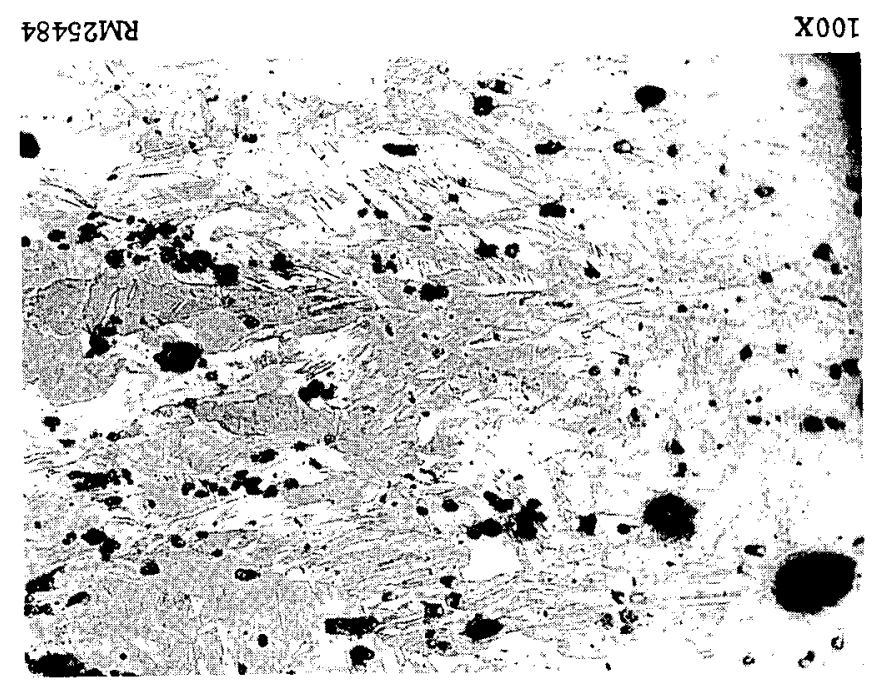

כ 098 7e patsal o

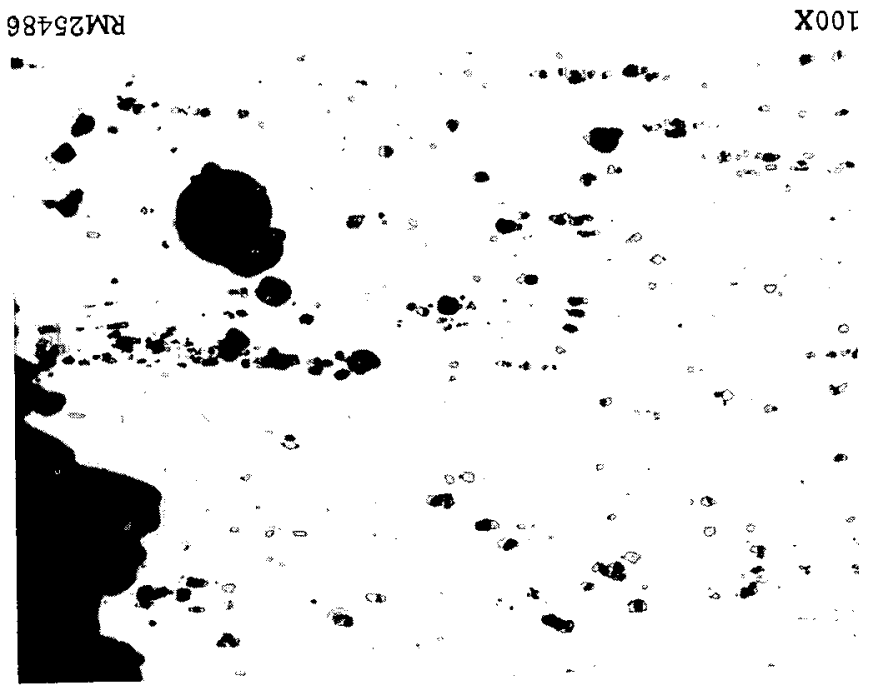

J OSz ie pajsal $\cdot$ e

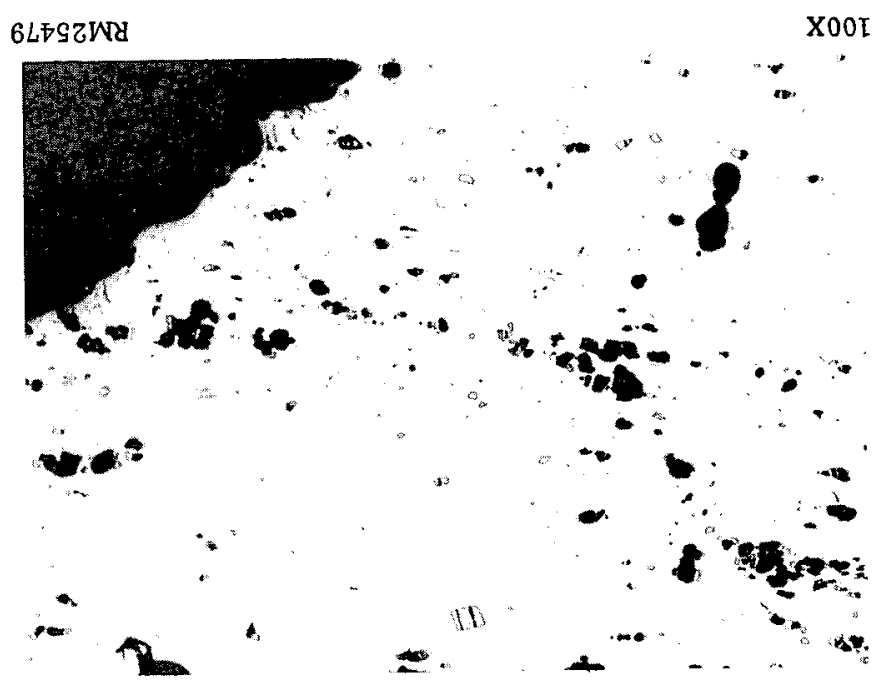




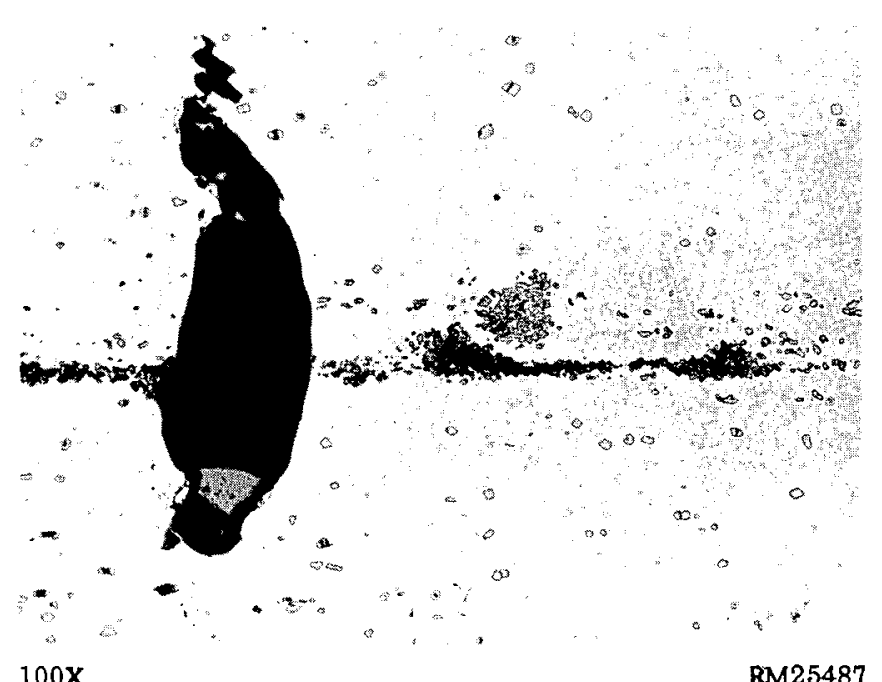

a. As Polished

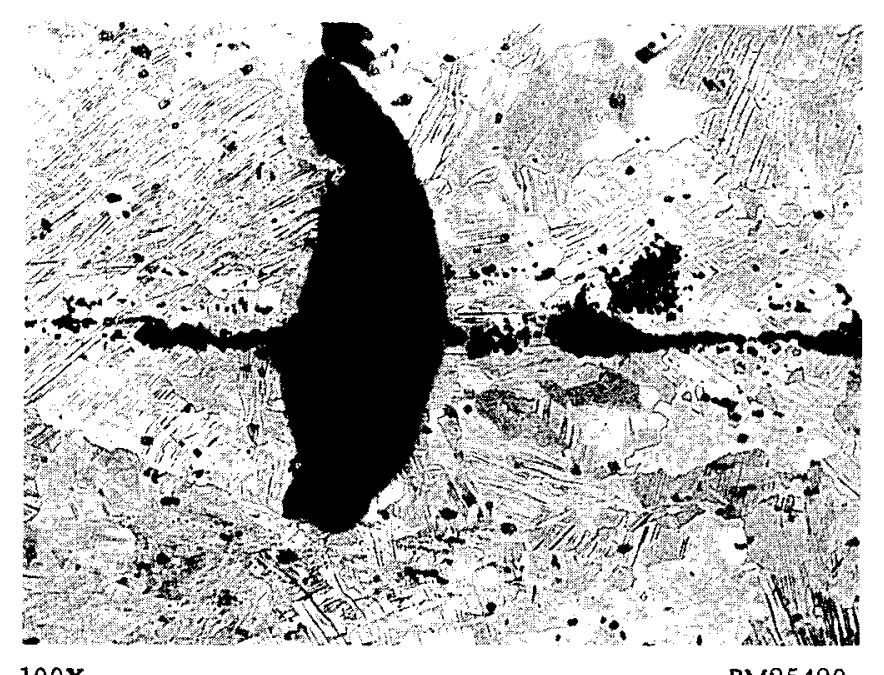

b. After Vacuum-Cathodic Etching

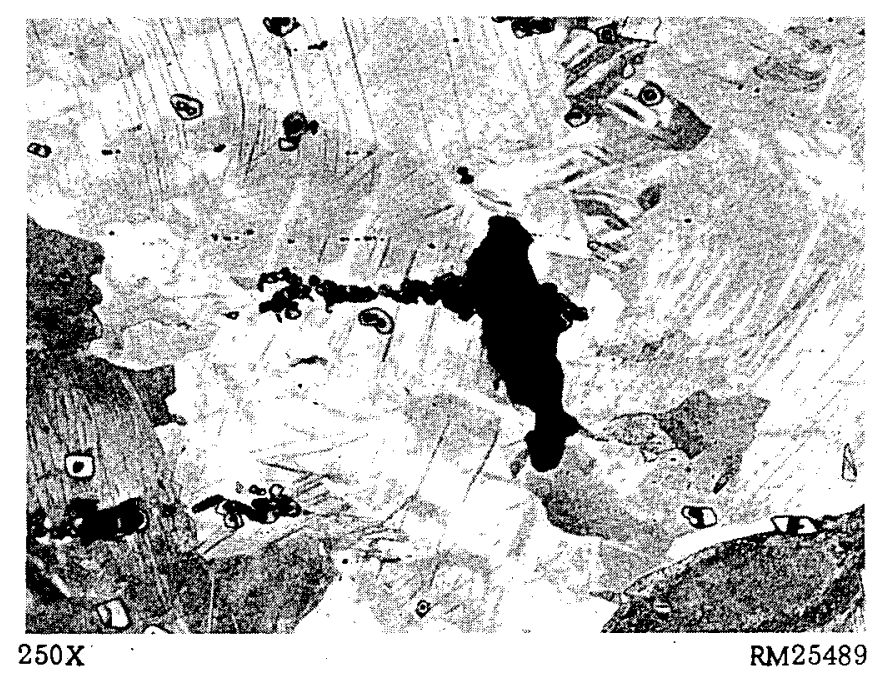

c. Chemically Etched

FIGURE I-23. ROLE OF AGGLOMERATED CARBIDES IN FRACTURE OF TYPE B URANIUM TENSILE SPECIMEN TESTED AT $350 \mathrm{C}$

Stress was applied in the horizontal direction in these photomicrographs. 


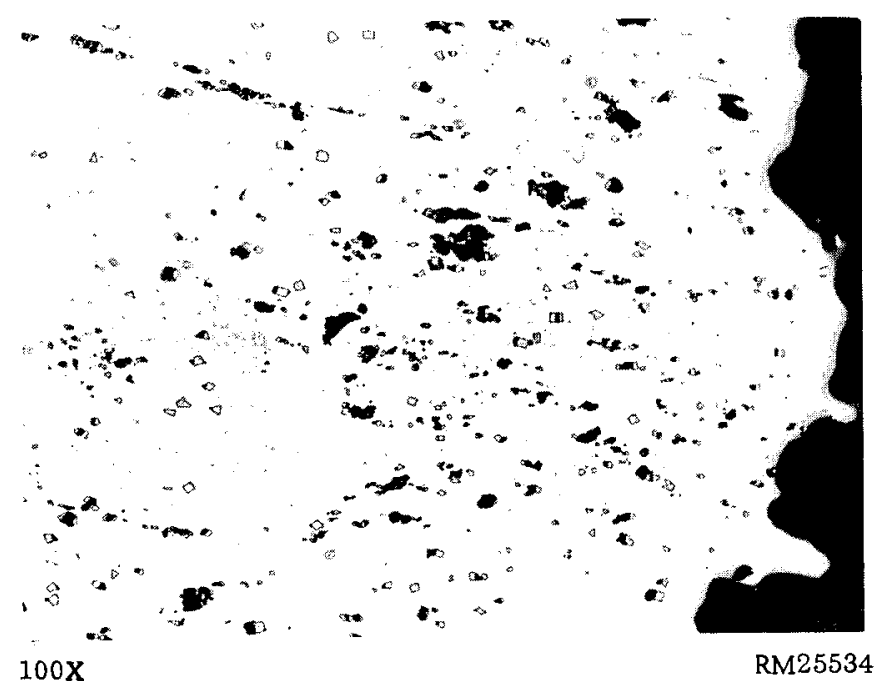

a. Tested at $250 \mathrm{C}$

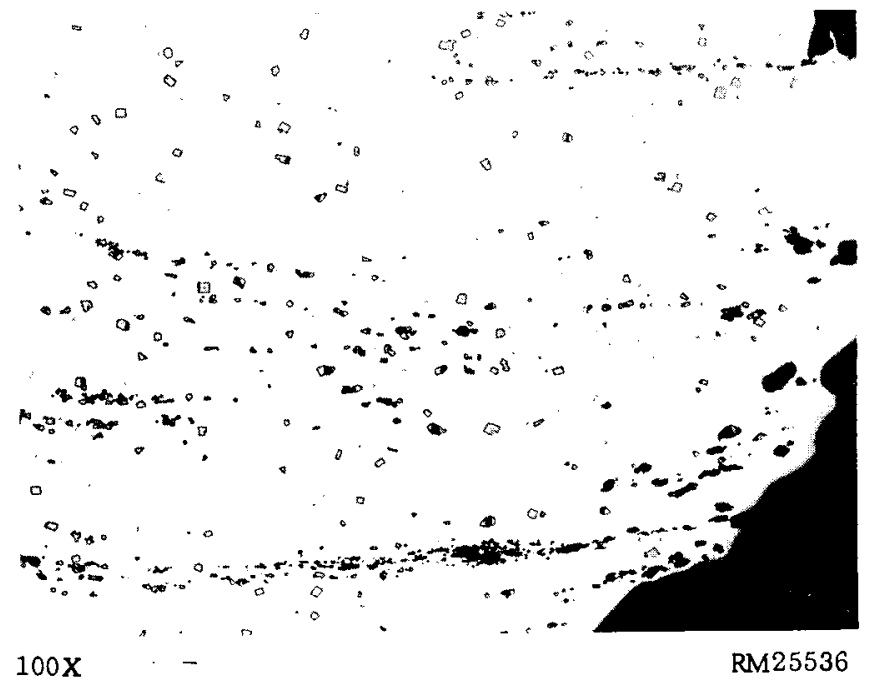

b. Tested at $350 \mathrm{C}$

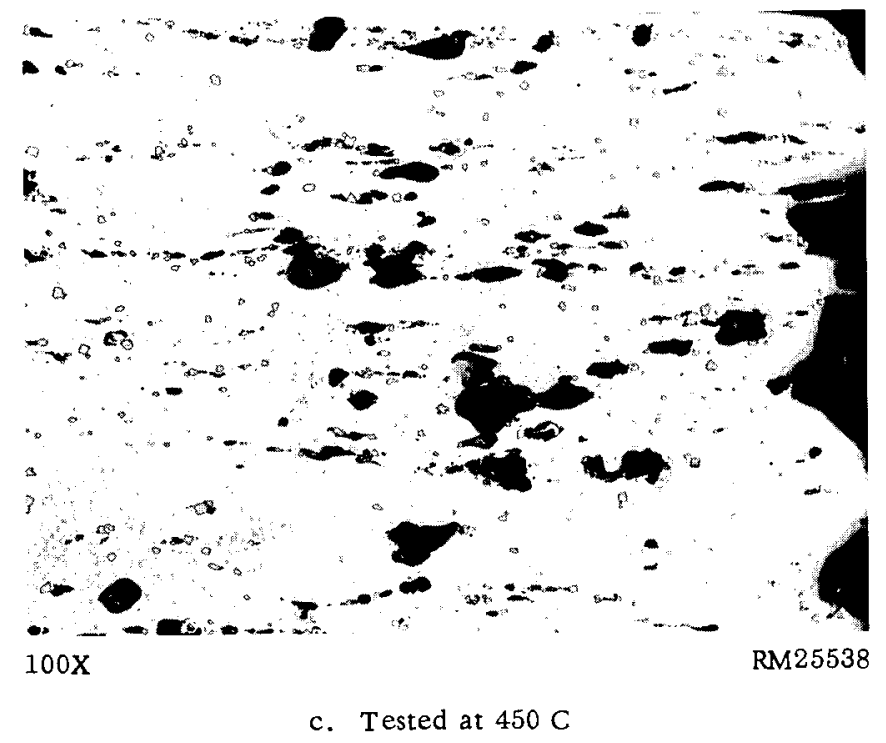

FIGURE I-24. AREAS ADJACENT TO THE FRACTURE IN TYPE F URANIUM TENSILE SPECIMENS 

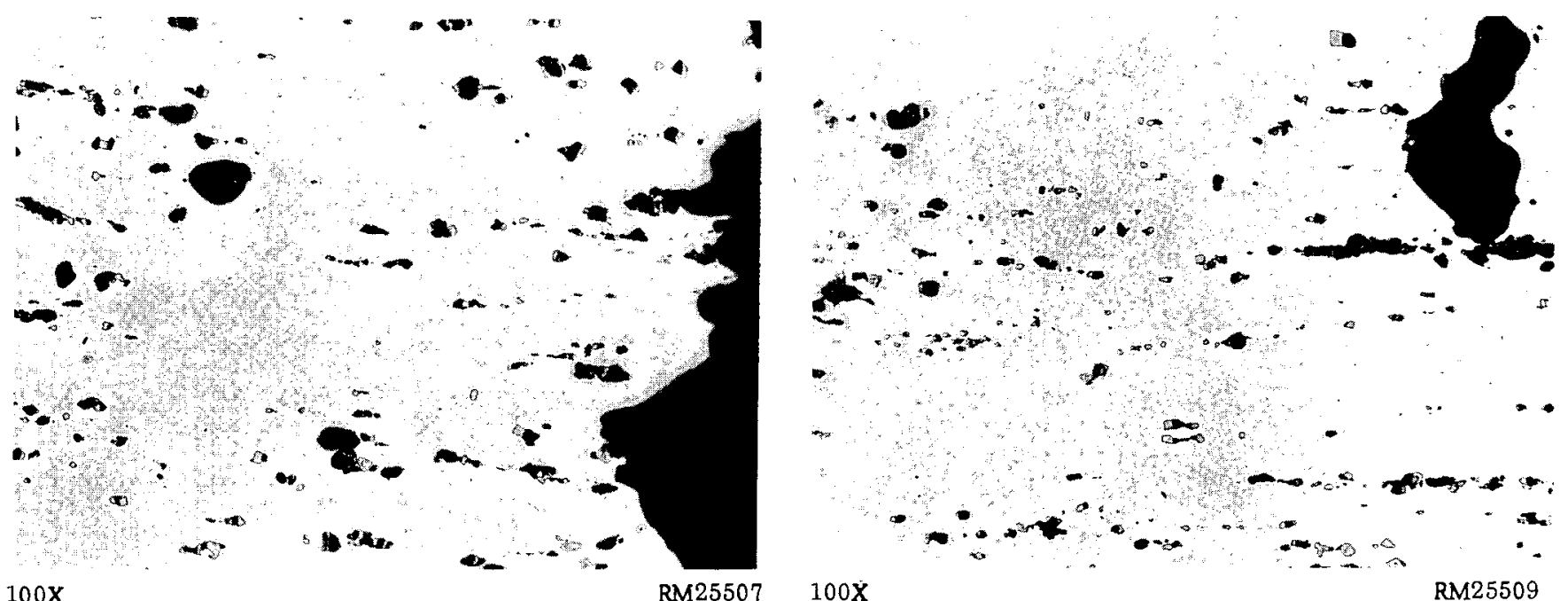

a. Tested at $250 \mathrm{C}$

b. Tested at $350 \mathrm{C}$

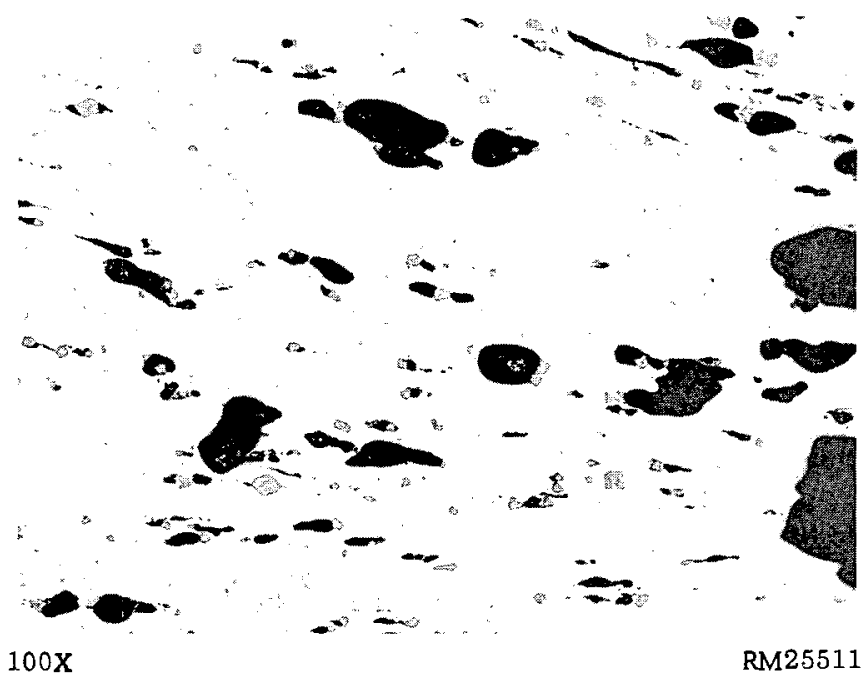

c. Tested at $450 \mathrm{C}$ 


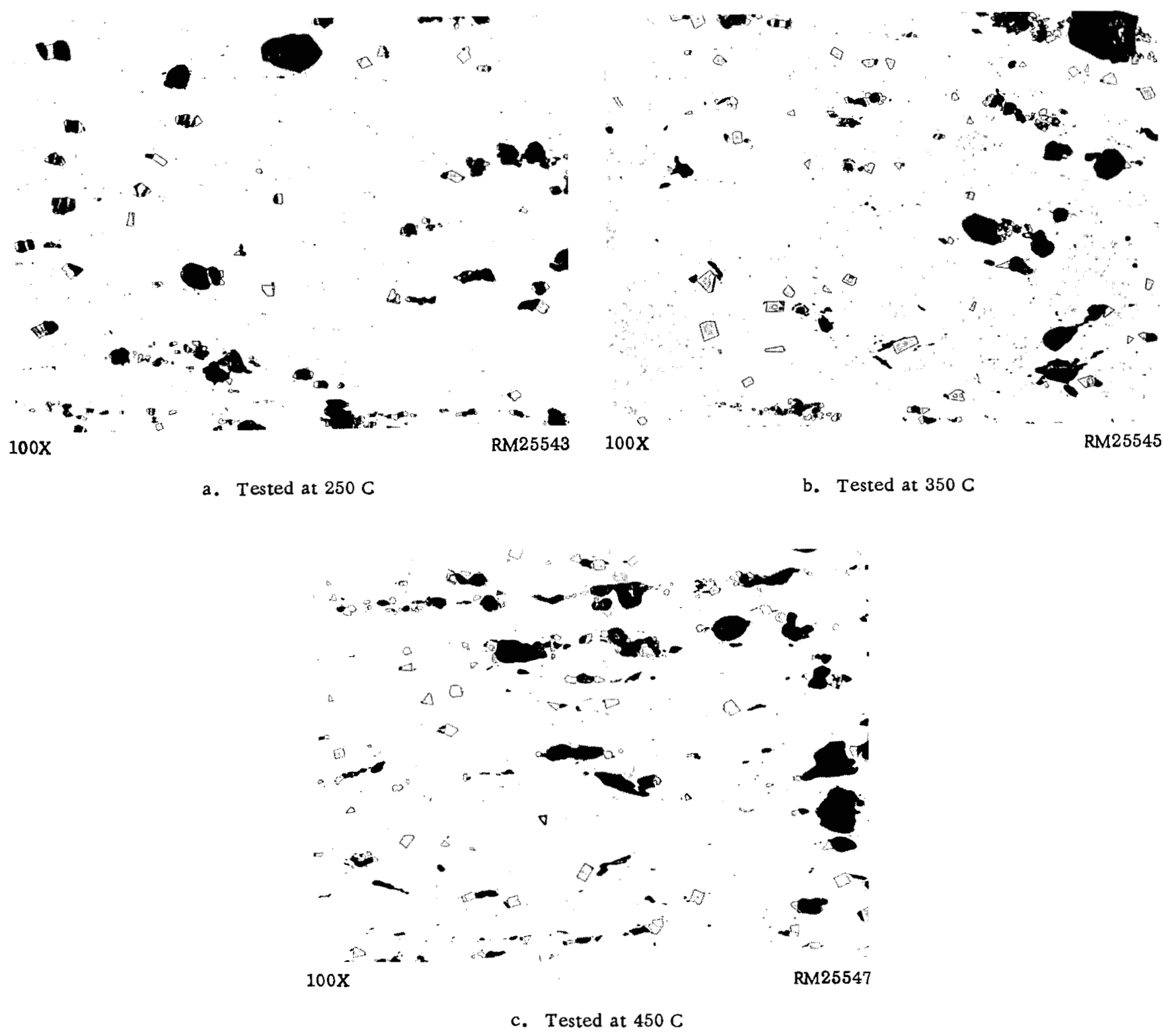

FIGURE I-26. AREAS ADJACENT TO THE FRACTURE IN T YPE G URANIUM TENSILE SPECIMENS 
somewhat larger than those shown in the preceding figures. In both cases the number of voids or cracks were less than in other materials, primarily because of the fewer number of carbides in the material.

\section{Conclusions}

In consideration of the results of the mechanical testing program and the subsequent metallographic evaluations the following conclusions have been made:

(1) The secondary minimum in elongation was noted in all but two of the materials tested. The absence of this phenomenon in the se two materials is unexplained.

(2) The mechanical properties exhibited by the high-aluminum material $(292 \mathrm{ppm})$ indicate that aluminum is effective even at this low concentration in improving the strength properties of uranium at elevated temperatures.

(3) Though nume rous etching techniques were employed little or no evidence of grain-boundary separation was noted in any of the specimens except those from the high-aluminum material.

(4) As in previous studies it is apparent that the elongation of the material is a function of the carbon content and the carbide distribution. Small carbides randomly dispersed tend to rupture and distribute the stresses throughout the specimens, whereas large carbides will concentrate the stresses and thereby decrease the total elongation attained during a given test.

(5) The effects of various iron levels in the specimens is not apparent from the se tests and more definitive studies might be indicated in this area.

(6) The role of silicon as a strengthener was suggested during the initial studies, but its effectiveness was not demonstrated by the one alloy containing a high silicon content that was tested during the latter part of this program.

The lack of evidence of crack initiation and propagation in the grain boundaries is not considered contradictory to the results obtained by Rhines in his studies concerning the low ductility exhibited by some materials at intermediate temperatures nor the results obtained by Bierlein, et al. (8) during the current studies at Hanford concerning the irradiation stability of high-purity uranium. In both of the aforementioned studies the materials employed afforded few sites other than grain boundaries where stress concentrations could occur, whereas all of the materials employed in the studies reported he rein contained a well-dispersed second phase not as sociated with the grain boundaries. This dispersed second phase, being more friable than the uranium matrix, fractured and afforded sites for stress concentrations which ultimately led to specimen failure. 
A further comparison of the Hanford data with the results of this tensile study revealed that the temperature of minimum ductility noted in the tensile tests is approximately $150 \mathrm{C}$ less than the temperature where the maximum volume increase was noted in the Hanford studies. This temperature difference may be the result of the different test environments and the greater number of impurity atoms present in the normal production-grade uranium. The effects of the se impurity atoms - individually and collectively - on the irradiation stability and physical properties of uranium are not well defined. Studies such as those in progress at Hanford(8) concerning the irradiation stability of uranium- $2 \mathrm{w} / \mathrm{o}$ zirconium alloys and the contemplated fabricability studies at National Lead Company of Ohio concerning the effects of impurity atoms should aid in correlating physical properties and irradiation stability. This is particularly true if, upon completion of the NLO program, selected alloys are evaluated on the basis of their irradiation stability and this property can be related to its physical properties.

Undoubtedly further correlations might be made with the data currently available; however, it is believed that additional studies should be undertaken in which a single base alloy is employed. In a study of the type envisioned it would be possible to evaluate individually and collectively the effects of carbon, iron, silicon, and aluminum on the mechanical properties of uranium and its fracture characteristics. Such a study coupled with a selective irradiation study should also be a valuable aid in delineating the composition most acceptable for high-temperature operation. Such a program if undertaken, should employ normal production-grade uranium since it has been shown that carbon levels of the magnitude normally encountered in this material are not deleterious to the performance of the material in reactor operation, and the presence of carbides in the material might afford sites for fission gas that might otherwise concentrate in selective sites and lead to rupture of the fuel.

\section{REFERENCES}

(1) Eberhard, B. J., SRL, Private Communication (September 7, 1962).

(2) Lloyd, L. T., and Chiswik, H. H., "Deformation Mechanisms of Alpha-Uranium Single Crystals", Trans. AIME, 203, 1206 (1955).

(3) Holden, A. N. , Physical Metallurgy of Uranium, Addison-Wesley Publishing Company, Inc., Reading, Massachusetts (1958).

(4) Daniel, N. E., BMI, Unpublished Information (1962).

(5) Fracture, Proceedings of an International Conference on the Atomic Mechanisms of Fracture Held in Swampscott, Massachusetts, April 12-16, 1959, John Wiley \& Sons, Inc., New York (1959), pp 20-53.

(6) Hayes, E. E., SRL, Unpublished Information (1961).

(7) Daniel, N. E., "Crack Initiation and Propagation in Uranium at Elevated Temperatures", BMI-X-10011 (October 5, 1963).

(8) "Metallurgy Research Operation, Quarterly Progress Report, April-June, 1963", HW-77954 (July 15, 1963). 


\title{
II. MICROSTRUCTURAL STUDIES OF CAST URANIUM
}

\author{
A. A. Bauer, C. R. Thompson, and C. W. Melton
}

\section{INTRODUCTION}

The microstructure of uranium has been studied extensively over the years and the general structural features observed in uranium are well characterized. This is especially true of wrought uranium which has been studied in much greater detail than cast material.

Studies to identify and characterize the inclusions in uranium have also been extensive. However, much of this effort has been concentrated, quite logically, on the large inclusions observed in uranium. These are readily observable metallographically and are subject to identification by fairly conventional techniques.

In this report the results of a brief program which was undertaken to evaluate the use of metallographic and electron microscopic techniques in detecting microstructural differences in cast uranium of varied chemistry and casting history are described. Of particular interest was evidence of differences in substructure and in fine-particle distribution and form between the various materials. Since this program was of a very short term, the major accomplishment was the development of suitable techniques. The effectiveness of these techniques is illustrated by a series of micrographs from which some preliminary conclusions concerning the effects of chemistry and casting history on microstructure have been drawn.

EXPERIMENTAL PROCEDURES

Materials and Specimen Selection

Specimens were taken from seven cast ingots for examination. The ingots were cast at NLO. Two of these were 8-in.-diameter production ingots, designated B- 85559 and B-85560. The remaining five were experimental ingots. Three ingots, B-49, B-50, and $B-57$ were $6-3 / 16$ in. in diameter and were slow cooled in the melting crucible. Two experimental ingots, B-51 and B-52, were chill cast in a 2-1/2-in.-diameter castiron mold.

Slices were cut from the top of each ingot immediately below the crop. Specimens for examination were cut from the center of the slice and $1 / 4 \mathrm{in}$. from the edge of each slice. Samples for chemical analysis were taken from these same slices.

The results of chemical analyses for selected elements are shown in Table II- 1. The major variations in chemistry occurred in carbon content. 
TABLE II- 1. CHEMICAL ANALYSES FROM URANIUM INGOTS CAST AT NLO

\begin{tabular}{|c|c|c|c|c|c|c|c|}
\hline \multirow[b]{3}{*}{ Element } & \multicolumn{7}{|c|}{ Chemical Analysis, ppm } \\
\hline & \multicolumn{2}{|c|}{ Production Ingots } & \multicolumn{5}{|c|}{ Experimental Ingots } \\
\hline & $\overline{\mathrm{B}-85559}$ & B- 85560 & $\mathrm{~B}-49$ & $\mathrm{~B}-50$ & $\bar{B}-51$ & $B-52$ & B-57 \\
\hline $\mathrm{C}$ & 495 & 441 & $281-458^{(a)}$ & 675 & 340 & 68 & 138 \\
\hline Al & 8 & 11 & 21 & 13 & 17 & 26 & 22 \\
\hline $\mathrm{Fe}$ & 141 & 137 & 147 & 133 & 130 & 144 & 154 \\
\hline $\mathrm{Si}$ & 97 & 95 & 127 & 127 & 135 & 116 & 95 \\
\hline
\end{tabular}

(a) Range in analysis is indicative of inhomogeneity in ingot.

Techniques of Specimen Preparation

Approximately $1 / 8$ in. was removed from the surface of each specimen by grinding and electropolishing to eliminate surface working which may have been introduced by the cutting operation in obtaining the specimens.

Three primary techniques of specimen preparation (Methods 1 through 3) were investigated after which specimens were examined both metallographically and in the electron microscope. A fourth preparation (Method 4) was used to prepare the specimens specifically for electron microscopic examination. The techniques of preparation are outlined below.

All specimens were ground through 600-grit silicon carbide paper. This was followed in the first three methods of preparation by a polish with $1-\mu$ diamond paste on Forstmann cloth and then by the following procedures:

Method 1:

(1) Polished with 5 per cent gamma alumina in 95 per cent $\mathrm{H}_{2} \mathrm{O}_{2}$ on Gamal cloth

(2) Electropolished with 8 parts ethyl alcohol, 5 parts ethylene glycol, and 5 parts phosphoric acid at $40 \mathrm{v}$ dc for 1 to $3 \mathrm{sec}$

(3) Electroetched in 18:1 acetic:chromic acid solution in Disa Electropol at $20 \mathrm{v} \mathrm{dc}$ for up to $2 \mathrm{~min}$.

Method 2:

(1) Polished with 5 per cent gamma alumina in 95 per cent $\mathrm{H}_{2} \mathrm{O}_{2}$ on Gamal cloth 
(2) Electropolished with $200 \mathrm{ml}$ acetic acid, $50 \mathrm{ml}$ phosphoric acid, and $5 \mathrm{~g} \mathrm{CrO}_{3}$ at $40 \mathrm{v}$ de for up to $10 \mathrm{sec}$

(3) Electroetched in same solution at $20 \mathrm{v}$ dc for up to $5 \mathrm{~min}$.

Method 3:

(1) Polished with 5 per cent gamma alumina in 95 per cent $\mathrm{H}_{2} \mathrm{O}_{2}$ on Gamal cloth

(2) Electropolished in 8:5:5 solution of ethyl alcohol, ethylene glycol, and phosphoric acid at $40 \mathrm{v}$ dc for 2 to $5 \mathrm{sec}$

(3) Vacuum-cathodically etched in argon at 25 to $30 \mu$ and $3500 \mathrm{v}$ for time up to $1 \mathrm{hr}$.

The specimen preparation designed specifically for electron microscopic examination consisted of the following steps after grinding:

Method 4:

(1) Polished with 6- $\mu$ diamond paste on cheesecloth

(2) Polished with $1-\mu$ diamond paste on cheesecloth

(3) Polished with $0.5-\mu$ diamond paste on cheesecloth

(4) Electropolished on glass-cloth-covered wheel with $22 \mathrm{ml}$ ethyl alcohol, $45 \mathrm{ml}$ phosphoric acid, $38 \mathrm{ml}$ ethylene glycol at $30 \mathrm{v}$ dc for $105 \mathrm{sec}$

(5) Electroetched in 1:1 acetic:chromic acid solution at $10 \mathrm{v}$ dc for 6 sec.

Plastic negative replicas and carbon-platinum replicas were obtained of the prepared specimen surfaces for electron microscopic examination.

Plastic negative replicas were prepared by flowing a 0.5 per cent solution of cellulose nitrate in amyl acetate over the surface of the specimen. After drying the replica was stripped off and shadowed with a vacuum deposit of platinum at a $45-$ deg angle.

The carbon-platinum replica was prepared by first replicating the surface with a 5-mil-thick sheet of cellulose acetate softened in acetone. This replica was platinum shadowed and then was covered with a vapor-deposited coating of carbon. The plastic was then dissolved away to obtain the final replica.

In developing these techniques initial efforts were concentrated on the productioningot material with occasional preparations of specimens from the other ingots. When suitable techniques were developed they were further evaluated by preparation of specimens from the remaining ingots. Within the limits of time available, a thorough examination of all ingots was impossible and significant information was derived mainly from the production ingots and from Ingots B-50, B-52, and B-57. Use of the latter ingots permitted comparisons of structure between low-carbon ingots which were either 
chill cast or slow cooled (Ingots $B-52$ versus B-57) and between slow-cooled ingots of high and low carbon content (Ingots $B-50$ versus $B-57$ ).

EXPERIMENTAL RESULTS

Metallographic Results

All photomicrographs shown in this section were taken from surfaces in a direction transverse to the axis of the cast ingots.

Typical photomicrographs of as-polished uranium showing the massive carbides in the as-cast structure appear in Figures II- 1 through II- 3 . This structure is produced after the electropolishing step [Step (2)] in Method 1. Large dendritic carbides as shown in Figure II- 1 were observed in the edge specimen from Ingot B-50 which was slow cooled and high in carbon. These were not observed in the center specimen from this same ingot although numerous elongated carbides which apparently are the beginning of dentrites were seen. More typical, cubic-form carbides are shown in the production ingot, B- 85559 .

A typical etched structure of this latter ingot is shown in Figure II- 4 . This structure is obtained after Step (3) in Method 1.

Figures II- 5 and II- 6 show the structures obtained by Method 2 after electroetching for 1 and $5 \mathrm{~min}$, respectively. After $1 \mathrm{~min}$ of etching, in addition to the large carbides, a cellular distribution of fine particles is visible. These particles are masked to a considerable extent when the etching time is increased and grain boundaries are delineated.

Method 3, in which the specimens are vacuum cathodically etched, produced the microstructures shown in Figures II-7 through II-13. This technique delineates all of the structural details developed by the previous methods and at the same time reveals considerably more substructural detail. The cellular pattern of fine particles is emphasized particularly in Figure II- 7 and in the darker etching areas of Figure II-8. These particles exhibit no resolvable form in the higher magnification photomicrograph of Figure II-9. It should be noted that the particular ingot from which these structures were obtained, B-52, was low in carbon (138 ppm) and was chill cast.

The structure of the low-carbon (68 ppm) slow-cooled ingot, B-57, is shown in Figures II- 10. Both grains and subgrains are larger in this ingot than in the chill-cast ingot. In addition, the fine particles are considerably larger and, rather than forming randomly, have apparently grown on preferred crystallographic planes of the uranium matrix. One other feature that appears different in the chill-cast and slow-cooled uranium structures is the width of the twins; the twins appear to have significantly greater breadth in the slow-cooled material.

The structure of the high-carbon slow-cooled ingot, Figure II- 1 I, is similar to that of the previous ingot except that the grain size appears slightly smaller and there are a greater number of large carbides. However, the greater carbon content does not significantly change the amount or distribution of the finer particles. 

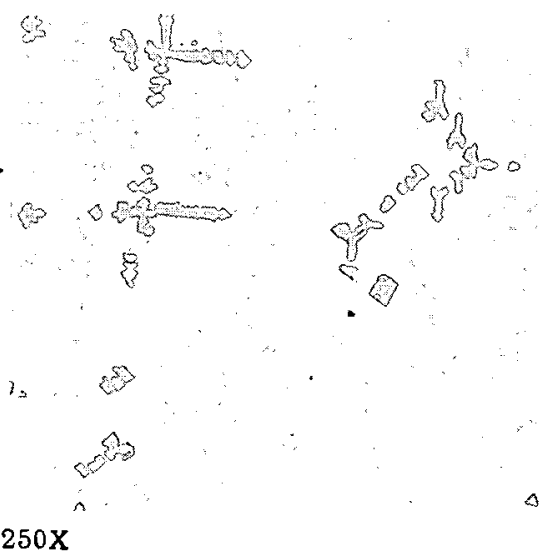

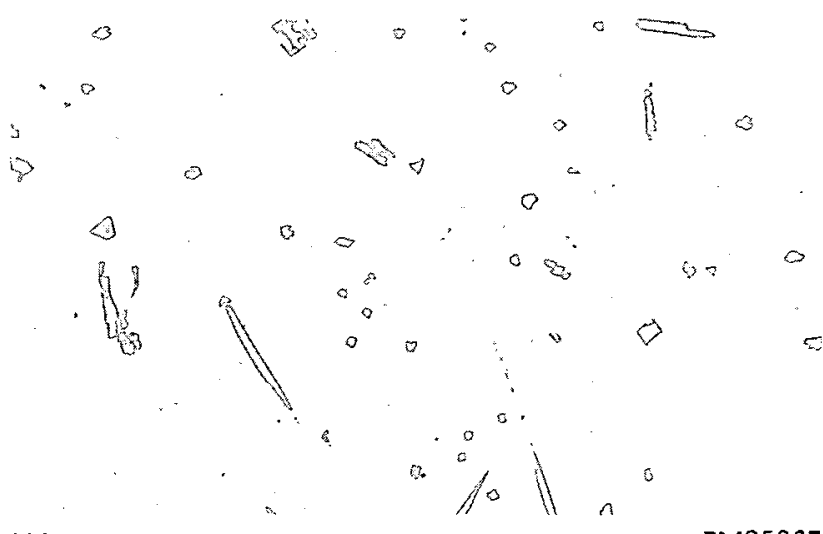

FIGURE II-1. CARBIDE DENDRITES AT EDGE OF INGOT B-50

Preparation technique: Method 1, electropolished state.

$0^{8}$

6

$100 \mathrm{X}$

RM25350

FIGURE II -3. CUBIC-FORM CARBIDES IN CENTER OF INGOT B-85559

Preparation technique: Method 1, electropolished state.

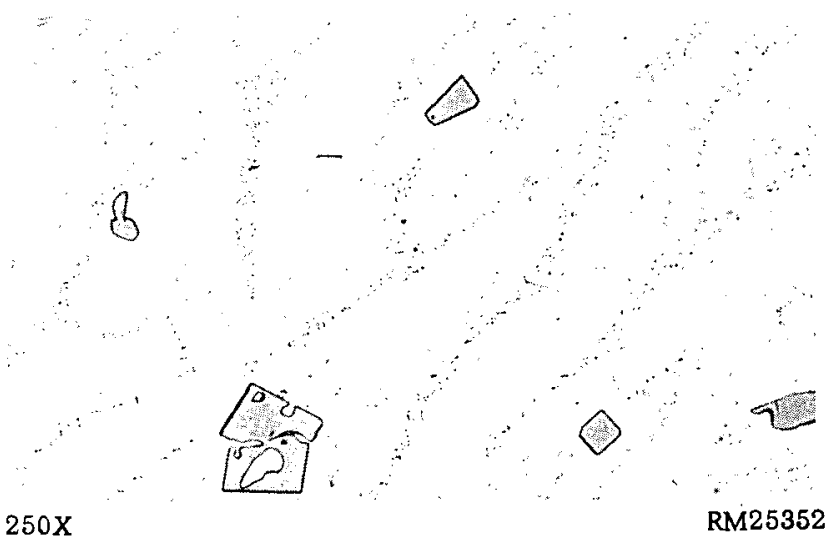

FIGURE II-5. CELLULARLY DISTRIBUTED PARTICLES IN CENTER OF INGOT B-85559

Preparation technique: Method 2, electroetched 1 min.

$100 x$

FIGURE II-2. ELONGATED CARBIDES AT CENTER OF INGOT B-50

Preparation technique: Method 1, electropolished state.

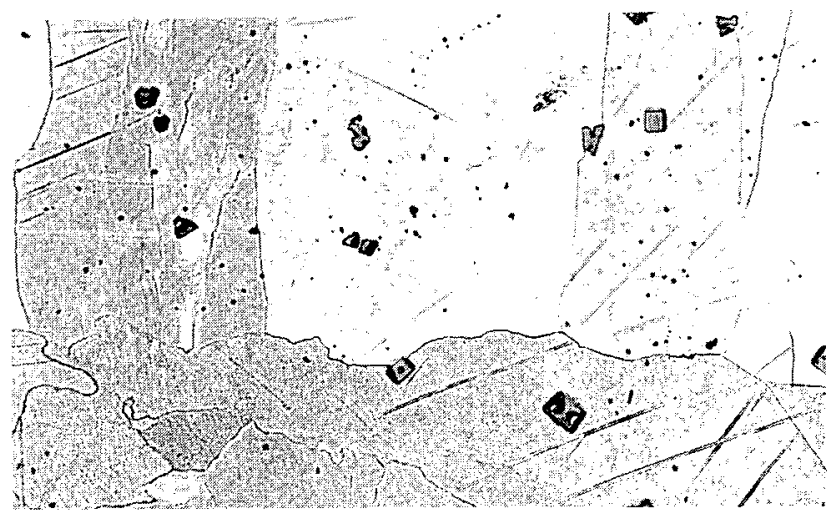

$100 \mathrm{X}$

RM25354

FIGURE II-4. GRAIN STRUCTURE IN CENTER OF INGOT B-85559

Preparation technique: Method 1, electroetched state.

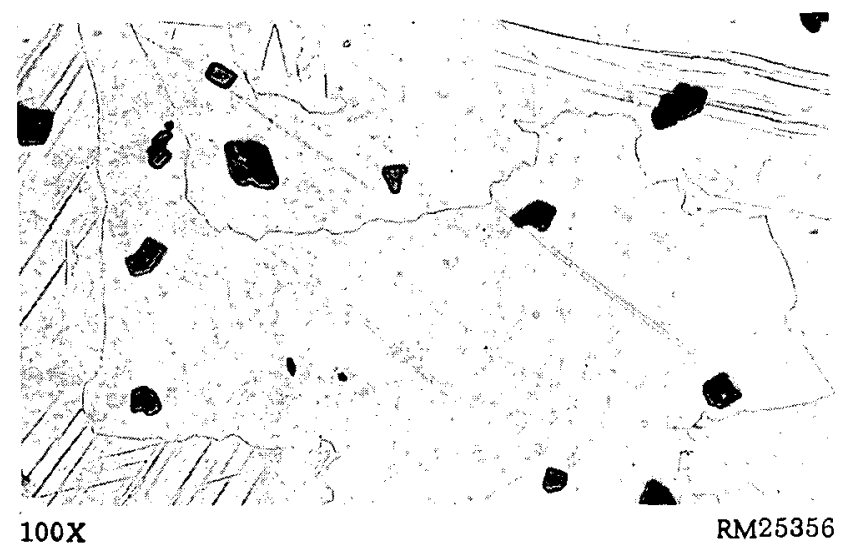

FIGURE II-6. GRAIN STRUCTURE IN CENTER OF INGOT B-85559

Preparation technique: Method 2, electroetched 5 min. 


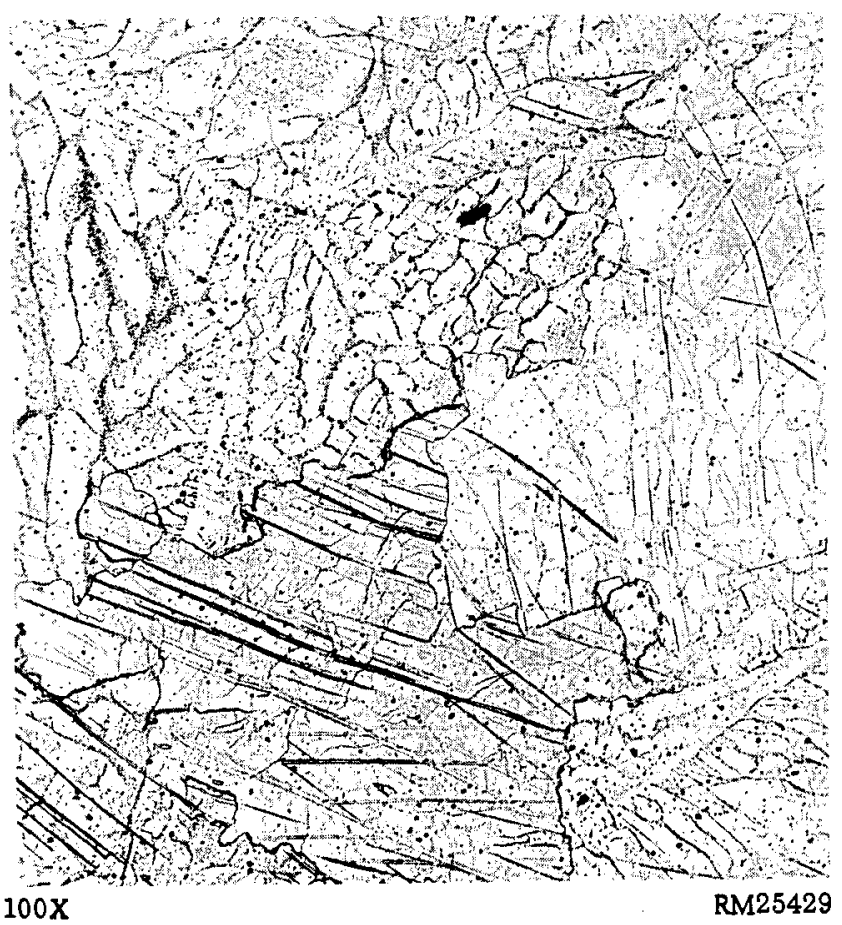

FIGURE II-7. CELLULAR OUTLINE OF FINE PRECIPITATE IN CENTER OF INGOT B-52

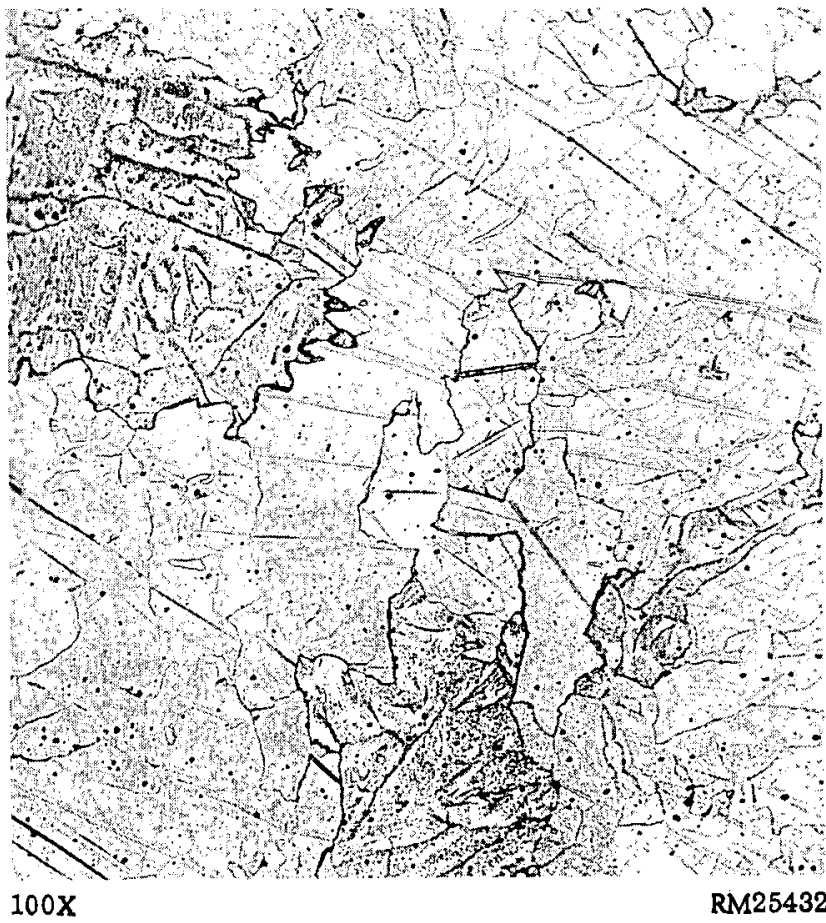

FIGURE II-8. FINE PRECIPIT ATE IN CENTER OF INGOT B-52

Preparation technique: Method 3, etched $1 \mathrm{hr}$. etched $1 \mathrm{hr}$.

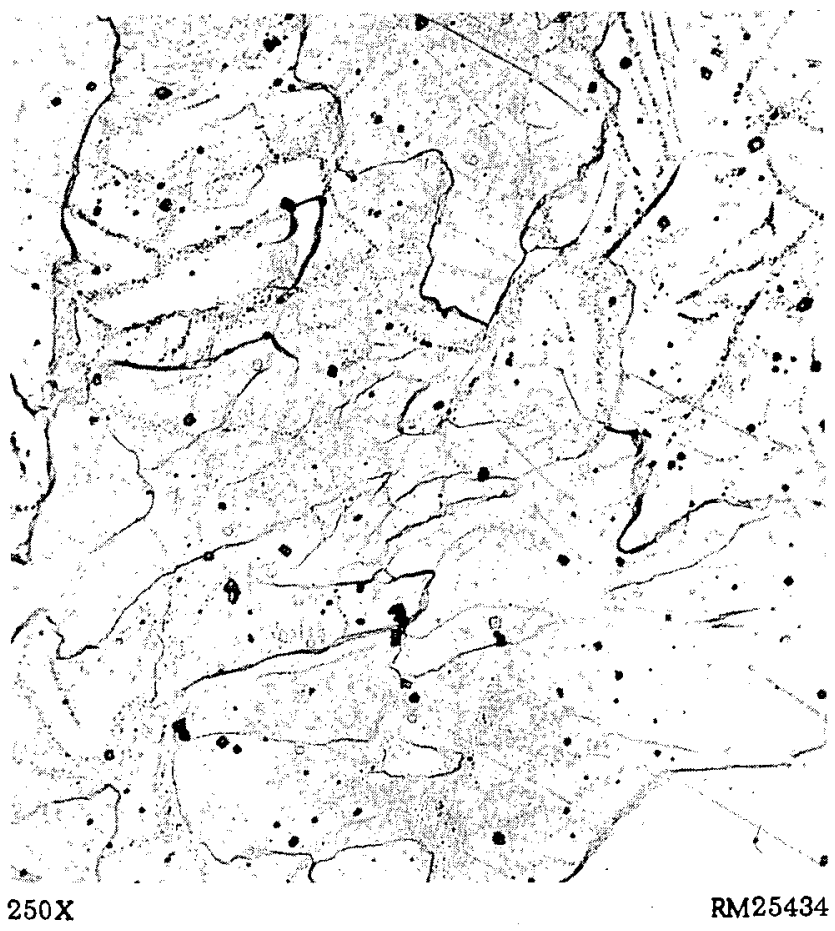

FIGURE II-9. UNRESOLVABLE PRECIPITATE IN CENTER OF INGOT B-52

Preparation technique: Method 3, etched $1 \mathrm{hr}$. 

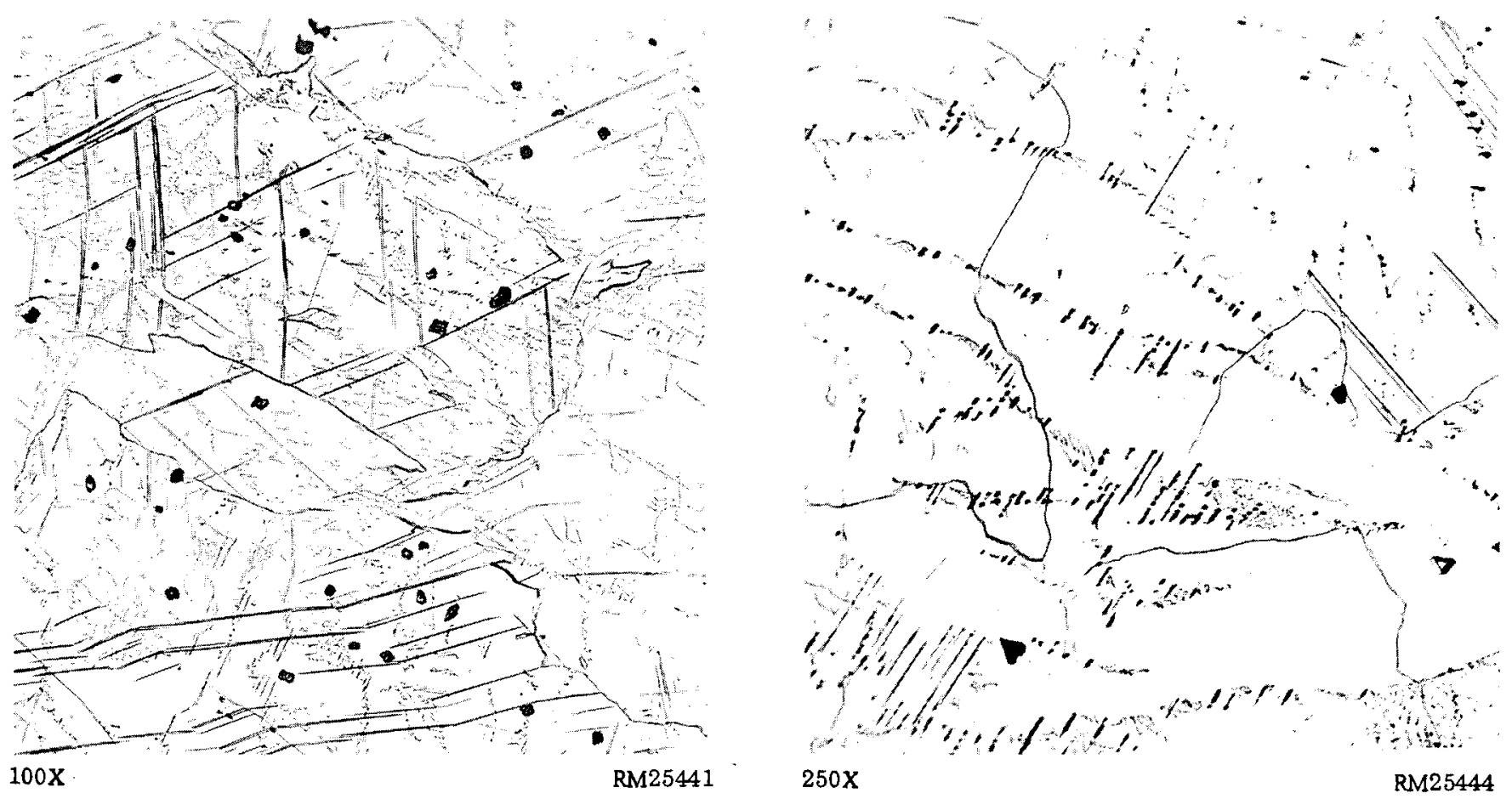

FIGURE II-10. LARGE GRAINS, SUBGRAINS, BROAD TWINS, AND ORIENTED FINE PRECIPIT ATE IN CENTER OF INGOT B-57

Preparation technique: Method 3, etched $40 \mathrm{~min}$.
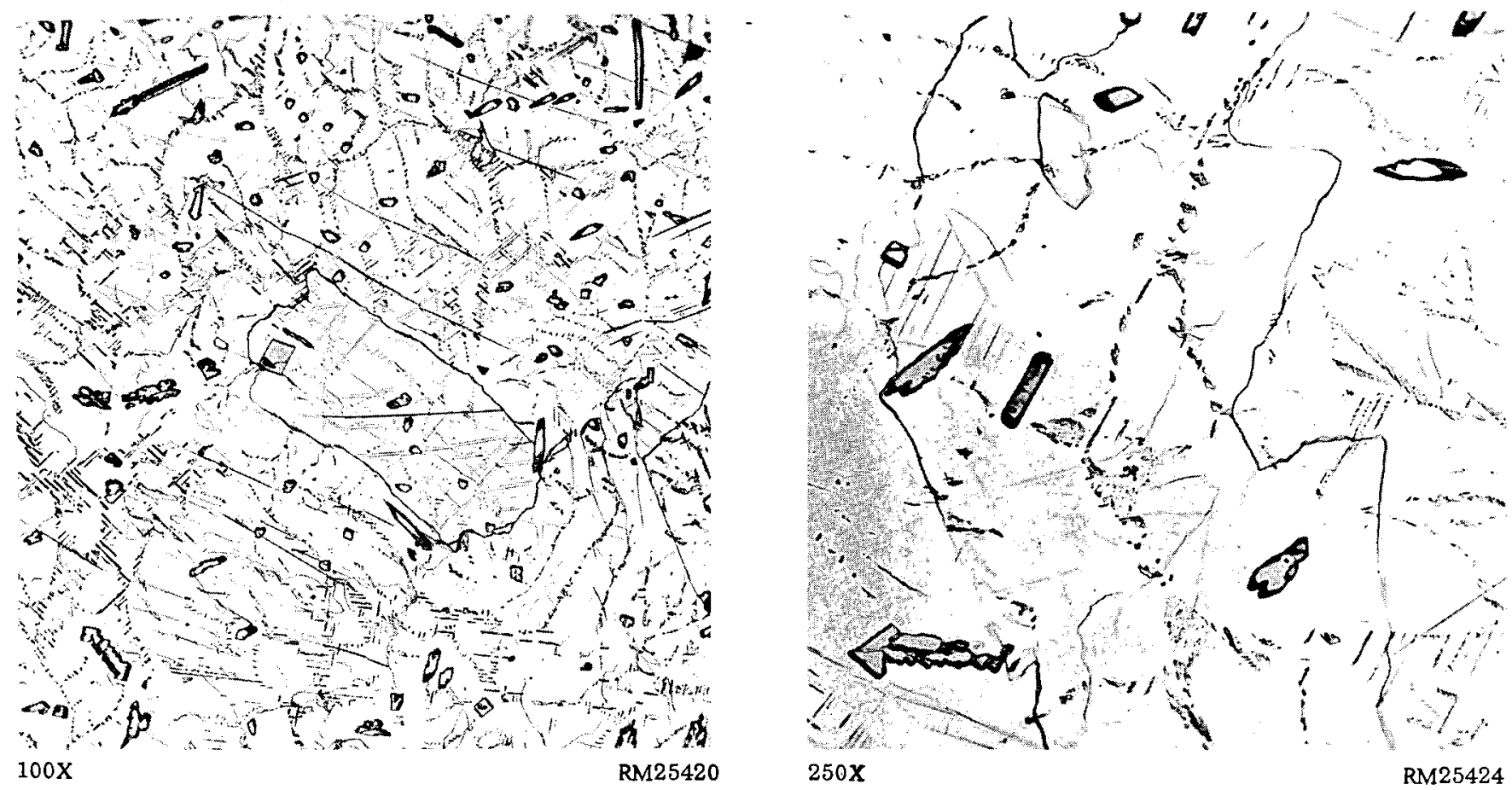

FIGURE II-11. STRUCTURE AT CENTER OF INGOT B-50

An increased number of large carbides and a smaller grain size as compared with the structures shown in Figure II-10 are evident. Preparation technique: Method 3, etched $40 \mathrm{~min}$. 


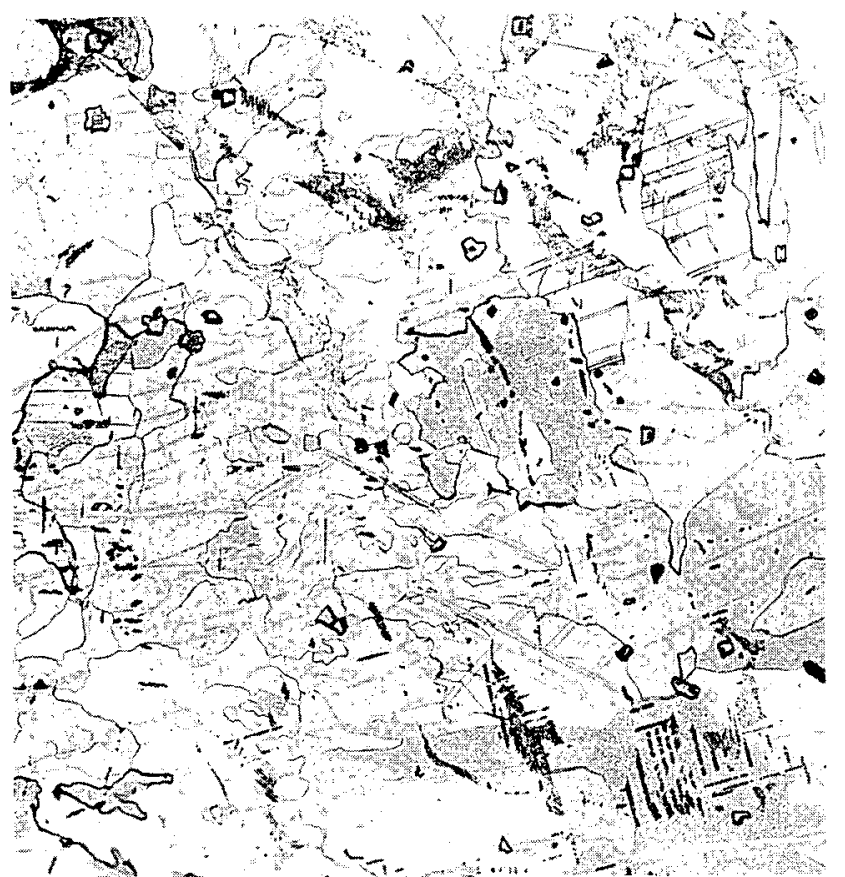
$100 \mathrm{x}$ -

RM25412

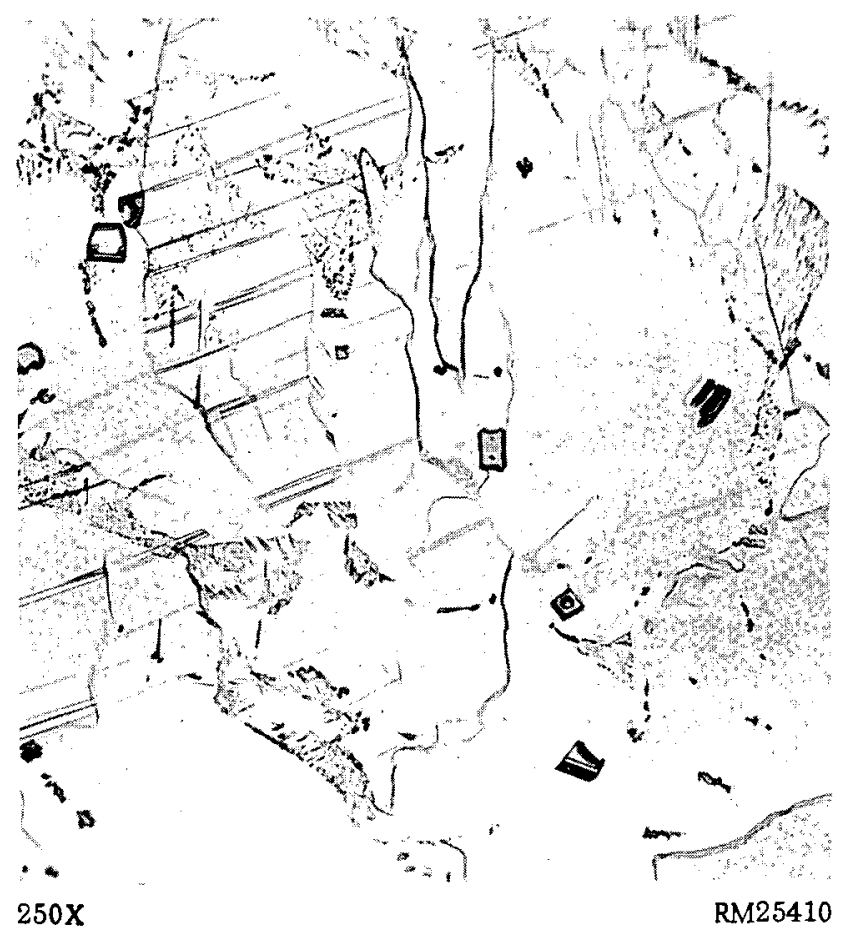

FIGURE II-12. EDGE OF INGOT B-49 SHOWING SMALLER GRAIN SIZE AND REFINEMENT OF FINE PARTICLE SIZE T YPICAL AT EDGE LOCATIONS

Preparation technique: Method 3, etched 1 hr.

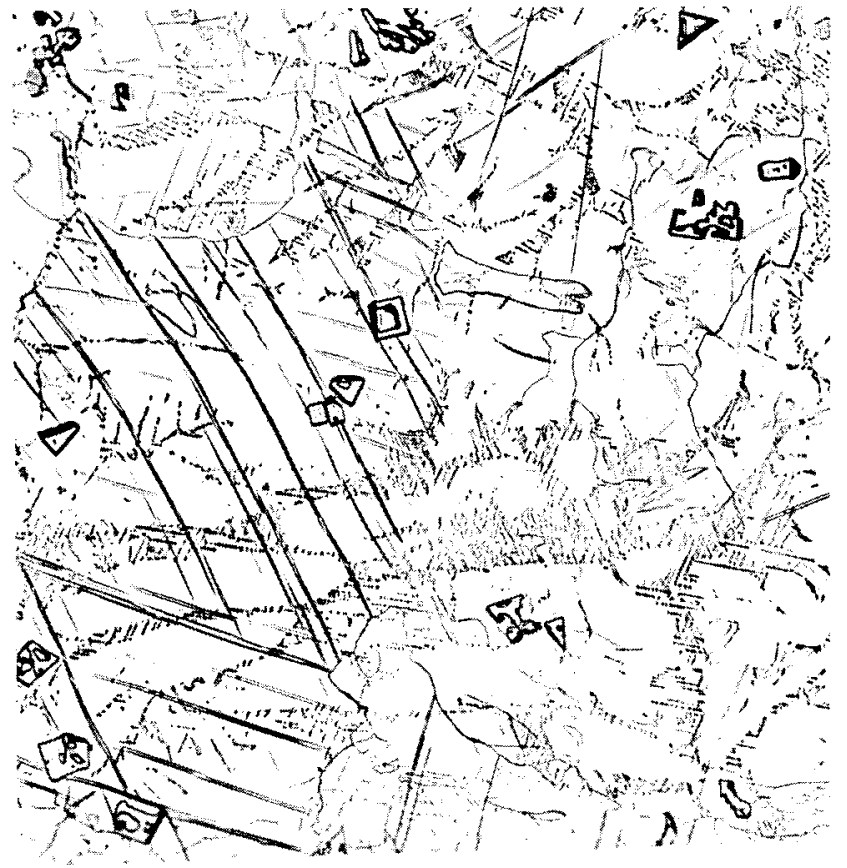

$100 \mathrm{X}$

RM25394

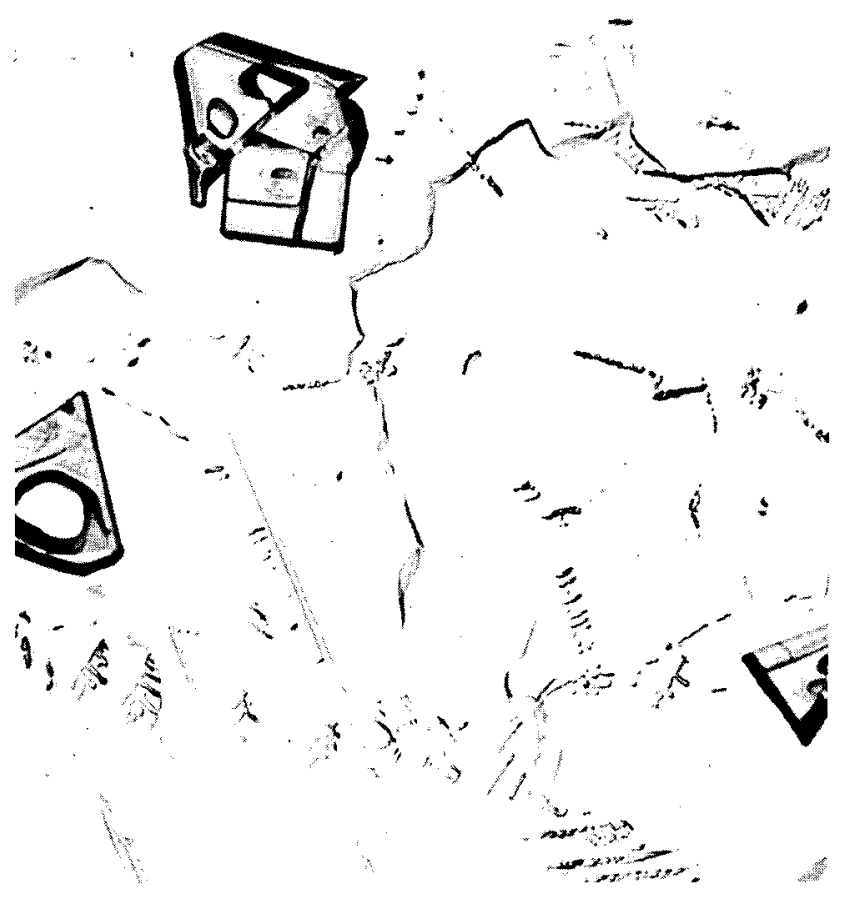

FIGURE II-13. EDGE OF PRODUCTION INGOT B-85559 EXHIBITING STRUCTURE SIMILAR TO THAT OBSERVED IN THE CENTERS OF SLOW-COOLED EXPERIMENTAL INGOTS

Preparation technique: Method 3 , etched $1 \mathrm{hr}$. 
All of the previous specimens were taken from the center of the ingot. Figure II- 12 shows the structure in a slow-cooled ingot, B-49, at the edge. The grain size is considerably smaller than in the previous slow-cooled ingots. A number of very small grains can also be seen which suggests that at least partial alpha-phase recrystallization has been initiated; this is probably due to higher cooling rates and higher stresses near the edge of the ingot. The fine particles are considerably smaller and are also contained in more widely separated regions than observed in specimens from the center of the ingot.

The structure at the edge of one of the production ingots, B-85559, is shown in Figure II-13. The structure is very similar to that at the center of the slow-cooled experimental ingots, indicating considerably lower cooling rates in the production material.

\section{Electron-Microscope Results}

Specimens were prepared for electron microscopic examination by all four methods outlined previously. Methods 1, 2, and 4 produced replicas which showed the same structural features although replicas from specimens prepared by Method 4 showed cleaner and more detailed structures than the other two methods of preparation. Specimens prepared by Method 3, the vacuum-cathodic etch, showed additional different features. Consequently, while electron micrographs were taken of specimens prepared by all four methods, only those prepared by Methods 3 and 4 are shown in this report.

Electron micrographs obtained from plastic negative replicas are shown in Figures II- 14 and II- 15. These can be compared with Figures II- 16 and II-17, which are from carbon-platinum replicas of specimens from the same ingot. Greater resolution is obtained with the carbon-platinum replicas as can be seen by examining these electron micrographs, For this reason, only a few plastic negative replicas were prepared during the course of this study, and all succeeding micrographs which are shown in this report were prepared from carbon-platinum replicas.

Figures II- 14 through II- 17 show the structures developed in specimens taken from the edge and examined in directions longitudinal and transverse to the axis of a production ingot, B-85559, when prepared by Method 4. Figure II- 14 shows a large carbide surrounded by a number of small particles, parts of which were transferred to the replica. Areas where transfer occurred appear black in the micrograph. A number of these small particles were removed by etching through a plastic negative and were identified by X-ray diffraction as uranium carbide. Figure II- 15 shows additional carbide particles and twins in the structure. The carbides in the transverse section tended to be slightly more elongated, as seen in Figure II-16, than in the longitudinal section. Figure II- 17 shows a large carbide containing a typical void in its center.

Figure II- 18 shows a small carbide particle of unusual form in Ingot B-85560. A number of small particles are also visible in this figure, some appearing within the larger carbide. These may be carbides but of different composition. One or the other may be combined with either oxygen or nitrogen, rendering the etching characteristics slightly different.

Figures II- 19 through II- 22 show fine carbide distributions in Ingot B-57. Figures II- 19 and II- 20 show two types of carbide particles at the edge. Characteristically, 


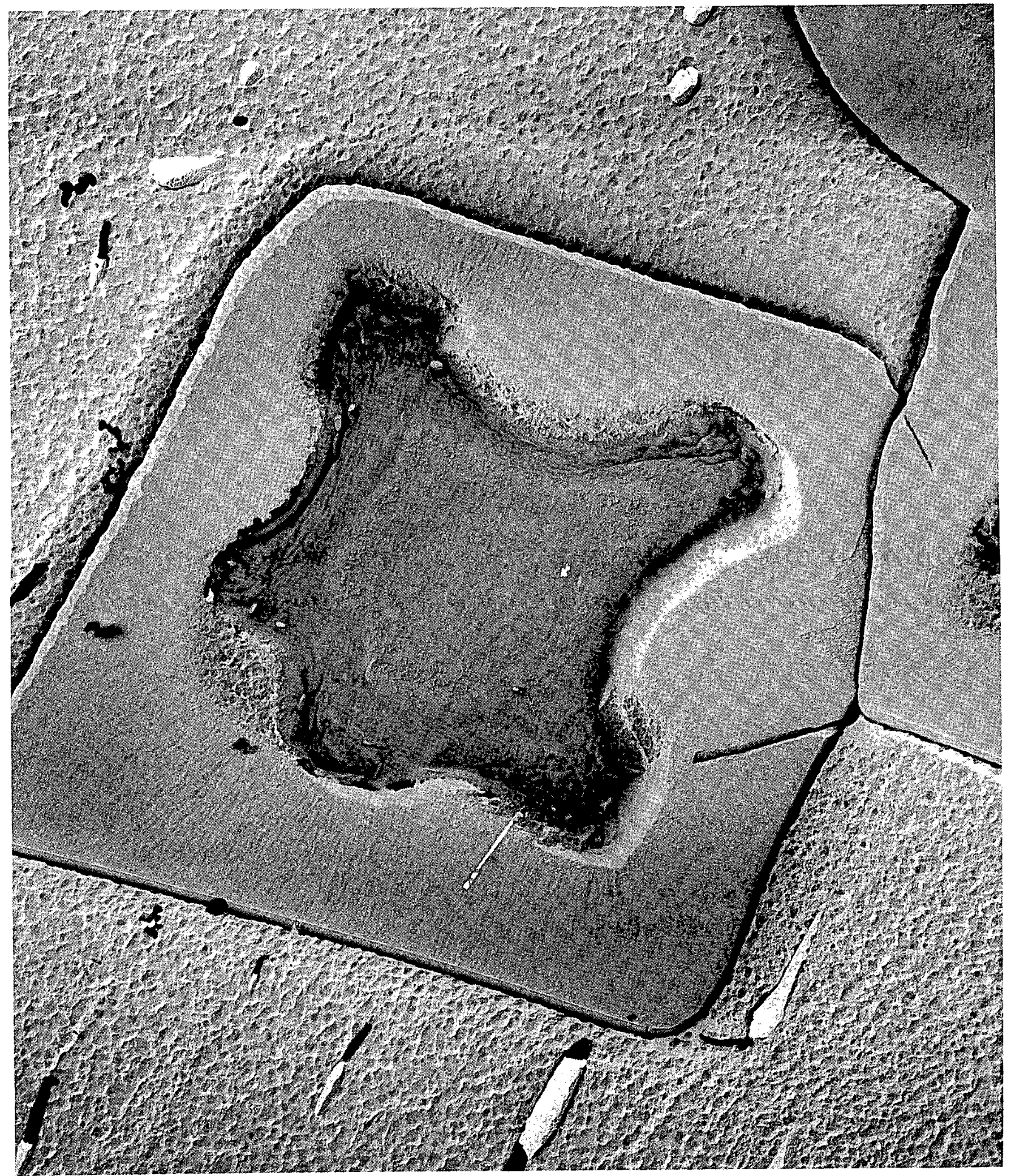

FIGURE II-14. LARGE CARBIDE AND SMALL PARTICLES IDENTIFIED AS URANIUM CARBIDE AT EDGE OF INGOT B-85559

Preparation technique: Method 4, plastic negative replica, longitudinal section. 


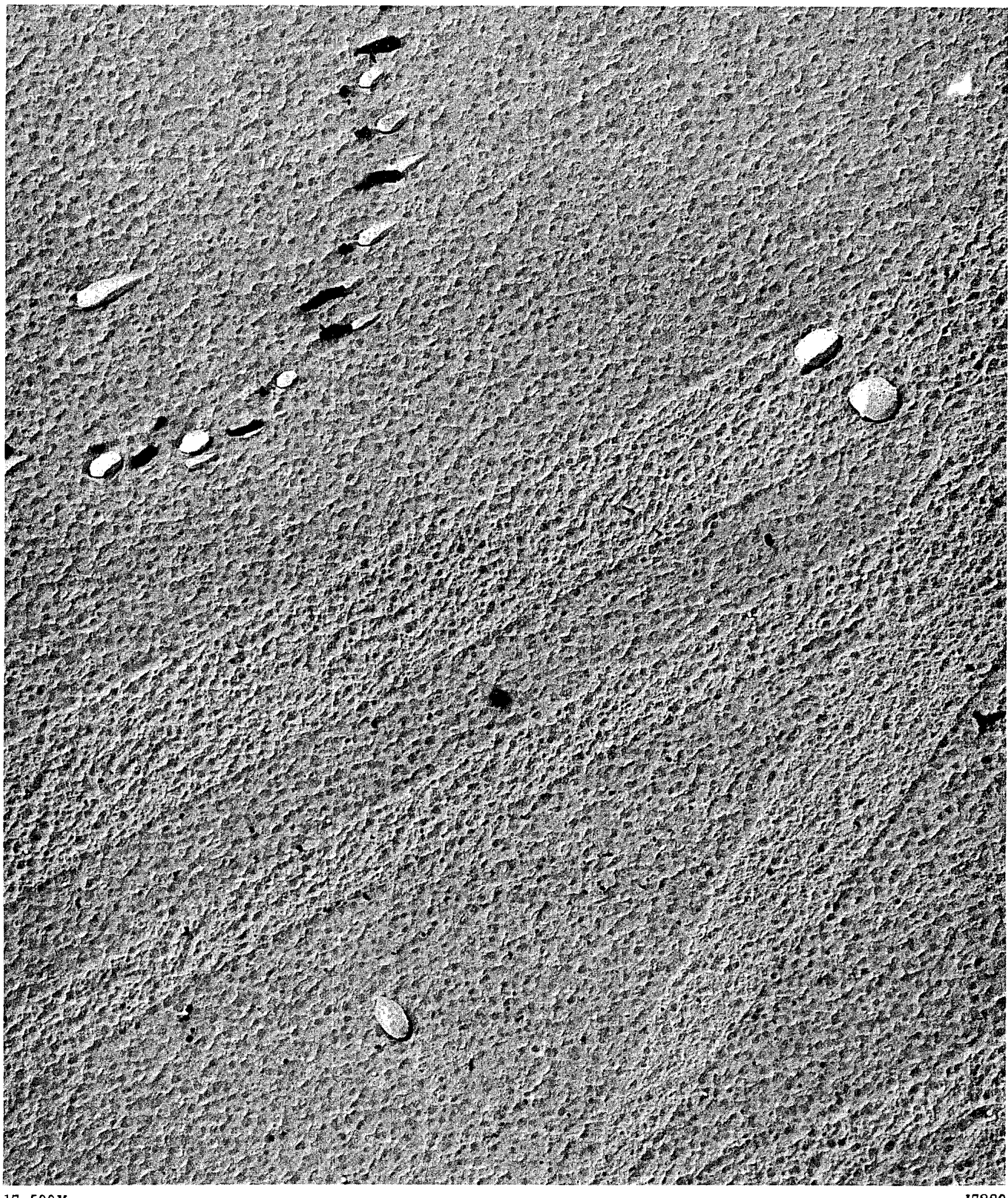




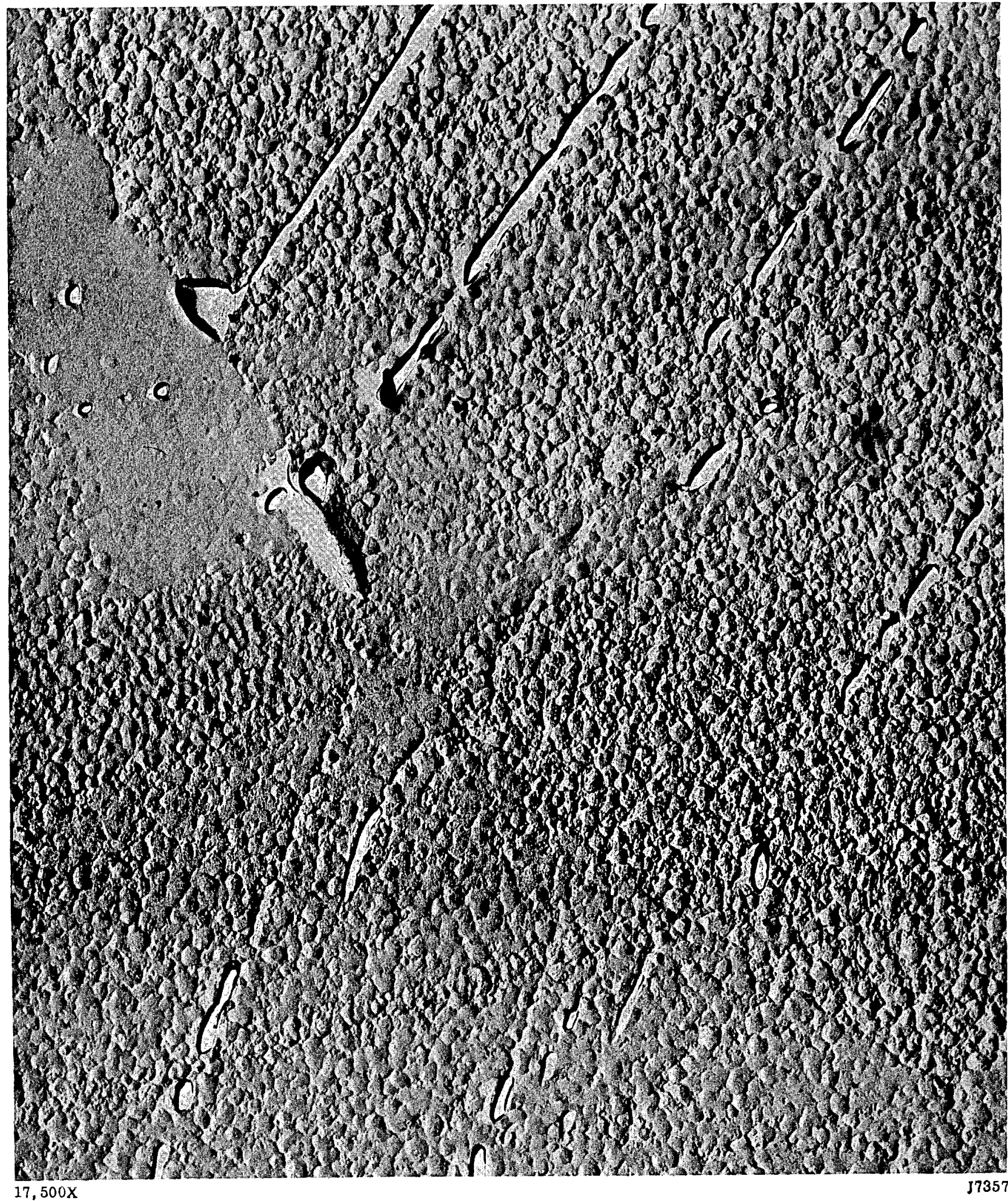

FIGURE II-16. ELONGATED CARBIDE PARTICLES AT EDGE OF INGOT B-85559 


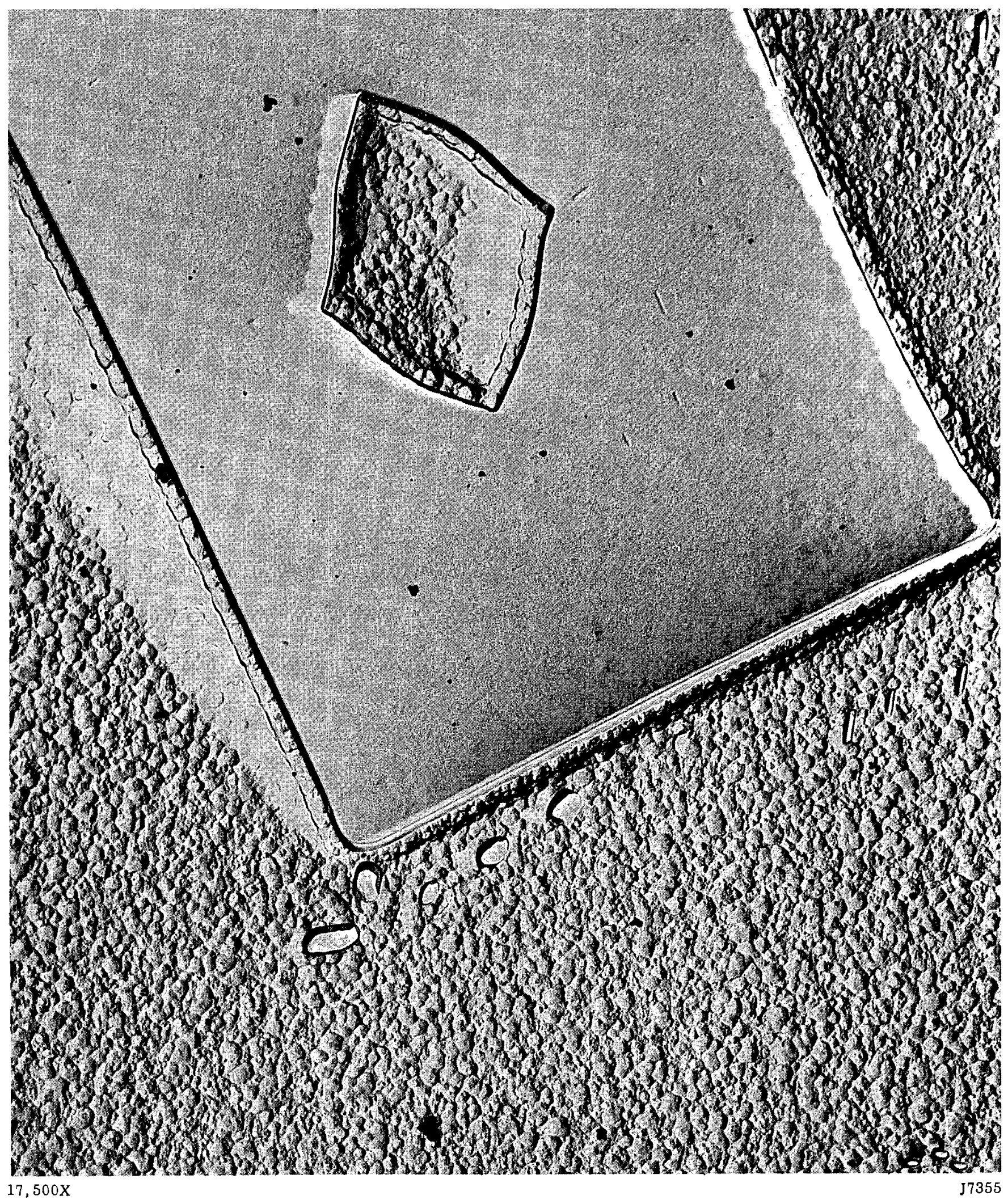

FIGURE II-17. LARGE CARBIDE WITH VOID IN CENTER AS SEEN IN INGOT B-85559

Preparation technique: Method 4, carbon-platinum replica,

transverse section. 


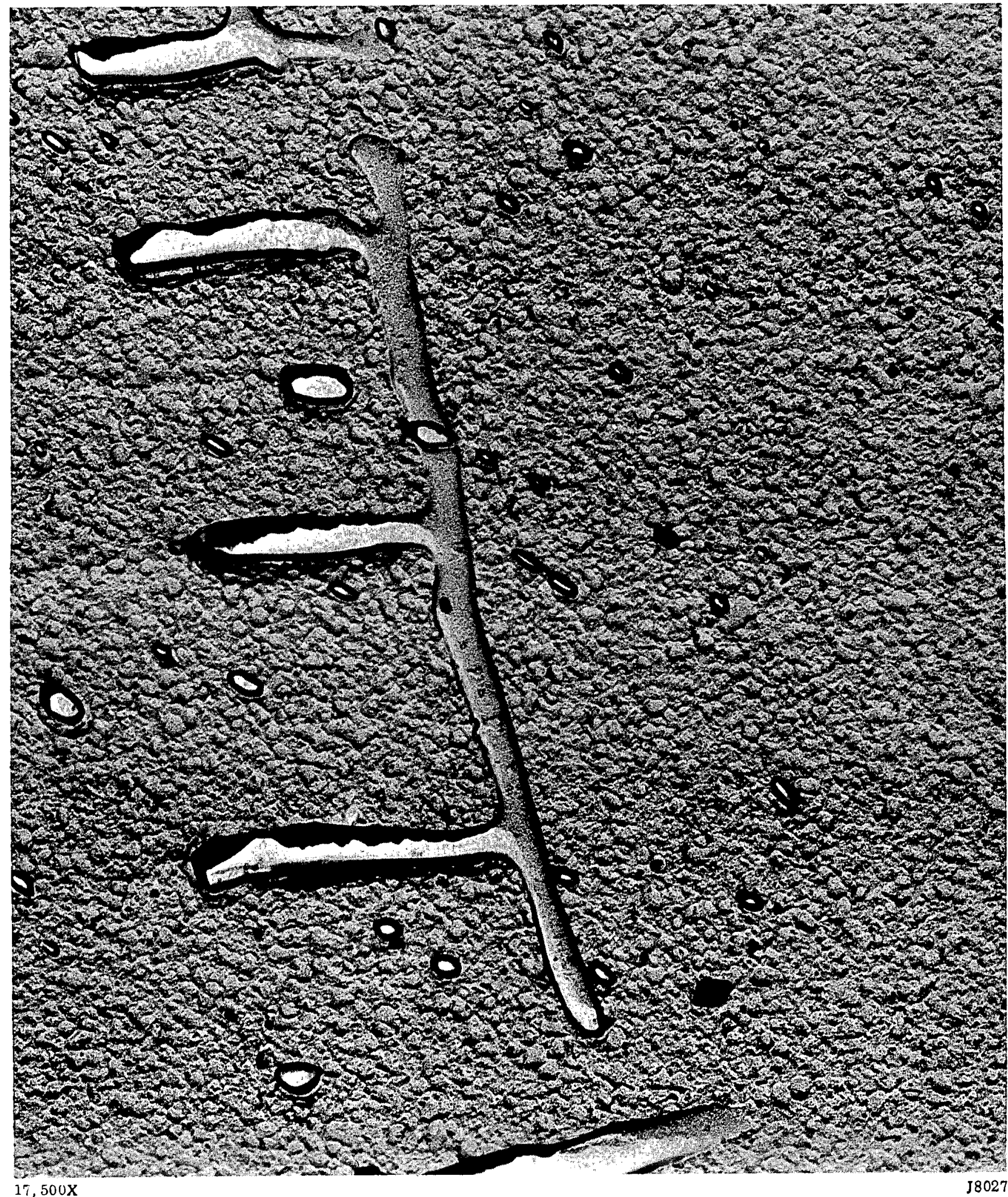

FIGURE II-18. SMALL DENDRITIC CARBIDE WITH OTHER SMALL INCLUSIONS IN INGOT B-85560

Preparation technique: Method 4, carbon-platinum replica,

transverse section. 


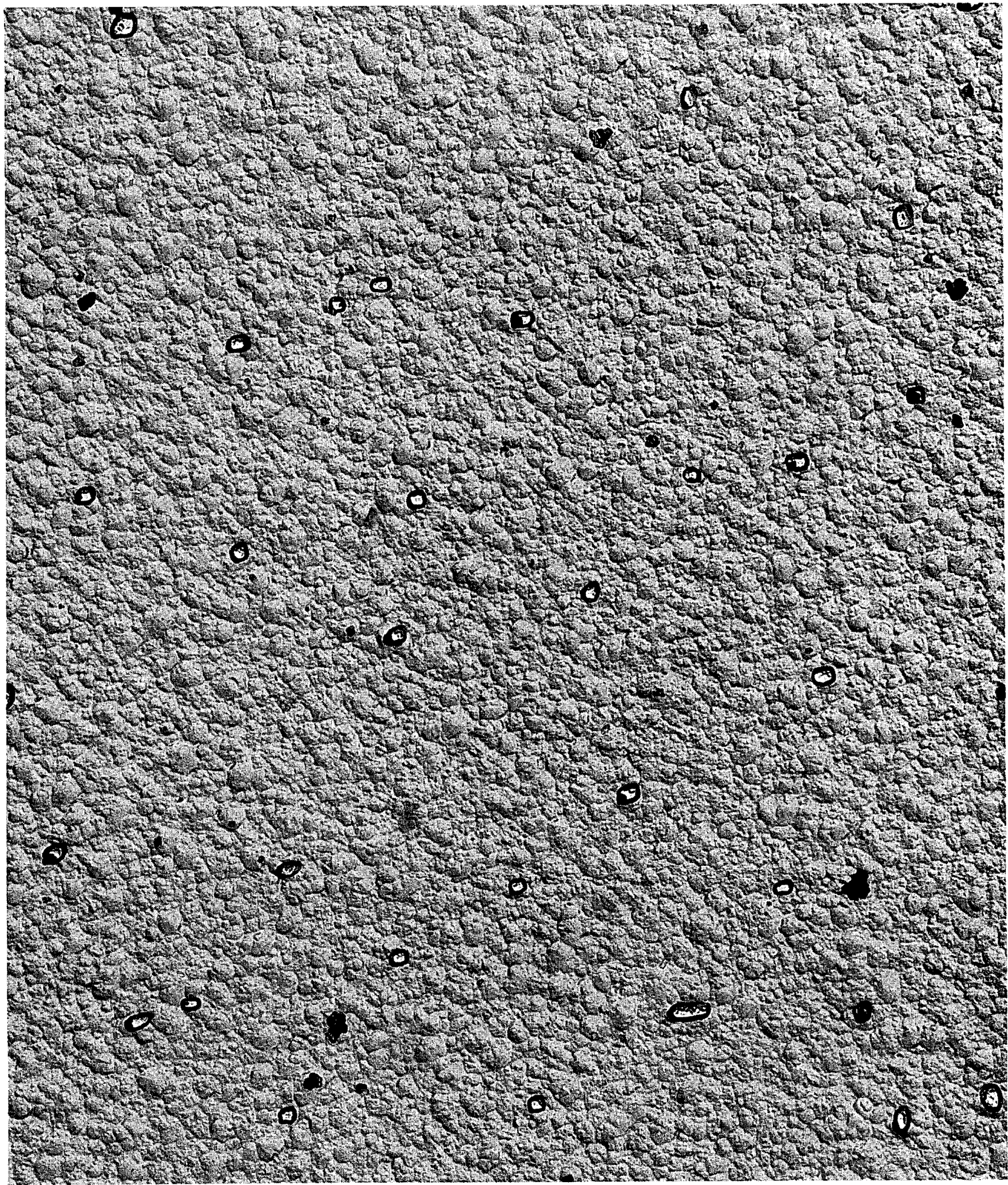




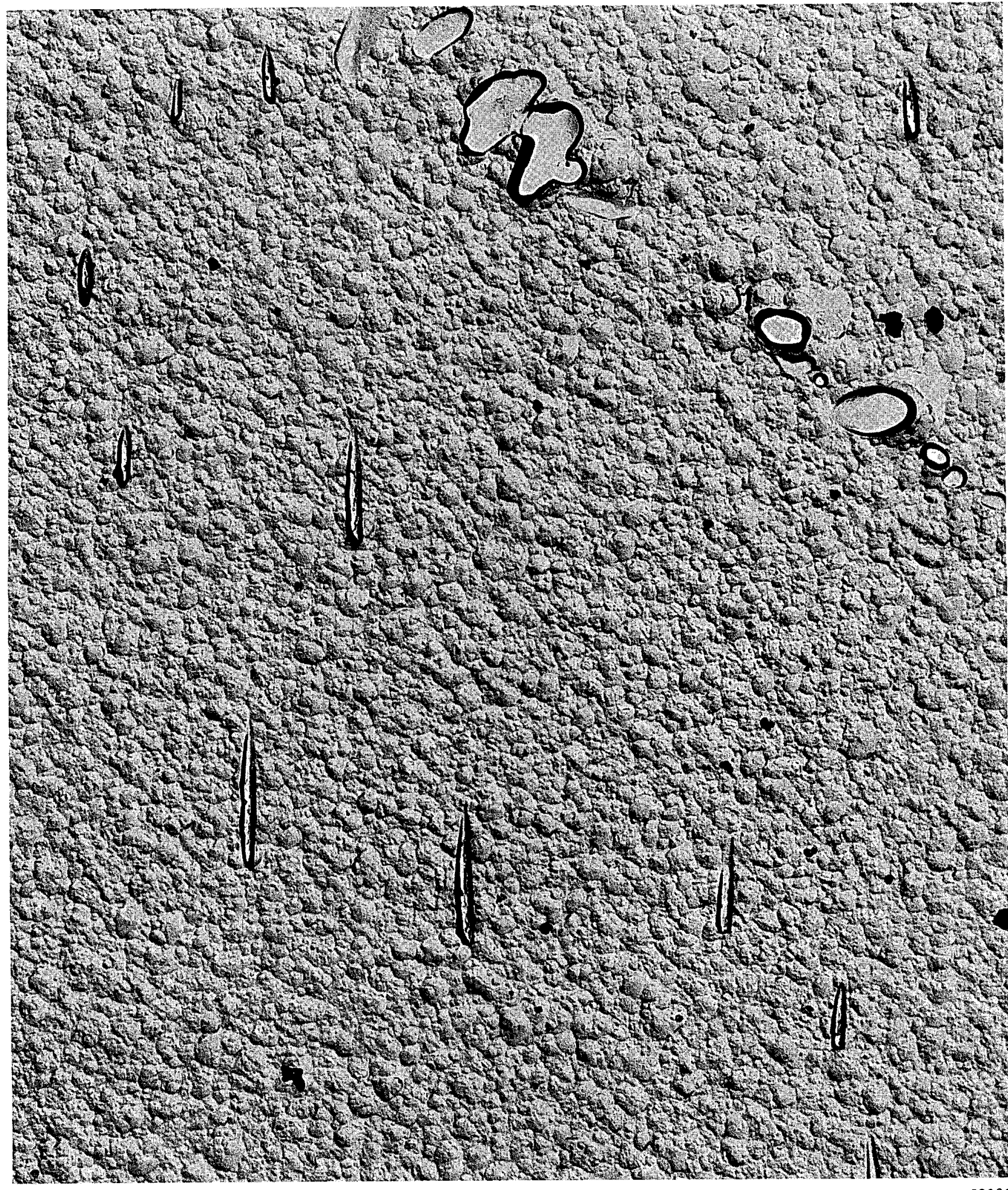




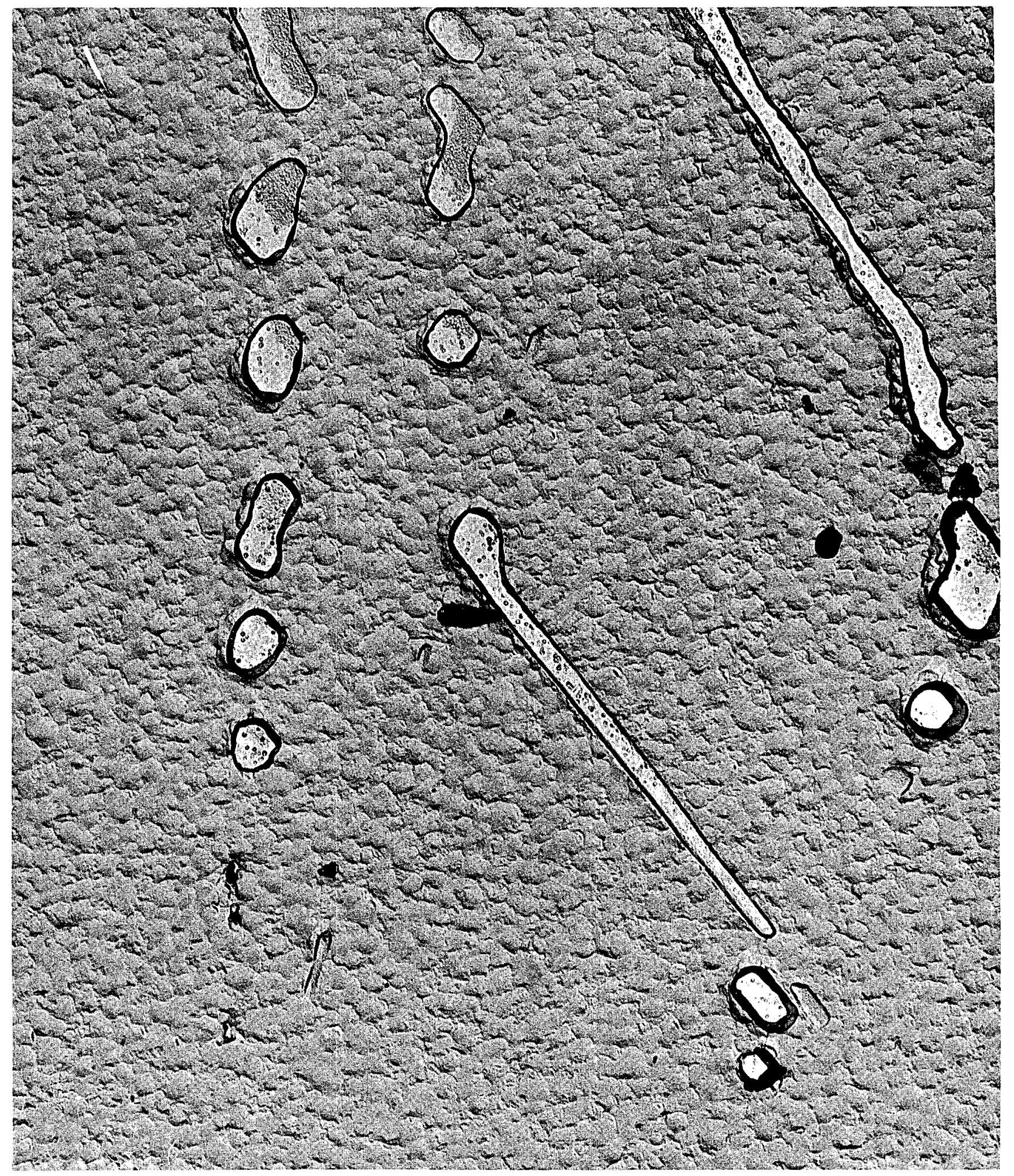

FIGURE II-21. LARGE ELONGATED PARTICLES IN CENTER OF INGOT B-57

Preparation technique: Method 4, carbon-platinum replica, transverse section. 


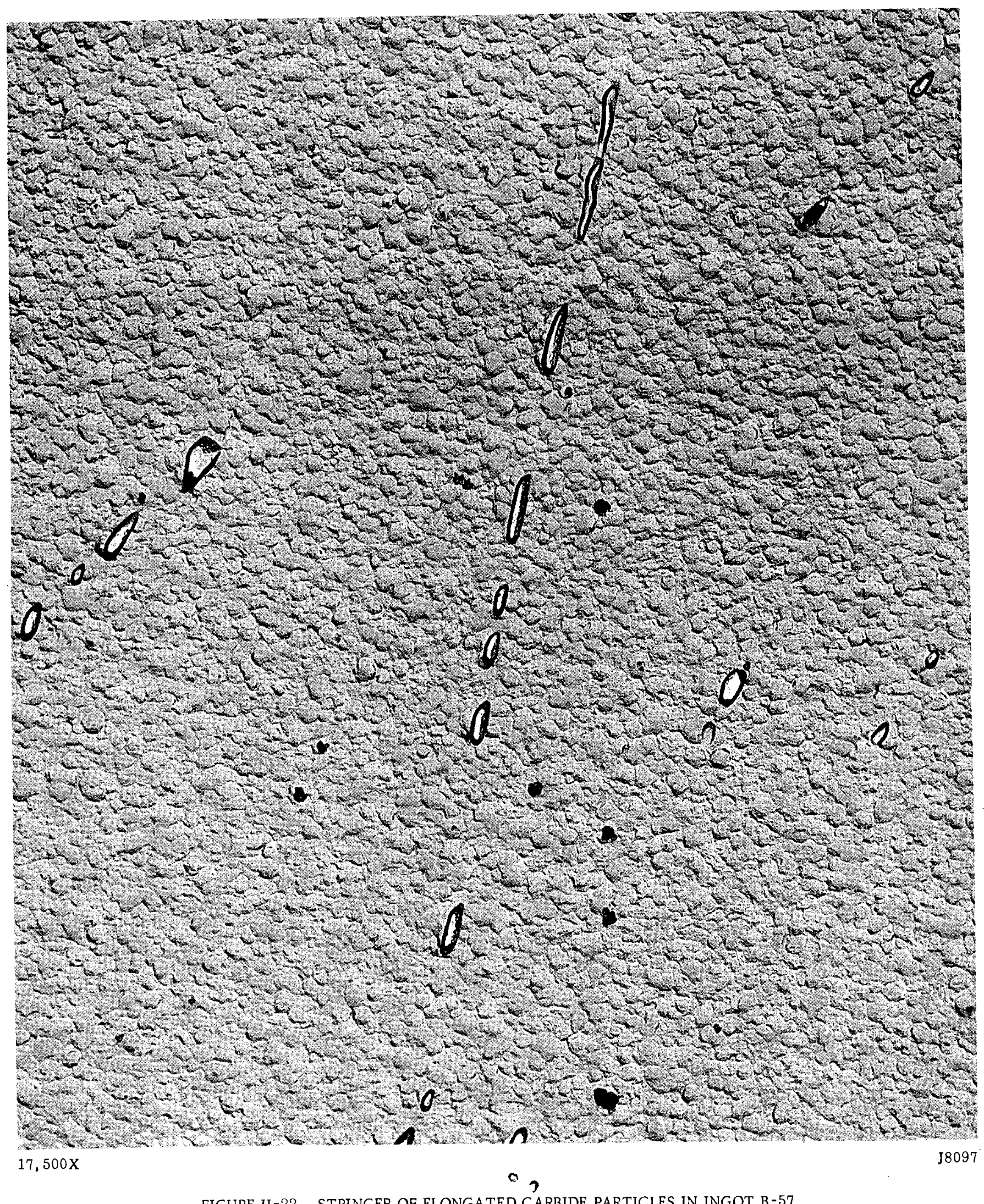

FIGURE II-22. STRINGER OF ELONGATED CARBIDE PARTICLES IN INGOT B-57

Preparation technique: Method 4, carbon-platinum replica,

transverse section. 
in all the experimental ingots, these particles tended to be coarser in the center of the ingots as illustrated by Figures II-2l and II-22. The carbides showed a greater tendency for alignment at the center of the ingot, presumably growing on crystallographic planes of the uranium matrix, as illustrated by Figure II- 22 .

Carbide distributions in Ingots B- 52 and B-50 are shown in Figures II- 23 and II-24.

The carbides in Ingot B-52, as illustrated by Figure II-23, tended to be somewhat smaller in size but also more random in size and distribution than in the other experimental ingots. This may be related to the higher cooling rate. The carbides in Figure II- 24 appear at either a grain or subgrain boundary.

All of the previous electron micrographs were obtained from replicas of surfaces prepared by Method 4. The remaining micrographs were obtained from specimens prepared by vacuum-cathodic etching as described in Method 3.

Figure II- 25 shows the structure of a cell boundary such as appears in Figure II- 7. It is seen to consist of a large number of carbide particles. A great deal of substructure was also visible in this same specimen. This is well developed in Figure II-26. The morphology is reminiscent of subgrain structures which are normally bounded by dislocation tangles or networks. The structural features outlining the substructure in this figure are of unknown origin, and while they may simply be etching artifacts they could be related either to dislocations or subtle compositional variations which are revealed by cathodic etching.

Carbides, twins, and substructure observed in Ingot B- 57 are shown in Figures II- 27 through II-29. The forms in Figure II-29 can be identified as steps and generally seem to have a particle or pit at one end.

A subgrain-type outline, similar to that observed in Ingot B-52 and shown in Figure II-26, is seen in Figure II- 30 for Ingot B-85559. In this case the substructure size appears much finer.

Carbides and substructure observed at a grain or subgrain boundary in Ingot B- 50 are shown in Figure II- 31.

\section{DISCUSSION AND CONCLUSIONS}

Of the techniques investigated, Method 4 is regarded as most useful for electronmicroscopy studies of small inclusions in uranium. Replicas from specimens prepared by this method showed clean and clear structural detail.

Vacuum-cathodic etching appears to be a powerful tool for revealing structure in uranium primarily for metallographic observation. Besides revealing all of the structural details developed by chemical etching, considerable substructure is revealed. Additional substructure is revealed by electron microscopic examination, although the nature of the structures is unknown, and additional study to evaluate the use of this technique for electron microscopy is needed. It would be desirable to perform thin-film 


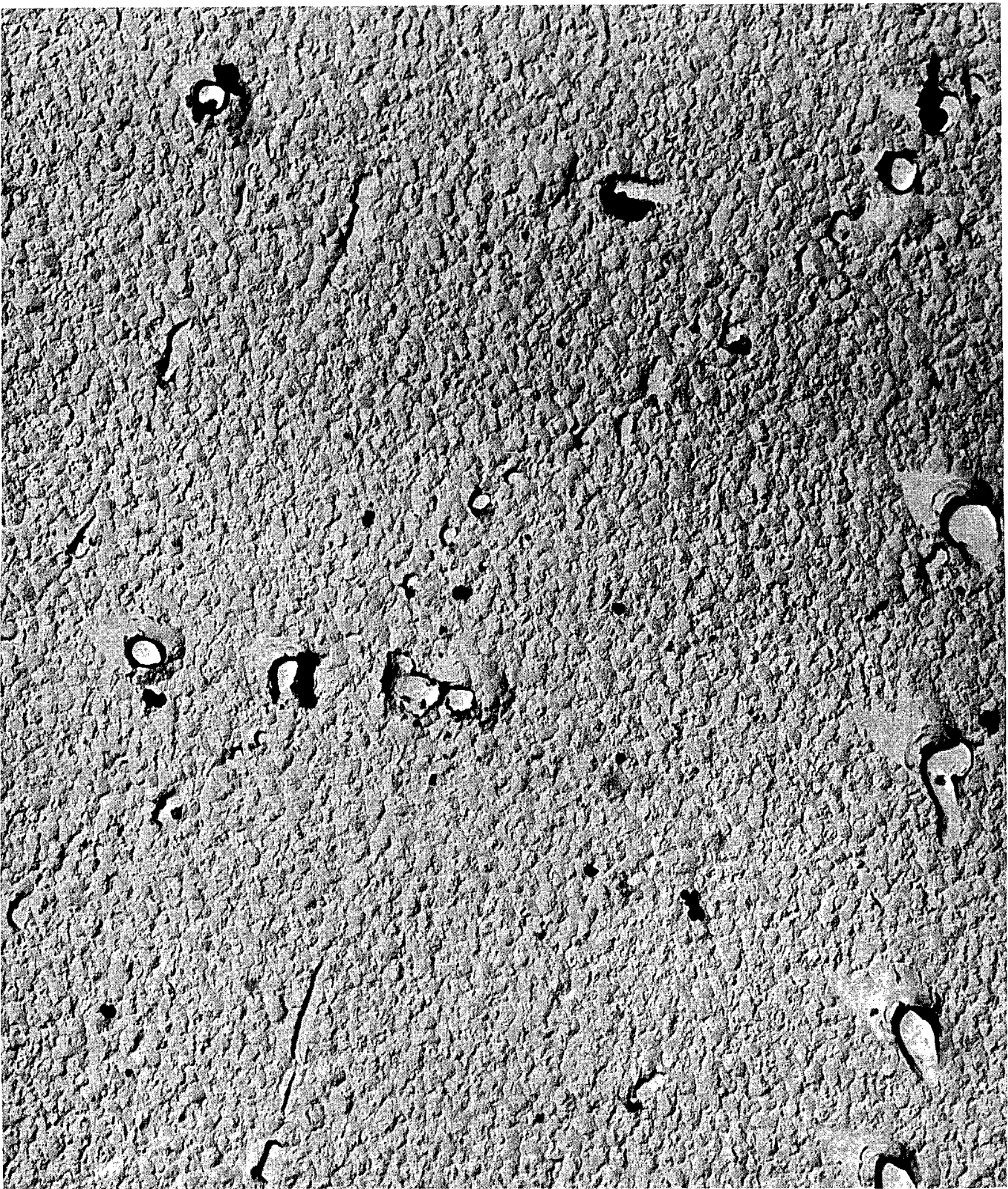
$17,500 \mathrm{x}$

FIGURE II-23. RANDOMLY SIZED IRREGULAR CARBIDE DISTRIBUTION IN CENTER OF INGOT B-50 


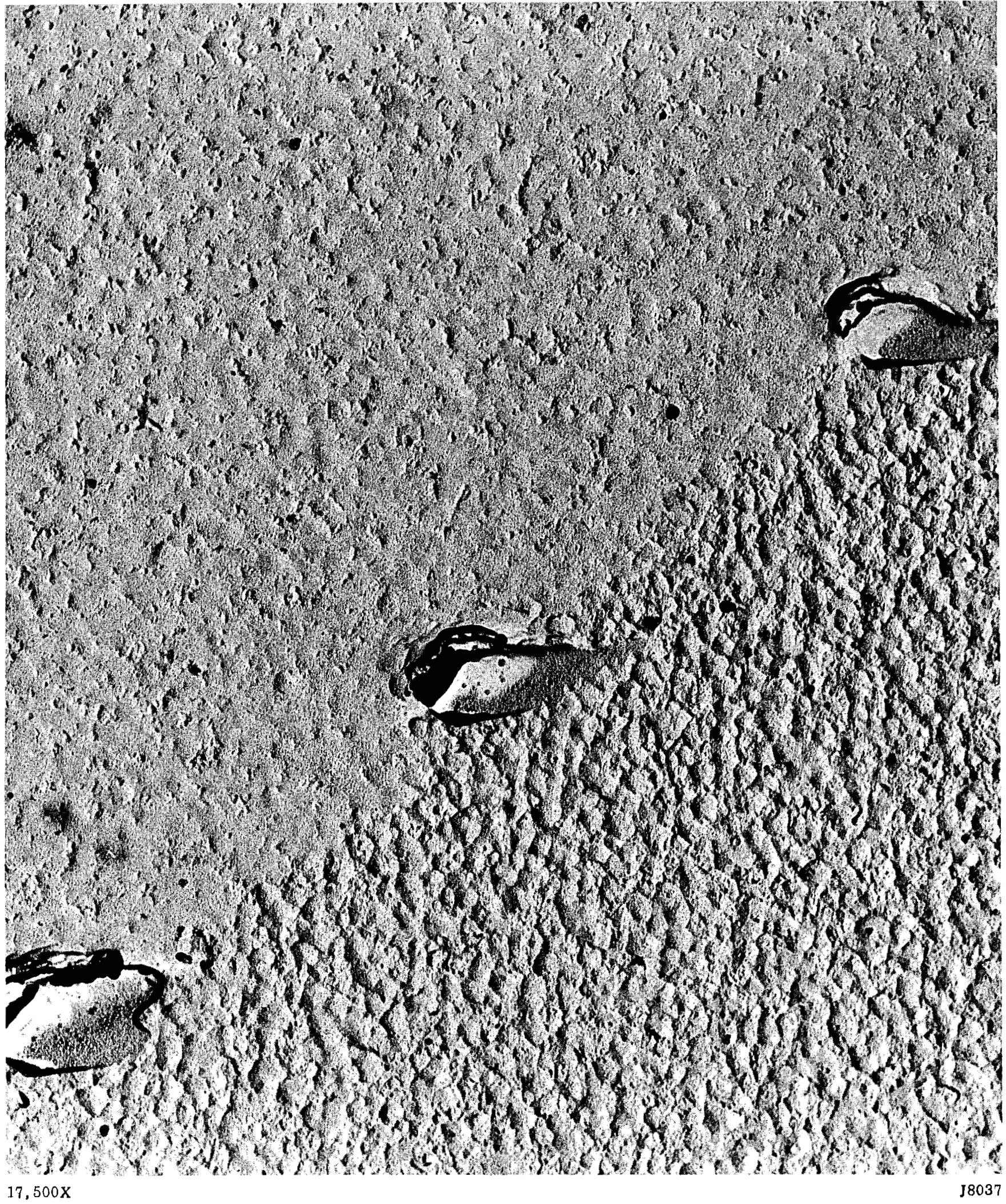

FIGURE II -24. CARBIDES AT GRAIN OR SUBGRAIN BOUNDARY IN CENTER OF INGOT B-52 


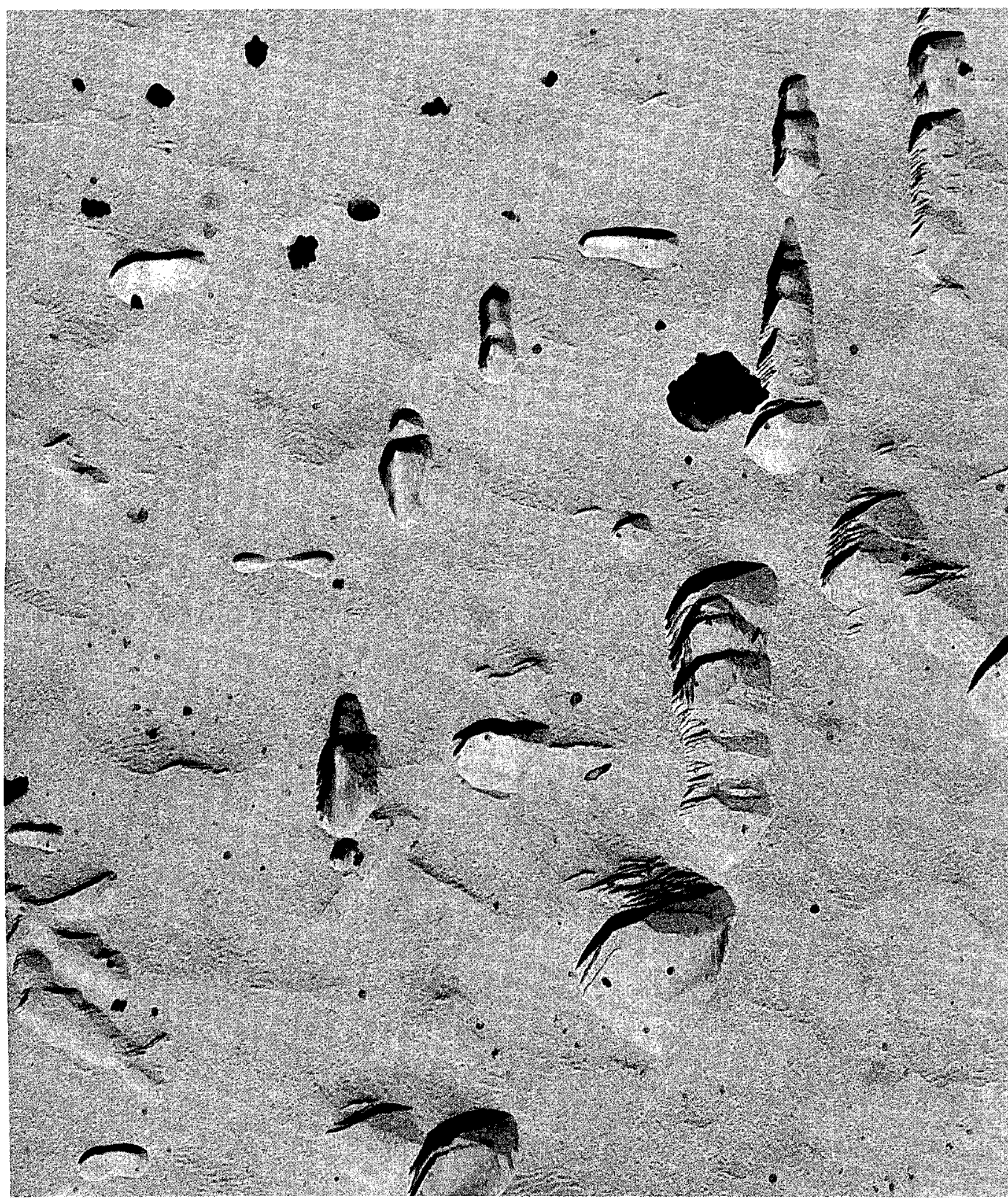

FIGURE II-25. CARBIDES IN CELL BOUNDARY AT CENTER OF INGOT B-52

The cell boundary structure is shown in Figure II -7 .

Preparation technique: Method 3, carbon-platinum replica, transverse section. 


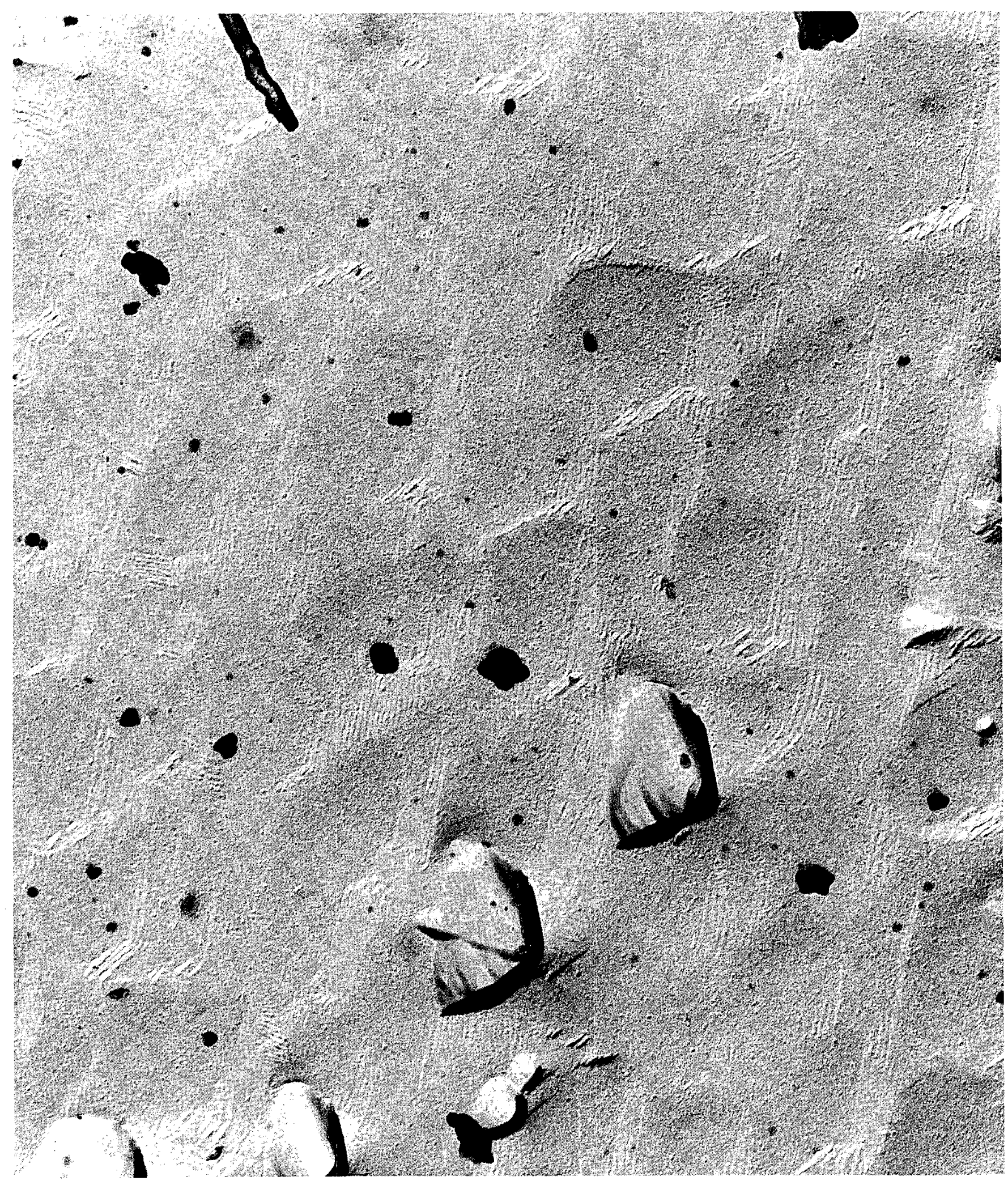

FIGURE II -26. SUBGRAIN-TYPE STRUCTURE AND CARBIDES IN CENTER OF INGOT B-52

Preparation technique: Method 3, carbon-platinum replica,

transverse section. 


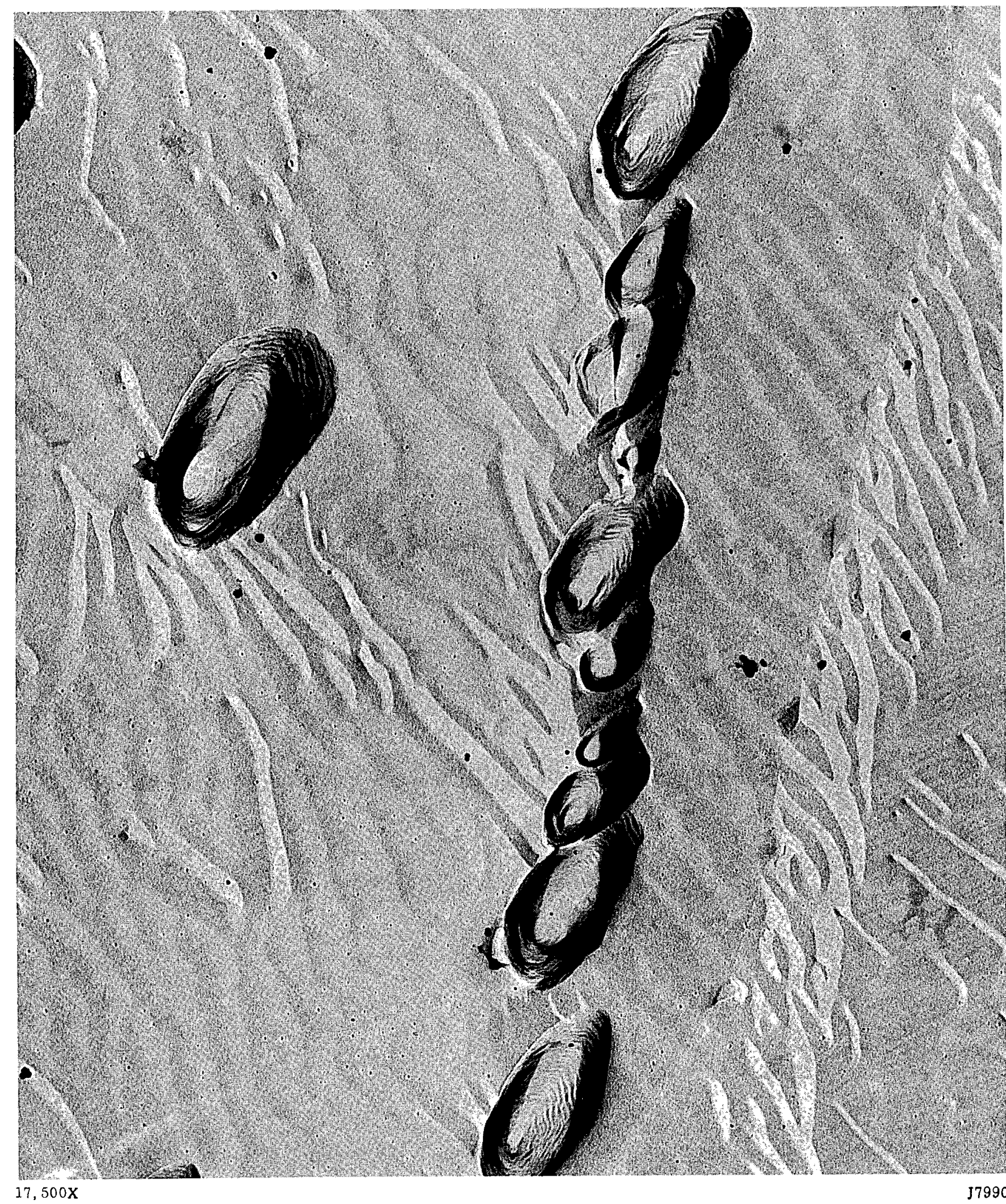

FIGURE II-27. CARBIDES AND STEPPED SUBSTRUCTURE IN CENTER OF INGOT B-57

Preparation technique: Method 3, carbon-platinum replica, transverse section. 


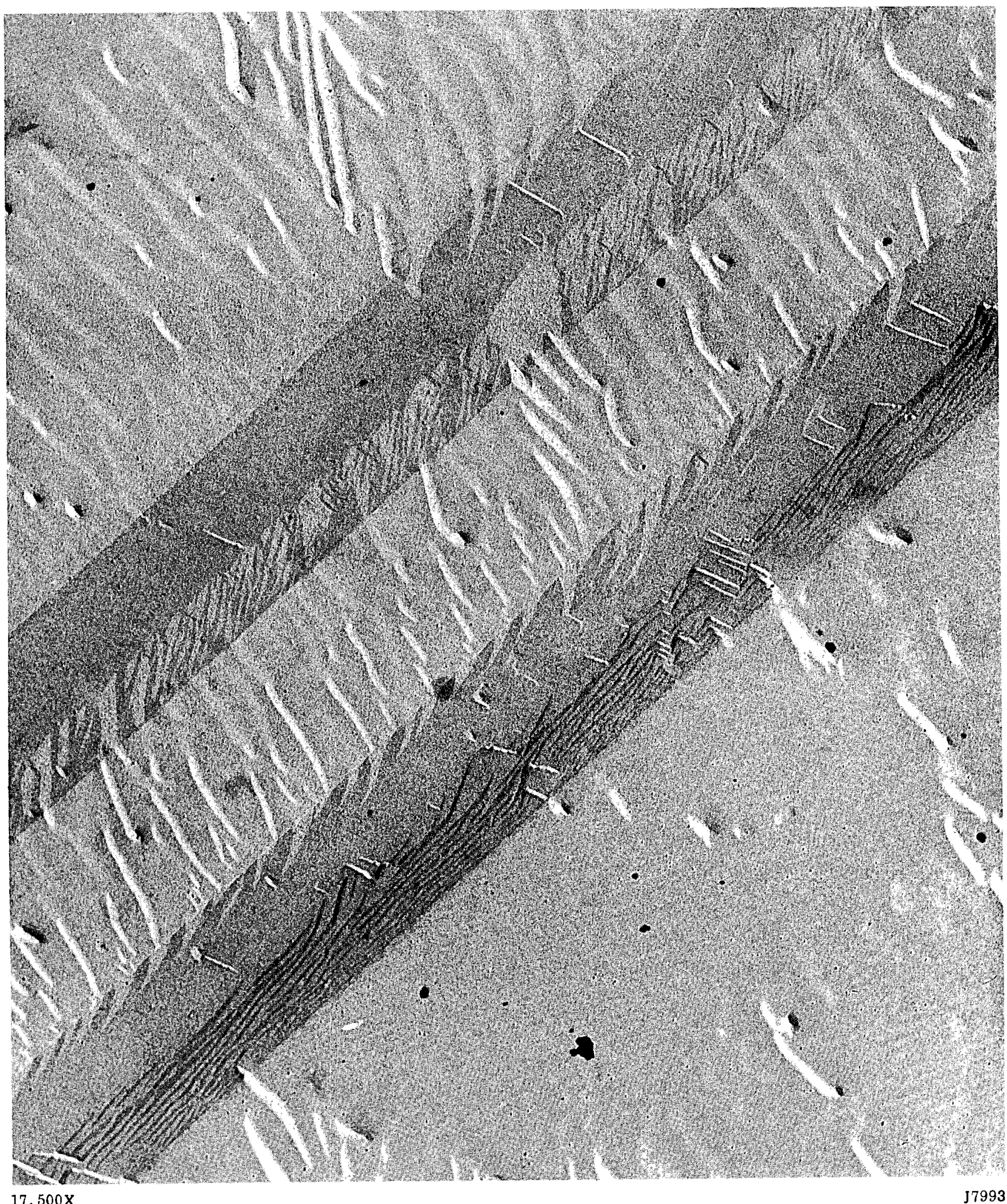

FIGURE II-28. TWINS AND STEPPED SUBSTRUCTURE IN CENTER OF INGOT B-57

Preparation technique: Method 3, carbon-platinum replica, transverse section. 


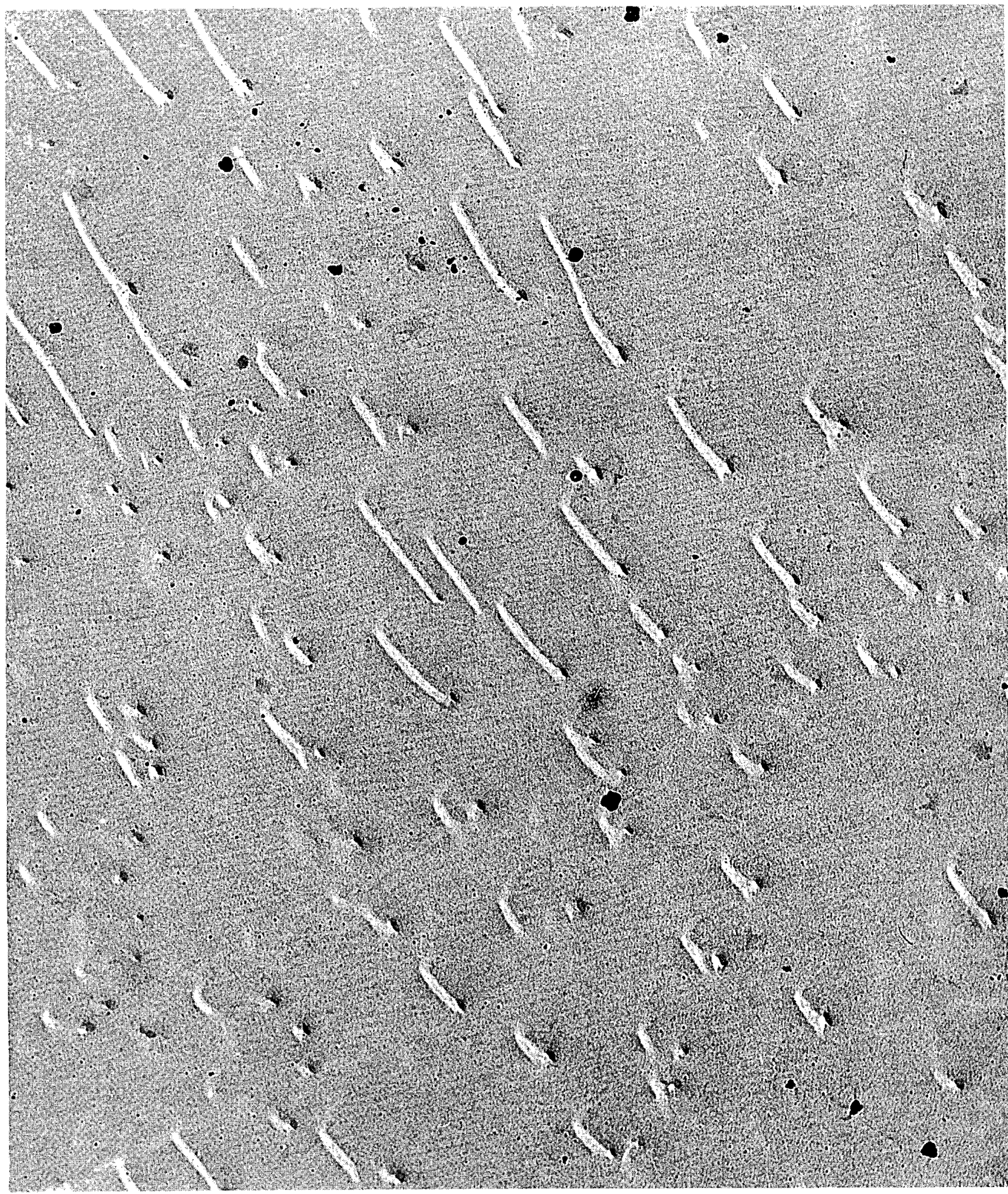

$17,500 \mathrm{X}$

J7988

FIGURE II-29. STEPPED SUBSTRUCTURE IN CENTER OF INGOT B-57

Preparation technique: Method 3, carbon-platinum replica, transverse section. 


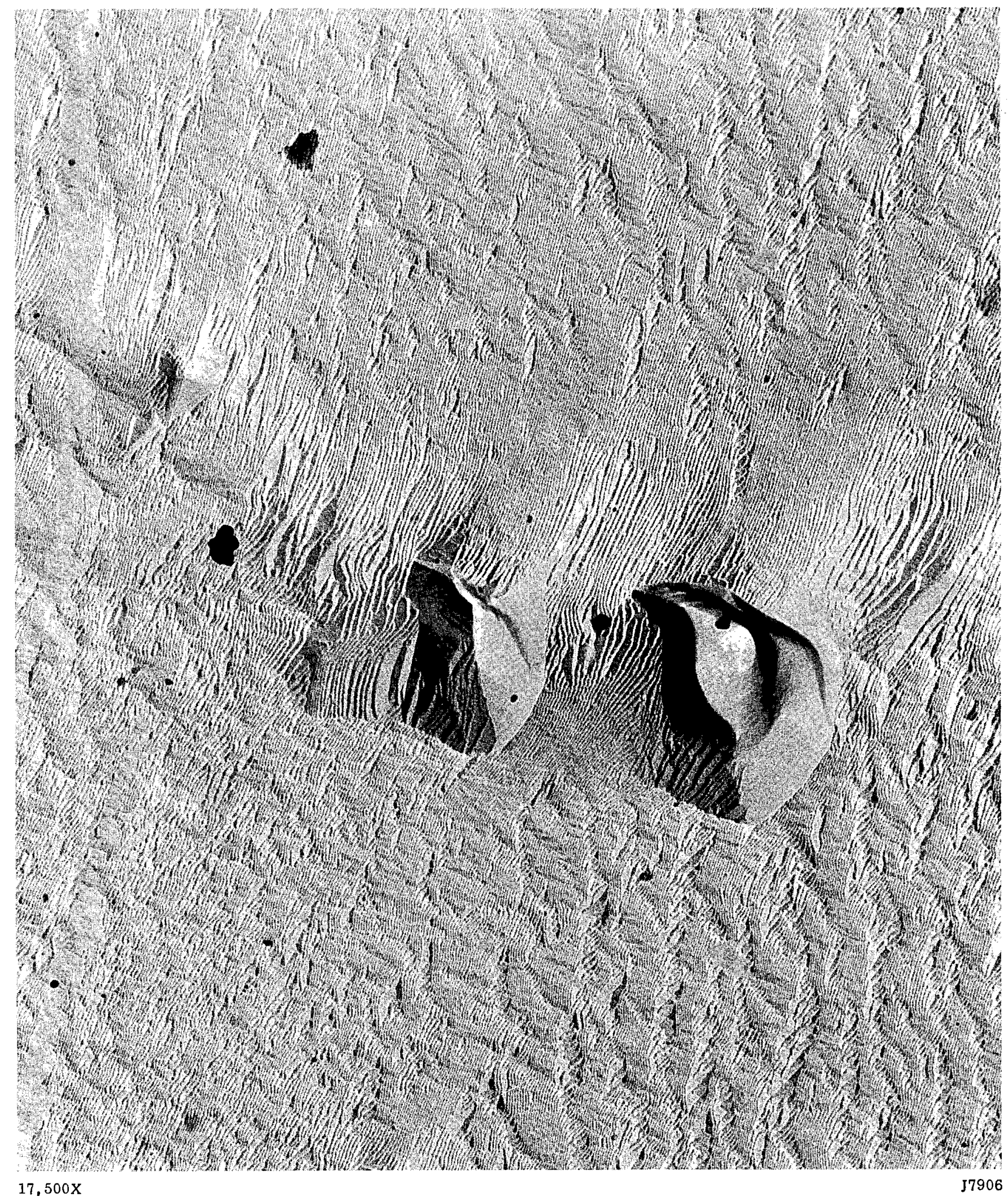

FIGURE II-30. SUBGRAIN-TYPE STRUCTURE AND CARBIDES IN EDGE OF INGOT B-85559

Preparation technique: Method 3, carbon-platinum replica,

transverse section. 


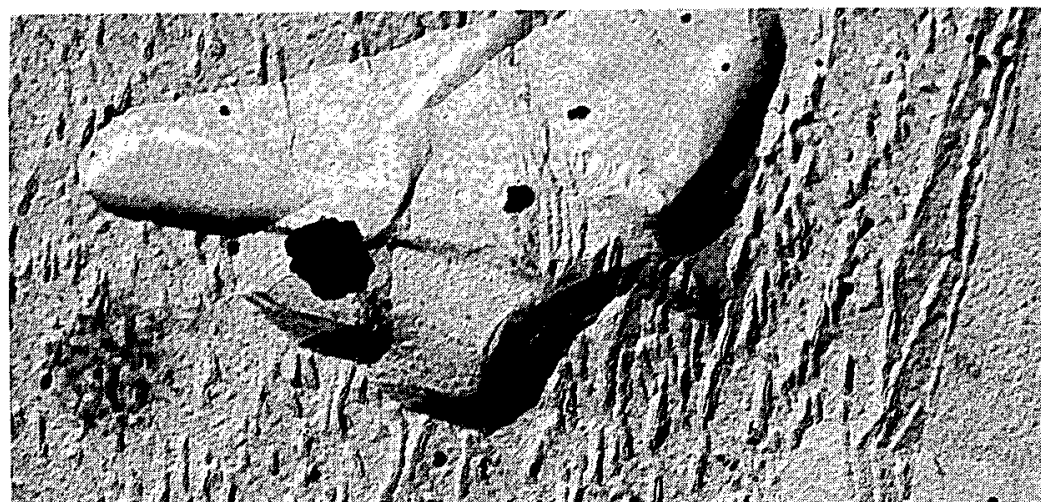
(1) (2) $x^{2}+x^{2}$ T.t.

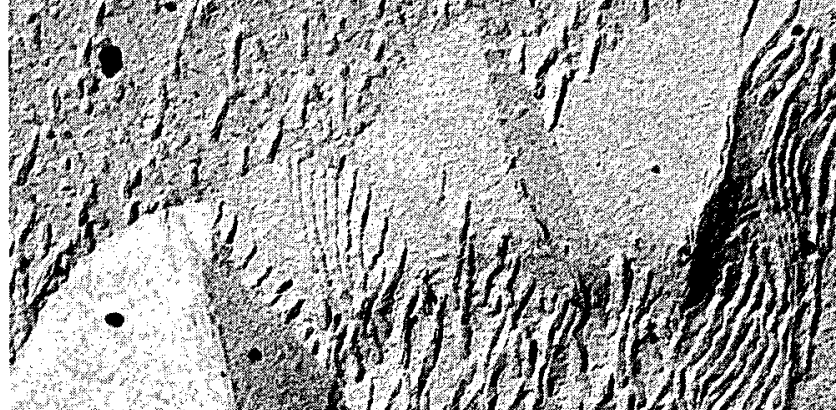

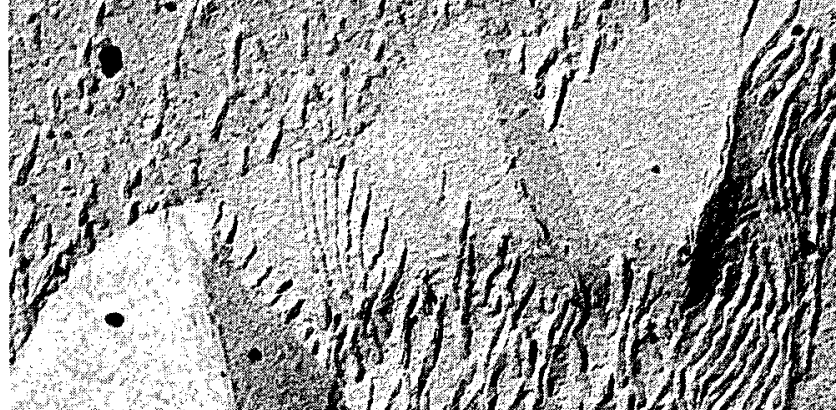
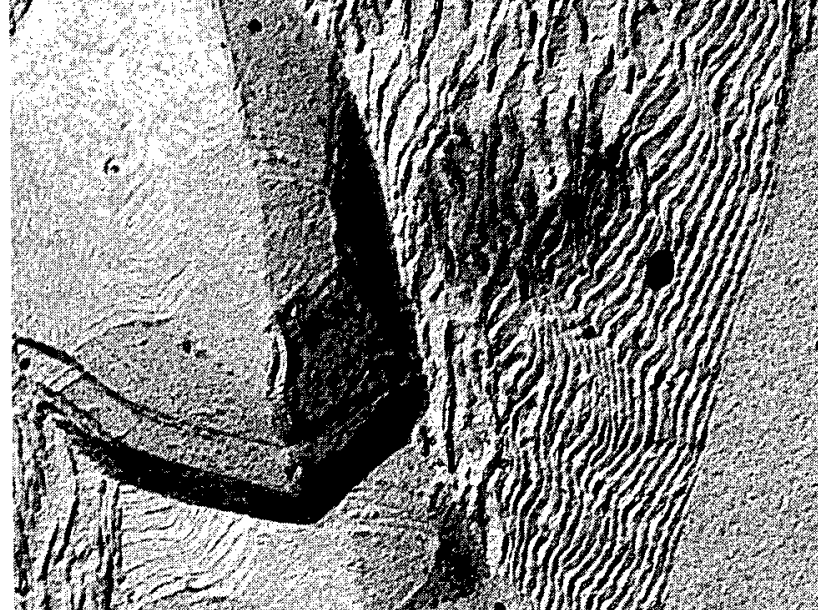

(x)

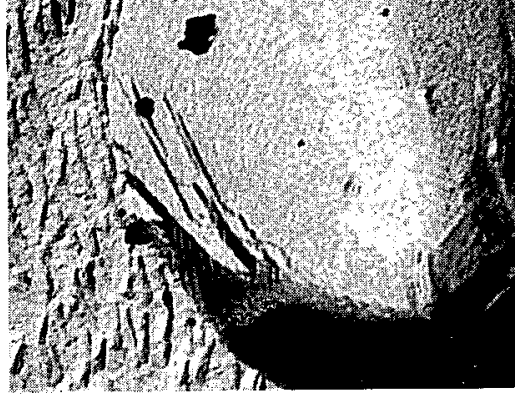

$17,500 X$

J7977

FIGURE II-31. CARBIDES AND SUBSTRUCTURAL CHANGE ACROSS GRAIN OR SUBGRAIN BOUNDARY IN CENTER OF INGOT B-50 Preparation technique: Method 3, carbon-platinum replica, transverse section. 
transmission studies of uranium to see if any correlation exists between the structures observed by the two techniques. Additional study to optimize the vacuum-cathodic etching procedures is also desirable. The micrographs shown in this report represent the results of a single successful preparation by this technique, and the effects of variable etching time, pressure, and voltage were not studied.

The results of this study of cast uranium microstructures revealed a number of interesting microstructural features and some significant structural differences between slow-cooled and fast-cooled ingots and between the structures at the edge and center of the slow-cooled ingots. Most of these observations are related to fine particles, identified as uranium carbide, which are present in the cast ingots. However, it must be pointed out that this study was extremely limited in scope, and, consequently, any conclusions reached must be considered as tentative in nature until confirmed by more detailed studies.

As a general observation, no particles other than carbide were observed or identified. Thus, it appears that in cast uranium the aluminum, iron, and silicon, when present as impurities in the amounts contained in these ingots, remain in solution. Working or annealing at alpha-phase temperatures may be required for their precipitation.

A single experiment was performed to determine the mode of formation of the fine carbide particles. For this purpose, a specimen was taken from a rod which had been produced by hot rolling a production ingot. This specimen was annealed at $1100 \mathrm{C}$ and furnace cooled. The resulting structure is shown in Figure II- 32 and indicates that the

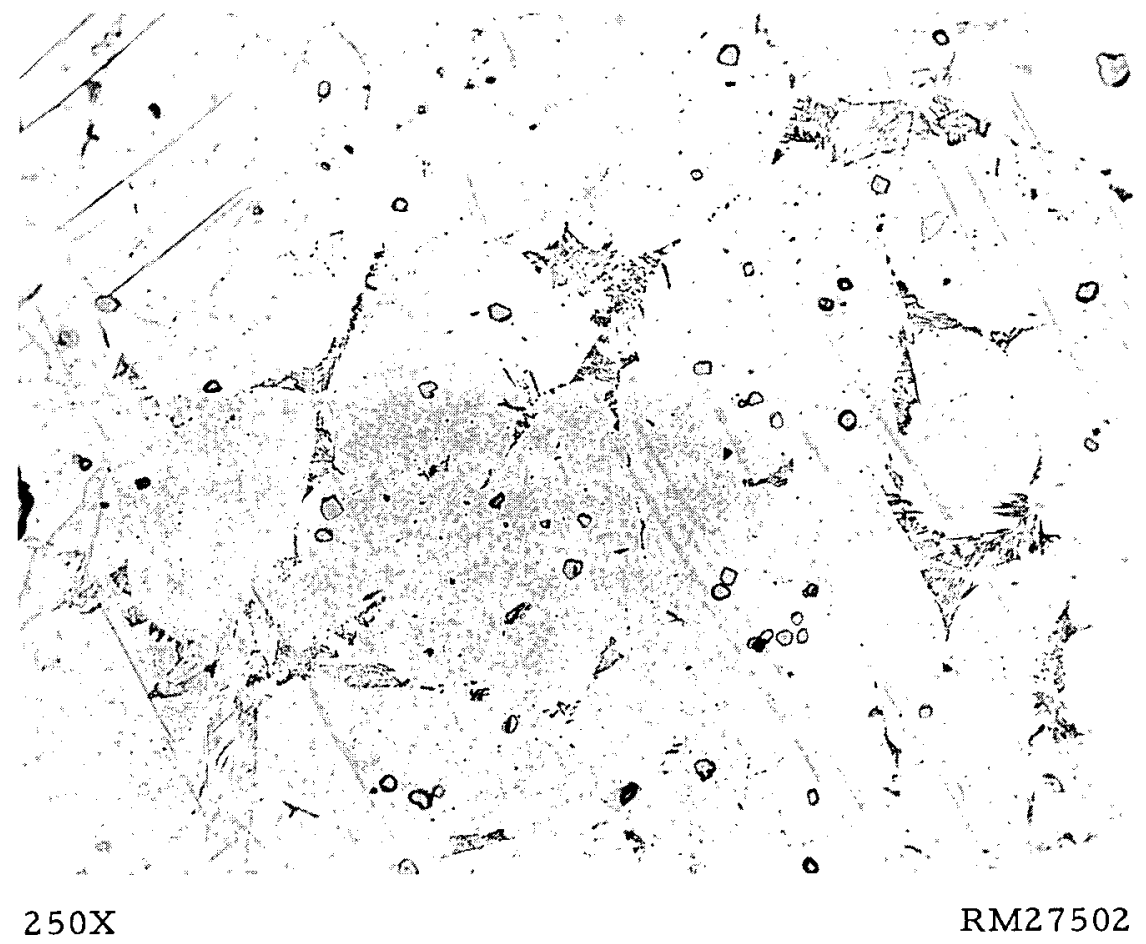

FIGURE II- 32. STRUCTURE OF HOT-ROLLED PRODUCTION INGOT MATERIAL AFTER ANNEALING AT 1100 C AND FURNACE COOLING

Note fine carbide precipitate. 
fine carbide is not a eutectic product but rather is a product of decreased carbon solubility accompanying a uranium solid-state eutectoid transformation. This conclusion is further supported by the observation that the formation and amount of fine carbide particles in cast uranium are independent of carbon concentration, within the limits of carbon concentrations investigated.

It is difficult to correlate the observed structures with a eutectic uranium-carbon diagram in view of the absence of an identifiable eutectic structure, and only a partial analysis of the structures is possible on the basis of the limited observations made in this study. However, it appears that carbide dendrites form in the melt when the carbon content is in excess of about $500 \mathrm{ppm}$. It also appears likely that the large cubic carbides result from decreasing solubility of carbon in the gamma phase of uranium.

The tentative conclusions reached as a result of this study are listed below.

(1) The amount or mode of formation of fine carbide particles is not related to carbon concentration; the principal effect of carbon concentration is on the number of large carbide particles present. Carbide dendrites tend to form and grow at the edge of high-carbon ingots.

(2) Carbon content has a slight effect on final grain size, the grain size being smaller when the carbon content is high.

(3) Grain and subgrain size is smaller in fast-cooled than in slow-cooled ingots.

(4) In slow-cooled ingots, the fine carbides tend to be aligned, apparently growing along crystallographic planes of the uranium. In fast-cooled material the fine carbide particles are more irregular and random.

(5) The fine carbides in a fast-cooled ingot also tend to be smaller and of more varying size than the carbides in slow-cooled ingots.

(6) The twins formed in a fast-cooled ingot tend to be narrower than the twins formed in a slow-cooled ingot.

(7) The fine carbides are smaller at the edge than at the center of the ingots.

(8) At the edge of the ingot, the fine carbides show a tendency for elongation in a direction perpendicular to the axis of the ingot, or in the direction of cooling.

(9) The grain size is smaller and the fine carbide particles tend to be smaller and clustered in more widely separated regions at the ingot edge than in the center of the ingot. Partial alpha recrystallization may be initiated at the ingot edge as a result of cooling stresses.

In examinations of the two production ingots, no significant structural differences between the ingots were observed.

The results of this study are quite preliminary in nature. It is recommended that the techniques developed be applied to more detailed studies of cast uranium structures. While such studies should include effects of ingot cooling rate and variable carbon 
content, the effect of variable levels of aluminum, iron, and silicon additions on cast structure also requires investigation. These studies should then be extended to worked and annealed material to trace structural changes produced by various production processes.

The vacuum-cathodic etching technique also warrants additional development to determine its applicability to specimen preparation for electron microscopy studies. At the present its usefulness is limited primarily to metallographic studies. Studies of etching variables and studies to identify the structures observed in the electron microscope are recommended.

FRS:NED:ELF:AAB:CR T:CWM/slp: eh 